Universidade de São Paulo

Instituto de Física

\title{
EFEITOS DE RADIAÇÃO EM DISPOSITIVOS ELETRÔNICOS COM FEIXES DE ÍONS PESADOS
}

\author{
Vitor Ângelo Paulino de Aguiar
}

Orientador: Prof. Dr. Nilberto Heder Medina

Dissertação de mestrado apresentada ao Instituto de Física da Universidade de São Paulo para a obtenção do título de Mestre em Ciências

\section{Banca examinadora:}

Prof. Dr.Nilberto Heder Medina (Orientador - IFUSP)

Prof. Dr.Odair Lelis Gonçalez (IEAv)

Prof ${ }^{a}$. Dra. Elisabeth Mateus Yoshimura (IFUSP) 


\section{FICHA CATALOGRÁFICA}

\section{Preparada pelo Serviço de Biblioteca e Informação}

do Instituto de Física da Universidade de São Paulo

\section{Aguiar, Vitor Ângelo Paulino de}

Efeitos de radiação em dispositivos eletrônicos com feixes de íons pedados. São Paulo, 2014.

Dissertação (Mestrado) - Universidade de São Paulo. Instituto de Física. Depto. de Física Nuclear.

Orientador: Prof. Dr. Nilberto Heder Medina

Área de Concentração: Física Nuclear Aplicada

Unitermos: 1. Física nuclear; 2. dispositivos semicondutores; 3. Efeitos da radiação; 4.ĺons pesados; 5 . Radiação ionizante. 
Não que seja eterna,

Posto que é chama,

Mas que seja infinita enquanto dure.

Vinícius de Morais, sobre a bolsa de pós-graduação 


\section{Agradecimentos}

Agradeço primeiro à minha família, em especial aos meus pais, Edson e Beti, meu irmão Guilherme e meus avós Walter e Waldemarina por todo apoio e compreensão e ajuda durante todo o curso de física e o desenvolvimento deste trabalho, pois não deve ser fácil ter um físico na família. Agradeço à Marília, por todo amor e compreensão que me dedica e que tanto me ajudou terminar esta dissertação.

Agradeço também àqueles que me ajudaram a dar os primeiros passos na pré-carreira acadêmica, professores Max, Colognesi e Paulo Giannini.

Aos grandes amigos da física, Danosa, Luiz, Mano, Al Queda, Bardo, Gomes, Hellmann's, Kamika e Ismael, pois sem eles eu não teria me formado (ou talvez até tivesse me formado antes, mas sem diversão nenhuma, sem churrasco, sem cerveja, sem pizza, sem truco e sem nenhuma boa história).

Aos grandes amigos que conheci no DFN e que foram fundamentais no desenvolvimento deste trabalho, não apenas ajudando em seu desenvolvimento, mas também trocando idéias, discutindo física e tomando hectolitros de café todos os dias: Renato, Elienos e Caio (sempre dispostos a ajudar com o ROOT), Erich (sempre discutindo física, ajudando com ROOT e nas montagens), Valdir e Jeremias (pelas várias idéias e toda a ajuda em montagens e com o Latex), Rafael, Paula e Saulo.

Aos professores Roberto Ribas, por toda ajuda com instrumentação e todos os esclarecimentos sobre poder de freamento, Alexandre Suaide, pela ajuda com o ROOT e a todos os outros professores e colegas do DFN, em especial do Grupo Gama, pela colaboração em diferentes etapas deste trabalho.

A todos os funcionários do DFN, pois sem eles este trabalho não teria sido realizado. Em especial, Otávio, Edmilson e Pedro pela confecção das peças na oficina mecânica, Celso e Luiz Marcos, por toda a ajuda com os sistemas de vácuo, João por todos os desenhos mecânicos, Zé Carlos, por ter preparado o cadinho mais heterodoxo de todos, Silvinho, Rone e Jorge, por manter a máquina funcionando, Wanda, Sérgio, Fábio, 
Messias e todos os outros que estiveram sempre dispostos a colaborar, dar idéias e resolver problemas.

Aos professores da FEI Marco Antônio Melo e Renato Giacomini e seus alunos Juliano e Augusto, pelo desenvolvimento do sistema de aquisição de dados que gerou os resultados deste trabalho (sem eles, eu estaria até agora buscando resultados).

Aos colegas do grupo de radiação em dispositivos eletrônicos: Shila, por todas as idéias e empolgação em diferentes momentos, além das importantes discussões sobre os resultados, Eduardo Macchione, por me ensinar muita coisa sobre instrumentação nuclear e ainda colaborar em todos os períodos incessantemente, Fernando Aguirre (versão sóbria do Al Queda) por sua colaboração nos períodos e na discussão de resultados, Seixas, por toda ajuda com o sistema de aquisição PXI.

Ao CNPq e ao Instituto de Física, pelo apoio financeiro e institucional.

Por último, agradeço ao Nemi por ter sempre uma idéia melhor que as minhas e fazer tudo funcionar (sem ele não teria nem meia página pra escrever aqui), além da grande ajuda na interpretação dos dados, e ao Medina, por ter dado todo apoio e orientação desde a iniciação científica, sempre dispondo de seu tempo para me ensinar física, acreditando em meu potencial e incentivando a dar o próximo passo.

A todos estes (e peço que me perdoem se esqueci de alguém) meu "muito obrigado". Certamente o melhor fruto deste trabalho são as amizades cultivadas no seu decorrer. 
Efeitos de radiação em dispositivos eletrônicos são uma preocupação em diversas áreas, como em missões espaciais, aceleradores de partículas de alta energia, entre outras. Entre os efeitos de radiação induzidos por íons pesados estão os chamados de Efeitos de Eventos Isolados (Single Event Effects - SEE), nos quais o impacto de um único íon pode ser capaz de gerar um efeito observável. Estes efeitos nunca haviam sido estudados no Brasil e seu estudo requer um acelerador de partículas capaz de prover feixes de íons pesados com baixo fluxo. A caracterização de dispositivos é feita medindo-se o número de eventos induzidos por radiação em função da transferência de energia por unidade de comprimento (Linear Energy Transfer - LET) do íon na camada sensível do dispositivo. Neste trabalho desenvolvemos um sistema para produção de feixes pesados para estudar SEE no Acelerador Pelletron 8UD, utilizando espalhamento Rutherford. A montagem permite obter feixes iônicos com valores de LET na superfície de silício na faixa de 1 a $40 \mathrm{MeV} / \mathrm{mg} / \mathrm{cm}^{2}$. O valor de LET na camada sensível do dispositivo depende da espessura de sua camada de passivação. Feixes pesados até ${ }^{48} \mathrm{Ti}$ podem ser utilizados para irradiações com feixe externo, isto é, fora da câmara de vácuo, e até ${ }^{107} \mathrm{Ag} \mathrm{em}$ vácuo, com uniformidade em intensidade acima de 90\%. A caracterização do MOSFET 3N163 foi a primeira medida bem-sucedida de SEE no Brasil, e foi possível correlacionar o LET dos íons com a amplitude do sinal gerado no dispositivo sob teste. A curva de seção de choque de SEE foi obtida, e para o dispositivo estudado os valores obtidos de seção de choque de saturação e LET de limiar foram de $2,94(10) 10^{-5} \mathrm{~cm}^{2}$ e 2,35(36) $\mathrm{MeV} / \mathrm{mg} / \mathrm{cm}^{2}$ respectivamente.

Palavras-chave: Single-Event-Effects, MOSFET, espalhamento Rutherford 


\section{Abstract}

Radiation effects on electronic devices are a main concern for many situations, such as space applications, high-energy particle accelerators, nuclear medicine, among others. A group of radiation effects induced by heavy-ions are called Single Event Effects, because a strike of a single ion can be enough to generate a damage on electronic devices. So far, SEE were not studied in Brazil due to the need of a high-energy, lowflux particle accelerator. Device characterization is done by measuring the number of events as a function of Linear Energy Transfer of the ion beam on the sensitive layer of the device under test (DUT). In this work we developed a Rutherford scattering setup for studying SEE at Sao Paulo 8UD Pelletron Accelerator. The setup can provide ion beams with Linear Energy Transfer values on the silicon surface ranging from 1 to 40 $\mathrm{MeV} / \mathrm{mg} / \mathrm{cm}^{2}$. The values on the active layer of the device depend upon the thickness of the dead-layer of the device. Ion beams up to ${ }^{48} \mathrm{Ti}$ can be used for irradiation of devices outside the vacuum chamber and up to ${ }^{107} \mathrm{Ag}$ inside the vacuum chamber, with a uniformity better than $90 \%$. The characterization of the MOSFET 3N163 was the first successful measurement of heavy-ion induced SEE in Brazil, and it was possible to correlate ion LET with signal amplitude generated by the DUT. A complete SEE cross-section curve was obtained, and for the device studied the values of saturation cross-section and threshold LET are 2.94(10).10 ${ }^{-5} \mathrm{~cm}^{2}$ and $2.35(36) \mathrm{MeV} / \mathrm{mg} / \mathrm{cm}^{2}$, respectively.

Keywords: Single-Event-Effects, MOSFET, Rutherford Scattering 


\section{Lista de Figuras}

2.1 Poder de Freamento Eletrônico . . . . . . . . . . . . . . . . . . 8

2.2 Freamento Eletrônico x Nuclear . . . . . . . . . . . . . . . . . . 10

2.3 Carga de Equilíbrio . . . . . . . . . . . . . . . . . . . . 14

3.1 Estrutura de bandas . . . . . . . . . . . . . . . . . . . . . 19

3.2 Diodo . . . . . . . . . . . . . . . . . . . . 24

3.3 Transistor de Junção Bipolar . . . . . . . . . . . . . . . . . . . . . 24

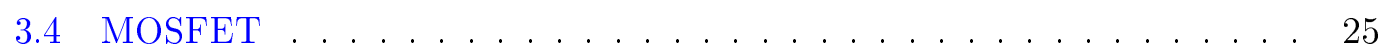

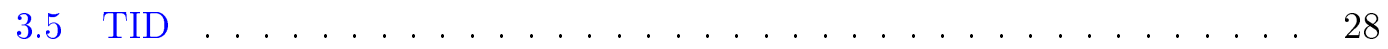

3.6 Defeitos cristalinos . . . . . . . . . . . . . . . . . . 29

3.8 Forma do pulso SEE . . . . . . . . . . . . . . . . . . . 32

3.9 Seção de choque SEE em um FPGA . . . . . . . . . . . . . . 33

4.1 Espalhamento elástico . . . . . . . . . . . . . . . . . . . 40

4.2 Cinemáticas direta e inversa . . . . . . . . . . . . . . . . . . . 41

4.3 Espalhamento por um potencial . . . . . . . . . . . . . . . 42

5.1 Fonte de íons . . . . . . . . . . . . . . . . . . . . 47

5.2 Carregamento do terminal . . . . . . . . . . . . . . . . . 48

5.3 Medida de ressonância magnética . . . . . . . . . . . . . 50

5.4 Acelerador Pelletron . . . . . . . . . . . . . . . . . 51 
$5.5 \quad$ Sala Experimental . . . . . . . . . . . . . . . . . 51

5.6 Esquema do Acelerador . . . . . . . . . . . . . . . . . . 52

5.7 Desenho esquemático da câmara da canalização 30B . . . . . . . . . 53

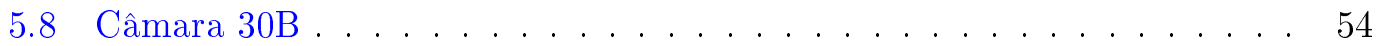

5.9 Sistema de feixe externo . . . . . . . . . . . . . . . . 55

5.10 Porta-placa . . . . . . . . . . . . . . . . 56

5.11 Alvos . . . . . . . . . . . . . . . . . 56

5.12 Seção de choque de Rutherford . . . . . . . . . . . . . . . 57

5.13 Detectores . . . . . . . . . . . . . . . . . . . 58

5.14 Eletrônica de aquisição . . . . . . . . . . . . . . . . . . . . 59

5.15 LET x Alcance . . . . . . . . . . . . . . . . . . . . . 60

5.16 Curvas de Bragg . . . . . . . . . . . . . . . . 61

5.17 Dispositivo decapado . . . . . . . . . . . . . . . . . . . 62

5.18 Comparador . . . . . . . . . . . . . . . . 63

5.19 Sistema de leitura por módulo PXI . . . . . . . . . . . . . . . 63

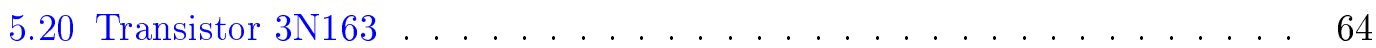

5.21 Esquema das montagems experimentais . . . . . . . . . . . 65

6.1 Produção de estados de carga . . . . . . . . . . . . . . . . . . . 67

6.2 Eficiência de troca de carga . . . . . . . . . . . . . . . . 68

6.3 Espectros interno e externo . . . . . . . . . . . . . . . . . 69

6.4 Uniformidade do feixe . . . . . . . . . . . . . . . . . . 71

6.5 Pulso espúrio obtido com o sistema PXI . . . . . . . . . . . . 72

$6.6 \quad$ Pulso espúrio no $3 \mathrm{~N} 163 \ldots \ldots \ldots \ldots 72 \ldots \ldots \ldots \ldots$

6.7 Espectro do detector barreira de superfície para íons leves . . . . . . . 74

6.8 Sinais de SEE . . . . . . . . . . . . . . . . . 75

6.9 Detalhe do sinal de SEE . . . . . . . . . . . . . . . 76 
6.10 Pontos experimentais da seção de choque de SEE . . . . . . . . . . 76

6.11 Histogramas de parâmetros dos picos de SEE induzidos por íons de cloro 78

6.12 LET x Amplitude . . . . . . . . . . . . . . . . . . 79

6.13 Correção do LET . . . . . . . . . . . . . . . . . . . . . . . . . 80

6.14 Espectro do detector barreira de superfície para íons pesados . . . . . . 81

6.15 Largura x Amplitude . . . . . . . . . . . . . . . . . . . . . 82

6.16 Ajuste teórico da curva de seção de choque de SEE do MOSFET 3N163 83 


\section{Lista de Tabelas}

6.1 Feixe externo: parâmetros experimentais e simulados . . . . . . . . . . . 69

6.2 Feixes e condições de irradiação . . . . . . . . . . . . . . . . 73

6.3 Parâmetros do ajuste teórico da curva de Weibull para os resultados de

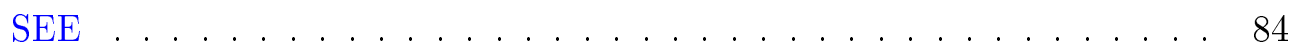




\section{Sumário}

1 Introdução 1

2 Interações da Radiação Ionizante em Meios Materiais 4

2.1 Conceitos Básicos . . . . . . . . . . . . . . . 4

2.2 Interações de Íons Pesados . . . . . . . . . . . . . . . . . . 6

2.2.1 Poder de Freamento Eletrônico . . . . . . . . . . . . . . . . 6

2.2.2 Poder de Freamento Nuclear _. . . . . . . . . . . . . . . . . 9

2.2 .3 Materiais Semicondutores . . . . . . . . . . . . . . . 11

2.3 Mecanismos de stripping de íons através de folhas finas . . . . . . . . . . 13

2.4 Cálculos de Taxa de Deposição de Energia do Íon no Meio . . . . . . . . 16

3 Efeitos de Radiação Ionizante em Dispositivos Eletrônicos 18

3.1 Dispositivos Semicondutores . . . . . . . . . . . . . . . . . 18

3.1.1 Estrutura de Dispositivos Semicondutores . . . . . . . . . . 23

3.2 Efeitos de Radiação Ionizante em Dispositivos Eletrônicos . . . . . . . . 25

3.2.1 Dose Ionizante Total (Total Ionizing Dose - TID) . . . . . . . . . 27

3.2.2 Dano por Deslocamento (Displacement Damage - DD) . . . . . 28

3.2.3 Efeitos por Eventos Isolados (Single Event Effects - SEE) . . . . 29

3.2 .4 Técnicas e Normas . . . . . . . . . . . . . . . . . 36 
4 Cinemática de Espalhamento Elástico 39

4.1 Espalhamento Elástico de Duas Partículas . . . . . . . . . . . . . . . . . 39

4.2 Seção de Choque de Espalhamento . . . . . . . . . . . . . . . . . . . 42

5 Materiais e Métodos 45

$5.1 \quad \mathrm{O}$ Acelerador Pelletron . . . . . . . . . . . . . . . . . 45

5.1 .1 Fonte de Íons . . . . . . . . . . . . . . . . . . . . . . . . 45

5.1 .2 Acelerador . . . . . . . . . . . . . . . . . 47

5.2 A Canalização 30B . . . . . . . . . . . . . . . . . . 53

5.2.1 Sistemas Desenvolvidos para Uso nos Experimentos . . . . . . . . 54

5.3 Configuração Experimental . . . . . . . . . . . . . . . 56

5.3 .1 Feixe Espalhado . . . . . . . . . . . . . . 56

5.3 .2 Dispositivos Sob Teste . . . . . . . . . . . . . . . . . 62

6 Resultados e Discussão $\quad 66$

6.1 Caracterização dos Feixes de Íons Pesados . . . . . . . . . . . . . . 66

6.1 .1 Troca de carga . . . . . . . . . . . . . . . 66

6.1 .2 Feixe Externo para Irradiação . . . . . . . . . . . . . . . . . . 68

6.2 Estudos de Efeitos de Eventos Isolados em Dispositivos Eletrônicos . . . 71

6.2.1 Sistemas Contador, NI-PXI e 3N163-Baixa Amostragem . . . . . 71

6.2.2 3N163-Alta Taxa de Amostragem . . . . . . . . . . . . . . 73

$\begin{array}{llr}7 & \text { Conclusão } & 85\end{array}$

$\begin{array}{lr}\text { Referências Bibliográficas } & 88\end{array}$ 


\section{Capítulo 1}

\section{Introdução}

A crescente utilização dos dispositivos semicondutores em sistemas de computação e armazenamento de dados nos últimos 50 anos fez com que se intensificassem os estudos sobre a confiabilidade de tais sistemas. A partir dos anos 60 vários estudos sobre como a radiação ionizante poderia afetar tais circuitos foram conduzidos tanto por órgãos de pesquisa estatais quanto pelos da iniciativa privada. Tais estudos exerceram influência direta nas novas aplicações dos dispositivos, entre elas a tecnologia aeroespacial e a de computadores em atividade ininterrupta sob radiação ionizante. Estes efeitos tornamse mais expressivos em ambientes cuja exposição à radiação ionizante seja bastante intensa, como, por exemplo, no caso de satélites, aceleradores de partículas, reatores nucleares e instalações de medicina nuclear.

A inserção do Brasil no rol dos países detentores de tecnologia aeroespacial e aptos ao desenvolvimento e lançamento de satélites passa obrigatoriamente pelo desenvolvimento de circuitos eletrônicos que sejam robustos ou tolerantes ao ambiente espacial, ou seja, capazes de gerar e armazenar dados confiáveis por vários anos sem a necessidade de manutenção. O projeto nacional de tais dispositivos é necessário, assim como a formação de know-how nacional sobre efeitos de radiação em dispositivos eletrônicos.

Nos últimos anos, esforços têm sido conduzidos por diversas instituições, como o 
Centro de Tecnologia da Informação Renato Archer (CTI), o Instituto de Estudos Avançados (IEAv - CTA), o Instituto Nacional de Pesquisas Espaciais (INPE), a Agência Espacial Brasileira (AEB) e o Centro Universitário da FEI (UniFEI). Tais esforços, entretanto, foram focados no estudo de efeitos de dose em dispositivos, estudos realizados com fótons e prótons, e danos por nêutrons.

O Laboratório Aberto de Física Nuclear (LAFN-USP), detentor do único acelerador de íons pesados do Brasil, o acelerador eletrostático Pelletron 8-UD de 8 MV e em vias de possuir também o pós-acelerador linear LINAC, fornece as condições para o estudo e qualificação de dispositivos para uso em ambientes com radiação ionizante consituída de íons pesados. O grupo de pesquisa de efeitos de radiação em dispositivos eletrônicos no LAFN é responsável pelo desenvolvimento dos métodos e técnicas experimentais para a medida de efeitos de radiação de íons pesados sobre dispositivos eletrônicos, além da colaboração no estudo dos efeitos em si. Posteriormente, tais métodos serão aplicados para a qualificação de dispositivos desenvolvidos no Brasil.

O objetivo deste trabalho foi desenvolver, caracterizar e aplicar um arranjo experimental dedicado a estes estudos que atenda às exigências internacionais, além de estudar o comportamento dos sistemas do acelerador Pelletron utilizando feixes de íons pesados com massa superior a 50 a.m.u., fundamental para as aplicações desejadas. A utilização do arranjo experimental proposto culminou nos primeiros estudos de efeitos de radiação com íons pesados em dispositivos semicondutores realizados no Brasil, em especial uma análise detalhada do comportamento do transistor 3N163 sob a influência de feixes de íons pesados.

Nesta dissertação são relatados os esforços realizados para cumprir estes objetivos. Este relato se inicia com uma revisão da interação da radiação com a matéria, apresentada no Capítulo 2, com especial destaque aos íons pesados, para então apresentar a estrutura de dispositivos semicondutores e os efeitos de radiação que se fazem presentes nesta tecnologia, além das particularidades deste tipo de estudo (Capítulo 3). 
No Capítulo 4 uma revisão da cinemática de espalhamento elástico coulombiano é feita para introduzir a técnica experimental empregada, detalhada no Capítulo 5. A apresentação e discussão dos resultados obtidos é apresentada no Capítulo 6, com posterior apresentação das conclusões deste trabalho (Capítulo 7). 


\section{Capítulo 2}

\section{Interações da Radiação Ionizante}

\section{em Meios Materiais}

Neste capítulo são apresentados os fenômenos e conceitos relacionados com a interação de radiação com a matéria, com especial destaque às interações de íons pesados em meios materiais sólidos.

\subsection{Conceitos Básicos}

Podemos separar a classe das radiações ionizantes, isto é, aquelas capazes de gerar ionizações (e excitações) dos átomos de uma porção de matéria, em três grupos: fótons (raios-X e raios gama), nêutrons e partículas carregadas eletricamente. Tais radiações depositam energia na matéria, dando origem portanto a uma dose no meio, que pode ter implicações nas suas características. A forma como ocorre esta deposição de energia é diferente para as diferentes radiações ionizantes.

- Fótons: os fótons com energia suficiente para ionizar um meio material podem interagir por meio de três processos principais: efeito fotoelétrico, onde toda a energia do fóton é transferida a um elétron atômico; efeito Compton, onde apenas 
uma parte da energia do fóton é transferida a um elétron, havendo portanto um fóton espalhado a um dado ângulo; e produção de pares, em que um fóton se transforma em um par elétron-pósitron. As seções de choque de ocorrência de cada um destes efeitos depende da energia do fóton e do número atômico do meio. De modo geral, ao atravessar um meio material, a intensidade de um feixe de fótons decai de forma exponencial com o aumento da espessura do meio ([1],[2]).

- Partículas Carregadas: por possuírem carga elétrica, interagem muito facilmente nos meios materiais, seja com o campo elétrico nuclear, seja com o campo elétrico atômico (mais provável). As partículas carregadas perdem energia de maneira quase contínua ao longo do meio material, interagindo com praticamente cada átomo no caminho e transferindo pequenas porções de energia. O elevado número de interações envolvidas e a natureza probabilística destas torna este um processo estocástico, de modo que apenas valores médios de transferência de energia podem ser conhecidos. À perda média de energia por unidade de comprimento de trajetória dá-se o nome de stopping power, ou poder de freamento. No caso de partículas leves (elétrons e pósitrons), a perda de energia ocorre também por meio de irradiação (bremsstrahlung), contribuição irrisória no caso de particulas pesadas de baixa energia. A perda gradual de energia das partículas carregadas dá origem a um alcance máximo destas, cujas variáveis são a energia e carga do íon e do o número atômico do meio, quando se tratar de partículas carregadas pesadas. Convém mencionar que elétrons sofrem grandes desvios de trajetórias nas interações, ao passo que íons pesados sofrem pouco desvio ([1],[2],[3]).

- Nêutrons: os nêutrons são partículas indiretamente ionizantes, uma vez que, por não possuírem carga elétrica, não interagem com os elétrons. Para gerar ionização, um nêutron deve interagir com o núcleo de um átomo do meio e, por espalhamento (elástico ou inelástico) produzir um átomo de recuo que provocará 
ionizações, ou provocar uma reação nuclear, e neste caso as partículas carregadas oriundas da reação irão produzir as ionizações no meio ([1],[2],[3]).

O estudo de efeitos de radiação ionizante em dispositivos eletrônicos passa pelo conhecimento detalhado destas interações. Nas próximas seções será dado maior detalhamento à interação de íons pesados (partículas carregadas) em meios materiais por ser este o objeto de estudo principal deste trabalho.

\subsection{Interações de Íons Pesados}

Um meio material é composto por um número muito grande de átomos $\left(\sim 10^{23}\right)$, que podem estar dispostos em arranjos cristalinos ou de maneira amorfa. Uma partícula qualquer, ao penetrar neste meio material, poderá interagir com vários destes átomos, sendo que, quanto maior o percurso percorrido dentro do meio material, maior será o número de interações sofridas. Este caráter estatístico das interações torna muito difícil de prever a energia perdida por um íon ao atravessar um meio material, ou mesmo estimar seu alcance dentro deste. Diversos esforços foram feitos desde o início do século XX por Bohr, Bethe, Bloch, Lindhard, entre outros para desenvolver uma teoria abrangente para o stopping power, até avanços mais recentes com as tabulações e parametrizações semi-empíricas de Northcliff e Schilling e de Ziegler, Biersack e Littmark ([4]). Podemos dividir o poder de freamento em duas componentes: eletrônico e nuclear.

\subsubsection{Poder de Freamento Eletrônico}

O poder de freamento eletrônico está relacionado a íons incidentes com velocidades maiores do que a velocidade média dos elétrons atômicos do meio (velocidade de Bohr, $v=c / 137$ ), e é a componente dominante do processo de perda de energia de partículas aceleradas em meios materiais. A interação do íon com os elétrons atômicos do meio pode provocar excitações (com posterior emissão de raios-X ou elétrons Auger) quando 
o parâmetro de impacto é alto (colisão "suave"ou periférica) ou ionizações, quando o parâmetro de impacto é baixo (colisão "dura"ou frontal) ([1]). Quando da ocorrência de ionizações, os elétrons ejetados podem possuir energia suficiente para deslocar-se a uma energia apreciável da trajetória inicial da partícula, depositando grande quantidade de energia fora da trajetória desta, sendo estes elétrons chamados de raios delta $(\delta)([2])$. Se a velocidade do íon é grande comparada à dos elétons atômicos, podemos calcular o poder de freamento pela Teoria de Bethe-Bloch ([5]), na qual a colisão é tratada no contexto da mecânica quântica com o uso da primeira aproximação de Born ([6]). Com a adição de correções para levar em conta efeitos relativísticos, as diferentes velocidades dos elétrons do meio e a polarização dos átomos com a passagem da partícula carregada, temos a expressão completa de Bethe-Bloch-Fano ([5],[4],[7]):

$$
\frac{d E}{\rho d x}=\frac{4 \pi N Z_{2} Z_{1}^{* 2} e^{4}}{m_{e} v^{2}}\left[\ln \left(\frac{2 m_{e} v^{2}}{\langle I\rangle}\right)+\frac{C(v)}{Z_{2}}+\frac{v^{2}}{c^{2}}-\ln \left(1-\frac{v^{2}}{c^{2}}\right)-\delta\right]
$$

onde $\langle I\rangle$ é a energia média de ionização, $\delta$ é a correção de polarização, $C(v) / Z_{2}$ é a correção de camadas, $m_{e}$ é massa do elétron, $Z_{2}$ o número atômico dos átomos constituntes do meio e $Z_{1}^{*}$ a carga efetiva do íon em trânsito. Em velocidades nãorelativísticas, a expressão se reduz a uma relação aproximada do tipo 1/E. A presença de uma "carga efetiva"na formulação de Bethe-Bloch-Fano implica que o poder de freamento é função da carga e velocidade do íon e do meio freador, de modo que a natureza do íon em questão, uma vez que entra apenas por meio da carga na equação, constitui um fator de escala. Desta forma, pode-se relacionar o freamento de íons pesados neste regime de velocidades com o de um íon mais leve (prótons, em geral), usando um fator de escala inversamente proporcional ao quadrado da carga efetiva $([7],[8])$.

Quando a velocidade do íon é baixa (comparável ou menor do que as velocidades orbitais dos elétrons), as teorias existentes apresentam concordância apenas qualitativa 


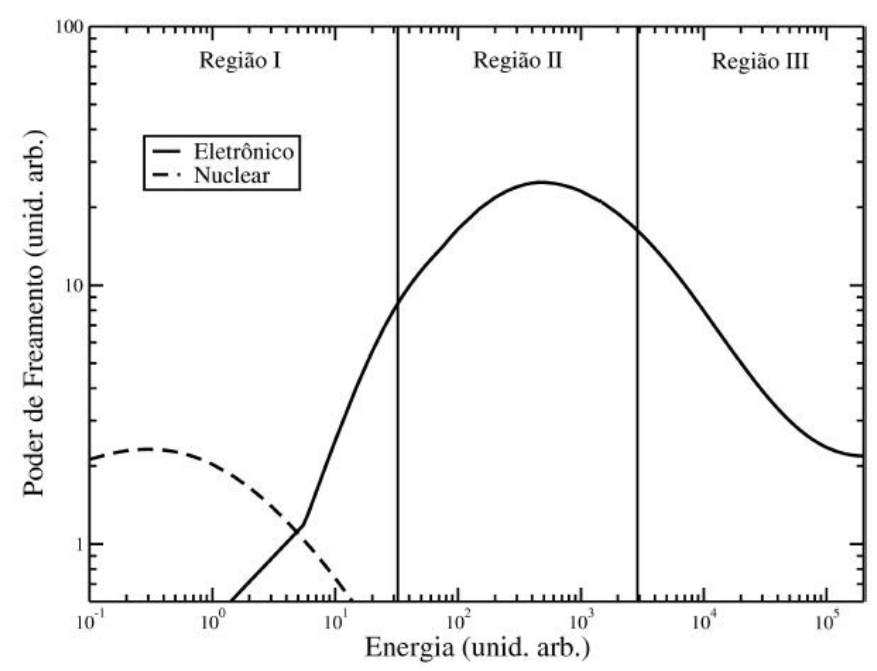

Figura 2.1: Dependência do poder de freamento eletrônico com a energia (reproduzida de [4]). A região III é bem descrita pela Eq. 2.1, ao passo que as regiões I e II são apenas aproximadamente descritas pelos modelos mecânico-estatísticos.

com a experiência em muitos casos. Usualmente, tais modelos baseiam-se numa descrição mecânico-estatística da eletrosfera, considerando esta como um gás de elétrons livres com densidade dada pelo modelo de Thomas-Fermi (em algumas formulações, o modelo é de Hartree-Fock) ([4],[7]). No caso dos íons pesados, a captura de elétrons do meio modifica a carga efetiva do íon, alterando sua interação com o gás de elétrons, num processo dinâmico onde a perda de energia é bastante acentuada, a que chamamos de pico de Bragg (região II da Figura 2.1).

As limitações dos modelos teóricos levaram ao desevolvimento de parametrizações semi-empíricas que se mostram muito úteis nos cálculos de poder de freamento, perdas de energia, etc, com objetivo prático nos laboratórios de Física Nuclear. A parametrização mais usada atualmente é aquela devida a Ziegler, Biersack e Littmark (ZBL) [8], e baseia-se num conjunto amplo de dados experimentais. Para o freamento a velocidades altas, utiliza-se o escalonamento com o freamento de prótons, enquanto que a baixas e médias velocidades utiliza-se o modelo estatístico, com fatores de correção determinados a partir dos dados experimentais. Mesmo empregando os modelos semi-empíricos, 
os desvios entre o cálculo e o experimental podem ser grandes em determinadas combinações alvo-íon-energia ([7],[4],[9],[10]), e tal situação é agravada quando o alvo é composto por mais de uma espécie atômica. Neste caso, a regra de Bragg diz que devemos fazer uma ponderação dos poderes de freamento de cada espécie, de acordo com a proporção em massa de cada uma no composto, e despreza os efeitos das ligações químicas, especialmente importantes no caso de compostos contendo $\mathrm{H}, \mathrm{C}, \mathrm{N}, \mathrm{O}, \mathrm{F}, \mathrm{S}$ e $\mathrm{Cl}([7],[8])$. A regra de Bragg ainda desconsidera que para vários elementos, como O e H, os poderes de freamento são medidos em fase gasosa.

\subsubsection{Poder de Freamento Nuclear}

O poder de freamento nuclear é, em geral, muito menor do que o eletrônico, dominando apenas em energias muito baixas (Figura 2.2). O processo de freamento nuclear se dá quando a velocidade do íon é comparável ou menor do que a dos elétrons atômicos do meio. Neste caso, a força atuante é a coulombiana blindada entre os núcleos, quando os elétrons com velocidade superior à do íon (inicialmente apenas os das camadas internas) produzem uma blindagem do potencial do núcleo, da forma:

$$
U(r)=\frac{Z_{1} Z_{2} e^{2}}{r} \phi\left(\frac{r}{a}\right) \quad \phi(0)=1 \quad \phi(\infty)=0
$$

onde o parâmetro a representa a distância crítica de blindagem [7]. A forma mais simples para a blindagem é o chamado potencial de Bohr, em que $\phi\left(\frac{r}{a}\right)=e^{-\frac{r}{a}}$. Embora funções mais complexas baseadas num formalismo mecanico-estatístico do átomo, como as desenvolvidas por Lindhard et al. ([4],[7]), apresentem melhor concordância com os valores experimentais, as parametrizações semi-empíricas como a ZBL [[4] [8]] são as que melhor apresentam concordância com os resultados experimentais, sendo portanto as mais indicadas para previsões de freamento. Na Figura 2.2 são apresentadas as curvas de poder de freamento calculadas pelo programa SRIM para íons de oxigênio em silício 
a energias baixas.

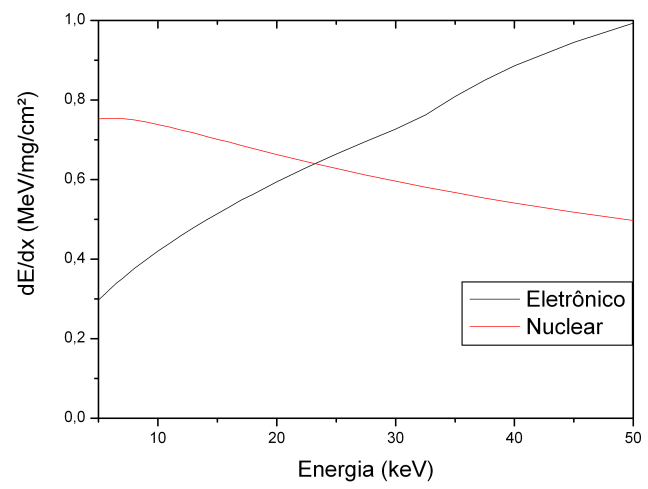

Figura 2.2: Curvas de poder de freamento calculadas com o programa SRIM [[8]] para íons de oxigênio em silício na região de baixas energias.

Uma vez que no freamento nuclear ocorre o espalhamento entre partículas de massas comparáveis, este é o processo responsável por grandes desvios angulares, acarretando num straggling angular (lateral) e em alcance das partículas, somando-se ao straggling em energia causado pelos processos de freamento eletrônico [7]. Tal efeito faz com o microvolume no qual a energia é depositada no final da trajetória de um feixe de partículas seja maior. O espalhamento entre massas comparáveis também origina um recuo, isto é, um átomo do meio sendo deslocado de sua posição original, podendo também depositar energia no meio [8]. Note-se que os processos de freamento nuclear não são capazes (na grande maioria dos casos) de gerar ionizações, de modo que sua perda de energia é classificada como Perda de Energia Não-Ionizante (Non-Ionizing Energy Loss - NIEL), que tem papel importante na formação de danos permanentes na rede cristalina, porém não gera carga nos dispositivos eletrônicos.

Além dos processos mencionados, um íon ainda pode perder energia por meio de reações ou processos nucleares (elásticos ou inelásticos) [1], caso em que os produtos do processo (fótons, nêutrons ou partículas carregadas) também irão depositar sua energia no meio através dos mecanismos já mencionados. 


\subsubsection{Materiais Semicondutores}

Um íon pesado, ao penetrar em um meio material, deposita energia neste ao longo de toda a sua trajetória, gerando ionizações, excitações, e danos ao material, como quebras moleculares e deslocamentos atômicos. Tal trajetória é chamada de traço da partícula no meio. Este traço é uma região que pode ser instável eletronicamente (quimicamente), caso as ionizações tenham sido responsáveis pela quebra de ligações químicas, como pode ocorrer, por exemplo, se um íon com energia suficientemente alta quebrar ligações ao atravessar uma camada de óxido de silício. Tal instabilidade eletrônica, entretanto, só ocorre em materiais dielétricos e semicondutores com alto bandgap [3], uma vez que nos materiais condutores o desequilíbrio eletrônico é prontamente corrigido devido aos efeitos da "nuvem eletrônica".

Caso a transferência de energia na colisão do íon com um elétron atômico tenha transferido mais energia do que a energia de ligação do elétron, os elétrons serão ejetados numa dada direção e terão um percurso dentro do meio antes de serem capturados por um átomo. Estes elétrons, aos quais chamamos de raios $\delta$ e cuja energia pode chegar a dezenas de $\mathrm{MeV}$ [11], depositarão energia ao longo de sua trajetória, contribuindo para uma distribuição da dose em um volume centrado na trajetória do íon. Ao longo da trajetória do íon inicial estará a maior parte do dano gerado (quebras moleculares) e deposição de energia, que será distribuída de forma não uniforme pelo raio do traço, da ordem de até centenas de nanometros $([12],[13])$. Raios $\delta$ de energia mais alta podem depositar energia a distâncias ainda maiores da trajetória do íon

Semicondutores são materiais com propriedades intermediárias entre as dos isolantes e dos condutores, e nestes o arranjo dos átomos e suas características eletrônicas levam à formação de bandas de valência e de condução com uma diferença de energia pequena entre elas (banda proibida - vide Figura 3.1b do Capítulo 3), de modo que as excitações podem promover um elétron à banda de condução ou a um dos estados "armadilhas", isto é, estados permitidos dentro da banda proibida, dos quais os elétrons podem ser 
liberados por efeitos térmicos ou por meio de radiação [3]. Os recuos de átomos da rede cristalina através dos processos de freamento nuclear criam deficiências na periodicidade da rede (defeitos cristalinos), contribuindo para a criação de novos estados armadilhas, ou seja, zonas de concentração de cargas.

Independente se o elétron foi promovido à banda de condução ou a um dos estados armadilha, cria-se uma lacuna na banda de valência, que atua como portador de carga positiva, cabendo ao elétron na banda de condução o papel de portador de carga negativa, enquanto elétrons armadilhados não atuam como portadores. Pode ainda ocorrer armadilhamento de lacunas, caso em que estas também deixam de participar da condução elétrica.

A promoção de elétrons à banda de condução depende da quantidade de energia depositada pela partícula na colisão e do tipo de material semicondutor, isto é, da largura da banda proibida (bandgap). No caso do silício, por exemplo, o bandgap é de $1,12 \mathrm{eV}$ a $300 \mathrm{~K}$, e a energia para a criação de um par elétron-lacuna é da ordem de três vezes este valor $(\sim 3,6 \mathrm{eV})$ [14], pois além da transferência de energia deve ocorrer transferência de momento. Caso uma partícula deposite uma energia de $50 \mathrm{MeV}$ no silício serão gerados cerca de 14 milhões de pares elétron-lacuna, além de possíveis pares gerados por raios $\delta$. Tal situação pode modificar-se na presença de um campo elétrico, quando os pares gerados podem produzir novas ionizações devido à aceleração.

Existem ainda algumas particularidades envolvendo a estrutura cristalina do silício: o poder de freamento é em geral calculado para íons penetrando no material em direções aleatórias (ou considerando o material como amorfo). Tal suposição assume que as interações são completamente aleatórias. Todavia, em sólidos cristalinos (monocristais, especialmente), pode ocorrer que os íons incidam sobre um plano cristalino específico, direção na qual a força coulombiana é tal que permite a passagem dos íons sem interagir com os elétrons mais ligados [15], o que diminui o poder de freamento e, portanto, a deposição de energia no meio por unidade de comprimento (ou volume), com a con- 
sequência de menor geração de portadores de carga no semicondutor. Tal fenômeno, conhecido como channeling, não foi levado em conta nos cálculos deste trabalho.

\subsection{Mecanismos de stripping de íons através de folhas finas}

Uma partícula carregada, ou até mesmo neutra, com alta velocidade (energia), ao atravessar um meio material, irá tanto perder elétrons para o meio quanto ganhar elétrons do meio. Sob certas condições, a perda irá sobrepujar o ganho de elétrons, e um íon carregado negativamente pode emergir do meio material positivamente carregado. Este fenômeno de troca de cargas (stripping), está intimamente relacionado aos aceleradores eletrostáticos do tipo tandem, em que um íon carregado negativamente é acelerado por um potencial positivo até uma folha de carbono onde ocorre a troca de cargas, de modo que o íon é novamente acelerado pelo mesmo potencial, agora repulsivo. Desta forma, o ganho de energia no acelerador é aumentado sem aumento de tensão.

A troca de cargas dos íons no meio material ocorre através das colisões entre os íons e os átomos do material (folha de carbono), sendo que um elétron é retirado do íon apenas se a energia transferida na colisão for maior que sua energia de ligação, de modo que os elétrons menos ligados são mais facilmente removidos ([16],[17],[18]). Sendo que tanto a perda quando a captura de elétrons pelo íon ocorrem quando o íon atravessa o meio, e a diferença entre as seções de choque de ocorrência destes dois fenômenos é que dá origem a uma distribuição de carga líquida positiva após o stripping, situação que pode ser descrita por meio da equação diferencial

$$
\frac{d Y_{q}(x)}{d x}=\sum_{q^{\prime}, q^{\prime} \neq q}\left[\sigma\left(q^{\prime}, q\right) Y_{q^{\prime}}(x)-\sigma\left(q, q^{\prime}\right) Y_{q}(x)\right]
$$

onde $Y$ denota as frações de íons com carga $q$ e $q^{\prime}$ (em unidades elementares), $\sigma\left(q^{\prime}, q\right)$ é a probabilidade de um íon de carga $q^{\prime}$ ter sua carga alterada para $q$ (analogamente para $\left.\sigma\left(q, q^{\prime}\right)\right)$ e $x$ é a espessura do meio. 
Existem diversas teorias para o cálculo destas seções de choque, algumas formulações baseadas na colisão elástica considerando o elétron em repouso, outras baseadas em modelos de eletrosfera como um gás de Fermi. De fato, a energia com que o íon incide sobre a folha (ou gás) de stripping influencia no mecanismo de perda de elétrons: energias relativísticas tendem a priorizar os processos de perda de um elétron por colisão, ao passo que em energias baixas e intermediárias dominam os processos de perda de vários elétrons por colisão [17], influenciando no resultado que se obtém para a distribuição de cargas do feixe. De modo geral, pode-se considerar que a ocorrência contínua destes processos, durante a passagem dos íons pela folha de carbono, faz com que o conjunto considerado aproxime-se de uma distribuição de carga de equilíbrio, que podemos calcular como sendo [19]:

$$
q_{e q}=Z_{1}\left[1-\exp \left(-\frac{0,97 v_{1}}{v_{T F}}\right)\right]
$$

onde $Z_{1}$ é o número atômico do íon, $v_{1}$ é a velocidade do íon e $v_{T F}$ é a velocidade de Thomas-Fermi dos elétrons do íon. A carga de equilíbrio em função da energia para diversos íons é mostrada na Figura 2.3.

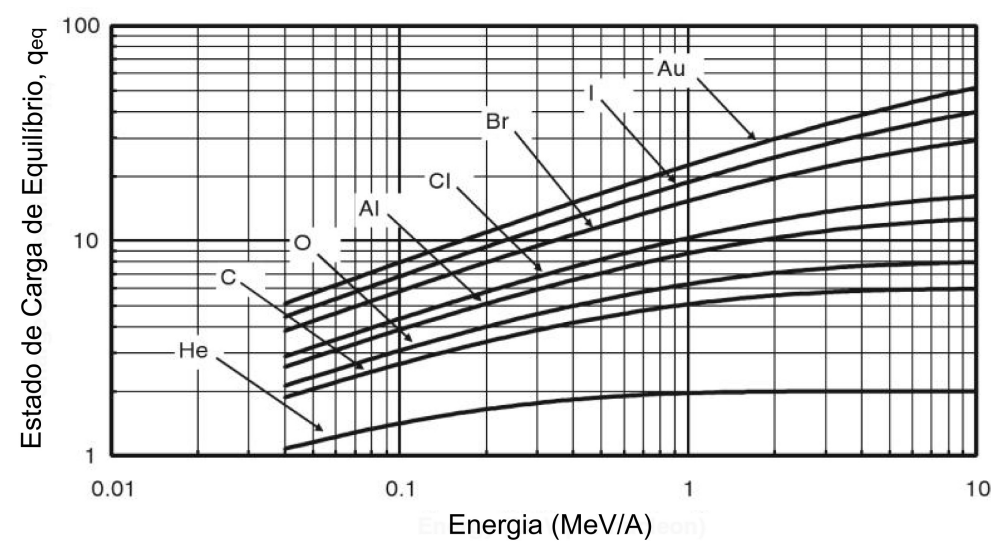

Figura 2.3: Dependência da carga de equilíbrio com a espécie iônica e a energia, segundo o modelo de Thomas-Fermi (adaptada de [19]) 
Evidentemente, o conhecimento apenas da carga de equilíbrio (que pode ser um valor fracionário) não possui interesse prático ao usuário do acelerador: é necessário conhecer a probabilidade de ocorrência de cada um dos estados de carga possíveis de serem gerados para um dado feixe a uma dada energia. Existem programas para este tipo de cálculo, como o CHARGE [20], que é utilizado no Laboratório Pelletron. O cálculo das probabilidades de ocorrência de cada estado de carga com este programa é feito considerando-se que a distribuição de estados de carga é uma distribuição gaussiana assimétrica da forma da Equação 2.5:

$$
F_{q}=F_{m} e^{\left(-\frac{0,5 t^{2}}{1+\epsilon t}\right)}
$$

onde $F_{q}$ e $F_{m}$ são as probabilidades do estado q e probabilidade máxima, respectivamente, e t é dado por:

$$
t=\frac{q-q_{0}}{\rho}
$$

Os parâmetros $\rho, \epsilon$ e $q_{0}$ são determinados através do ajuste de funções semi-empíricas do número atômico e velocidade do projétil [21], e para a utilização de stripper de carbono são dados através dos parâmetros [20]:

$$
\begin{gathered}
\epsilon=0 \\
\rho=0,38 Z^{0,51}(i(1-i))^{0,20}
\end{gathered}
$$

onde

$$
i=1-e^{\left[-55,8 Z^{-0,421} \beta^{0,890}\right]}
$$

para $\mathrm{Z}$ entre 6 e 15 e por:

$$
\begin{gathered}
\frac{\epsilon}{\rho}=0,0007 Z-0,7 \\
\rho=0,48 Z^{0,45}(i(1-i))^{0,26}
\end{gathered}
$$


onde

$$
i=1-1,03 e^{\left[-47,3 Z^{-0,380} \beta^{0,860}\right]}
$$

para $\mathrm{Z}$ maior que 15 , sendo que o produto iZ representa a carga mais provável e $\beta=v / c$.

Tal distribuição de equilíbrio só é atingida se a espessura do meio onde ocorre o stripping for maior que uma espessura crítica [19], além de não predizer corretamente os dados para altos estados de ionização [21]. Deve-se levar em conta que a medida das intensidades de cada estado de carga no acelerador é afetada também pela óptica deste.

\subsection{Cálculos de Taxa de Deposição de Energia do Íon no Meio}

Para o estudo de efeitos de íons pesados dotados de energia cinética em sistemas eletrônicos devemos conhecer a taxa de deposição de energia do íon no meio para avaliar a geração de pares elétron-lacuna. Enquanto o poder de freamento é a perda de energia por unidade de trajetória do íon no meio, definimos o Linear Energy Transfer (LET) como a quantidade de energia depositada por unidade de percurso do íon no meio. Claro é que a energia depositada no meio é aquela perdida pelo íon, o que nos levaria a igualar as duas quantidades, porém duas observações devem ser feitas:

- O LET é uma quantidade definida localmente, de modo que, dada uma energia de corte $\Delta$, raios $\delta$ com energia superior a esta não são contabilizados na energia depositada no microvolume considerado, havendo portanto uma diferença entre o valor de LET e o de stopping power (stopping power restrito) ([1],[2]).

- É muito difícil realizar os cálculos de LET com valores de corte, sendo para isto necessárias simulações de Monte Carlo envolvendo os raios $\delta$, sendo ainda difícil prever em quais condições cada valor de energia de corte será válido, pois esperase que o valor assumido represente uma deposição de energia tão distante que 
não influencie o estudo em questão, hipótese pouco provável ao se tratar de um semicondutor polarizado no qual nem mesmo se pode saber em que posição os íons o estão atingindo.

Desta forma, neste trabalho os cálculos de LET foram feitos considerando-se $\Delta=\infty$, situação em que o LET é numericamente igual ao poder de freamento de colisão do íon no meio.

Os cálculos foram realizados por meio dos softwares SRIM/TRIM [8] e LET Calculator [22], que utilizam as parametrizações semi-empíricas ZBL para os cálculos de poder de freamento, além de simulações de Monte Carlo para vários íons que permitem a visualização direta da curva de Bragg. Os programas geram tabelas de saída de stopping power e alcance de íons até $\mathrm{Z}=92$ em centenas de meios materiais, e tais tabelas foram usadas como banco de dados tanto para os cálculos de freamento de íons pesados tanto em janelas de feixe e folha espalhadora de ouro quanto no próprio dispositivo eletrônico sob ensaio. Tais bancos de dados foram combinados aos cálculos de cinemática e seções de choque para estimar rapidamente as perdas de energia do feixe nas diversas condições de irradiação e LET no dispositivo. 


\section{Capítulo 3}

\section{Efeitos de Radiação Ionizante em Dispositivos Eletrônicos}

Neste capítulo serão apresentados os fenômenos decorrentes da interação da radiação ionizante em dispositivos semicondutores de uso em eletrônica, suas consequências e os métodos para seu estudo.

\subsection{Dispositivos Semicondutores}

A maior parte dos sistemas eletrônicos é baseada na utilização de dispositivos semicondutores, que constituem desde células fotoelétricas a processadores e memórias de computadores pessoais. Tal gama de aplicações se deve ao fato de que dispositivos semicondutores permitem que a corrente elétrica flua em apenas um sentido ou então com uma intensidade controlada externamente, como numa válvula tríodo. Dentre os materiais semicondutores, podemos destacar o silício como sendo o mais importante, embora também existam outros como o germânio e materiais compostos como, por exemplo, o arseneto de gálio.

O silício é um elemento da família IV-A e possui quatro elétrons de valência. Um 
conjunto grande de átomos de silício pode se arranjar de maneira amorfa ou na forma cristalina, caso em que os átomos ocupam posições determinadas na rede, de modo que o potencial apresenta periodicidade. De modo geral, quando dois átomos de eletronegatividades semelhantes estão próximos, os orbitais eletrônicos de um são hibridizados aos do outro (acoplamento entre estados), de maneira que os pares de elétrons ocupam um orbital compartilhado por ambos os átomos, caracterizando uma ligação covalente. Numa rede cristalina com $n$ átomos, os níveis de energia, já próximos, sofrem acoplamentos e criam amplas faixas de energia (bandas) de estados permitidos, havendo também valores de energia intermediários e portanto não permitidos (bandas proibidas) $([14],[23])$.
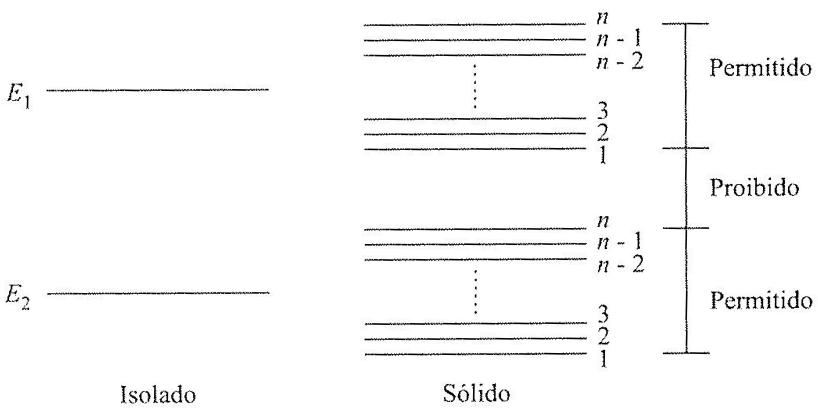

(a) Formação da estrutura de bandas em rede

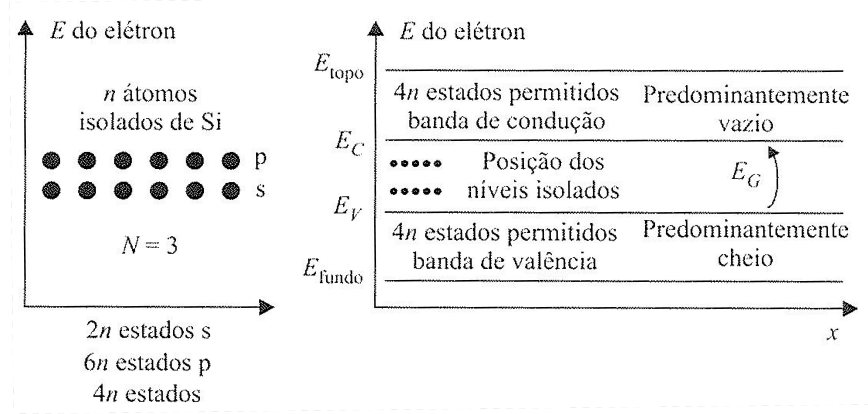

(b) Estrutura de Bandas no Silício

Figura 3.1: (a)Formação de estrutura de bandas em rede. (b)Estrutura de banda e ocupação do silício (Figuras reproduzidas de [23]). 
A largura da banda proibida depende do material, podendo ser alta ( $>3 \mathrm{eV}$ isolante), baixa ( $\sim 3 \mathrm{eV}$ - semicondutor) muito baixa ou até negativa (condutores). O acoplamento preserva o número de estados passíveis de ocupação, ou seja, no caso do silício, em que o orbital 3s é totalmente ocupado e o estado 3p possui 2 elétrons, havendo então estados disponíveis para 4 elétrons, numa rede de $\mathrm{n}$ átomos, cada banda irá comportar 4n elétrons, respeitando-se o princípio da exclusão de Pauli e a ocupação preferencial dos níveis de energia mais baixa. Pode-se determinar as energias das bandas pelo modelo de Kronig e Penney [23], que calcula os níveis de energia de um elétron (na primeira aproximação de Born [6]) submetido a um potencial periódico (rede cristalina) dos núcleos. A solução da equação de Schrödinger é dada em função da barreira de potencial entre os átomos e da distância entre eles.

Ocorre condução elétrica na presença de um campo elétrico apenas nas bandas não totalmente ocupadas, por um motivo simples: as bandas totalmente ocupadas não possuem estados livres para serem ocupados pelo elétron, que ganha energia cinética ao ser acelerado pelo campo [23]. De modo geral, chamamos a banda preenchida de banda de valência e a banda permitida semi-preenchida ou vazia é chamada de banda de condução. A promoção de elétrons de uma banda à outra ocorre por efeitos térmicos (mesmo à temperatura ambiente) ou por radiação, desde que, em qualquer dos casos, ocorra uma transferência de energia superior à largura da banda proibida, além da tranferência de momento, dependendo do material semicondutor. Defeitos cristalinos quebram a periodicidade do potencial e levam a formação de estados localizados (com poucos níveis de energia) permitidos dentro da banda proibida. Podemos chamar estes estados de "estados-armadilha", pois armadilham elétrons na banda proibida.

Ao ocorrer a promoção de um elétron da banda de valência à banda de condução, existe um estado vazio na banda de valência, permitindo que esta também possa conduzir elétrons. Esta "lacuna"comporta-se na presença de um campo elétrico como uma carga positiva de mesmo módulo que a carga do elétron, podendo ser considerada, as- 
sim como o elétron, um portador de carga . Embora a condução se dê apenas através dos elétrons, este artifício de considerar as lacunas como partículas é de uso prático no cálculo de dispositivos.

O silício e o germânio são chamados de semicondutores intrínsecos: o número de portadores de carga a uma dada temperatura é muito baixo, sendo a distribuição de ocupação dos estados dada pela função de distribuição de Fermi-Dirac (Equação 3.1). O aumento da concentração de portadores é feito por meio da adição (por crescimento epitaxial, difusão térmica ou implantação iônica) de elementos dopantes, que são solubilizados de forma substitucional na rede cristalina do silício. Caso seja adicionado um elemento da família IIIA (boro, alumínio, índio, etc), que possui um elétron a menos que o silício na camada de valência, haverá uma ligação covalente incompleta na rede, e, portanto, uma lacuna extra. Tal geração de um portador positivo faz com que este semicondutor seja chamado de material tipo p. A inserção de um elemento da família VA (fósforo, astato, antimônio, etc), também de forma substitucional, adiciona um elétron extra à rede, que, por não ocupar nenhum estado possível na banda de valência, é promovido à banda de condução. A concentração elevada de portadores negativos faz com que este semicondutor seja chamado de material tipo $\mathbf{n}$. A adição de dopantes altera a posição do nível de Fermi do semicondutor, aumentando a presença de portadores de carga a uma dada temperatura [23].

$$
f(E)=\frac{1}{1+e^{\left(E-E_{F}\right) / k T}}
$$

onde $\mathrm{f}(\mathrm{E})$ é a fração de portadores, $E_{F}$ representa a energia do nível de Fermi, k é a constante de Boltzmann e $\mathrm{T}$ é a temperatura (em kelvin).

Os portadores de carga movem-se através do material semicondutor através das ações de difusão e de deriva. Na difusão, os portadores se movem da região no cristal com maior concentração para a de menor concentração, ação que ocorre exclusivamente 
devido a efeitos térmicos. A ação de deriva ocorre na presença de um campo elétrico, quando os elétrons e lacunas movem-se em direções contrárias. As velocidades de deriva dos elétrons e lacunas dependem de suas mobilidades e do campo elétrico, variando com o campo até um valor máximo [23]. A velocidade de deriva sob a ação de um campo elétrico é dada pela Equação 3.2 :

$$
v_{d}=\mu \epsilon
$$

onde $\mu$ representa a mobilidade do portador e $\epsilon$ é o campo elétrico. A mobilidade dos elétrons em silício com baixa dopagem e a $300 \mathrm{~K}$ é de $1500 \mathrm{~cm}^{2} / V \mathrm{~s}$ e das lacunas nas mesmas condições é de $450 \mathrm{~cm}^{2} / V s$.

A existência de elétrons na banda de condução e lacunas na banda de valência não é um processo estático: a geração de portadores pode ocorrer por meio de processos que transfiram aos elétrons da banda de valência energia e momento suficientes para sua promoção à banda de condução, tais como: processos térmicos, efeito fotoelétrico (princípio dos detectores semicondutores do tipo $\mathrm{Si}(\mathrm{Li})$ e GeHP), deposição de energia por partículas carregadas (princípio dos detectores semicondutores do tipo barreira de superfície) ([3],[14]), entre outros. Na presença de um campo elétrico, pode ocorrer a multiplicação de portadores, se a energia adquirida por estes for suficiente para a criação de novos pares. A recombinação de portadores pode ocorrer por meio da transição direta entre as bandas no caso de semicondutores como o GaAs, ou por meio de transição indireta através dos estados-armadilha na banda proibida para semicondutores como o silício, pela necessidade da transferência de momento adicionalmente à de energia. Quanto maior a taxa de recombinação de portadores, menor o tempo de vida médio de um portador minoritário, e o tempo de vida necessário depende das aplicações e deve ser especificado no projeto de um dispositivo semicondutor, através da especificação de impurezas geradoras de armadilhas ([14],[23]). 


\subsubsection{Estrutura de Dispositivos Semicondutores}

De modo geral, dispositivos semicondutores são construídos através de combinações entre materiais tipo p, tipo n, metais e isolantes. Os processos de fabricação envolvem etapas químicas e de fotolitografia [23]. A junção mais simples é a junção p-n (diodo), em que um material tipo p e um tipo $\mathrm{n}$ são justapostos. Tal configuração cria uma região de depleção na junção, com a aniquilação de portadores e criação de um campo elétrico que compensa a ação da difusão (situação estática). Na presença de um campo elétrico na configuração de polarização direta, uma corrente passa através do dispositivo, corrente esta dependente da dopagem dos materiais p e n, e portanto, da concentração de portadores. Sob polarização inversa, a região de depleção é aumentada e nenhuma corrente se observará, porém caso ocorra a criação de portadores (por exemplo, por incidência de radiação), os portadores serão separados pelo campo elétrico e criarão um pico de voltagem até sua aniquilação pela fonte externa de campo [14]. Este tipo de junção forma os detectores do tipo barreira de superfície utilizados em Física Nuclear para detecção de partículas carregadas.

A junção metal-semicondutor, além de fazer o contato elétrico do semicondutor com o meio externo, possui algumas propriedades semelhantes à junção p-n, com características retificadoras. Na junção metal-semicondutor, o nível de Fermi dos materiais se iguala na região da junção e aparece uma barreira de potencial que impede que os elétrons de um material migrem para o outro.

A junção MOS (Metal-Oxide-Semiconductor) é uma das mais importantes nos dispositivos modernos. A junção MOS caracteriza-se por um metal (Al, Au ou outro material condutor) sobre uma camada de óxido de silício (isolante), depositado sobre o silício. Tal configuração é chamada de terminal de porta (gate) e aplicando uma tensão ao metal e ao silício (por meio de uma junção metal-semicondutor), obtém-se um capacitor. A aplicação da tensão cria cargas líquidas tanto no semicondutor quanto no metal (isolado). A partir de um certo valor de tensão, a concentração de portadores no 
silício torna-se alta o suficiente para que um campo elétrico possa fazer corrente fluir através do semicondutor [23].

As diversas junções permitem a construção de diversos dispositivos, tais como:

- Diodos e pontes retificadoras (Figura 3.2);

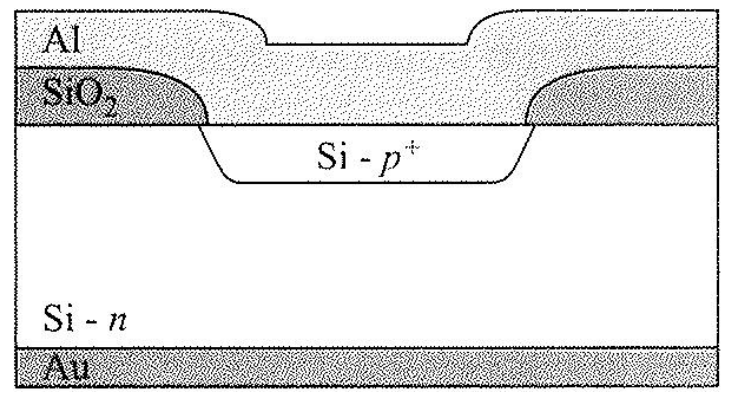

Figura 3.2: Representação esquemática de um diodo de junção p-n (reproduzido de [23])

- Diodos LED e Laser;

- Transistores de Junção Bipolar: duas junções (npn ou pnp) são feitas em série e controla-se a corrente entre as pontas (fonte e dreno) aplicando-se tensão no material central (base) (Figura 3.3);

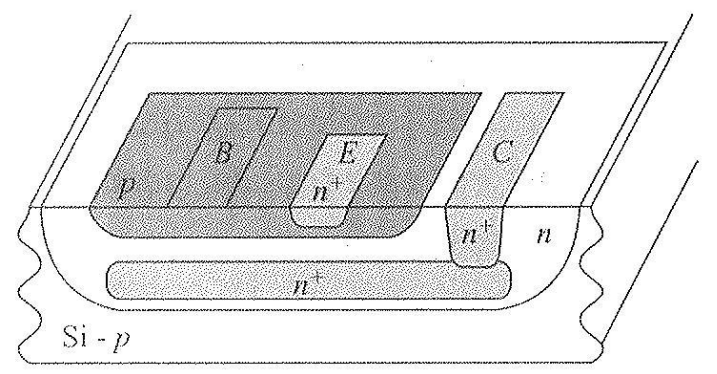

Figura 3.3: Representação esquemática de um transistor de junção bipolar (reproduzido de [23])

- Transistores de Efeito de Campo tipo MOS (MOSFET): em vez de injetar tensão na base, o transistor do tipo MOSFET tem a corrente entre a fonte e o dreno 
controlada através do campo gerado pelo capacitor formado pela junção MOS (Figura 3.4).

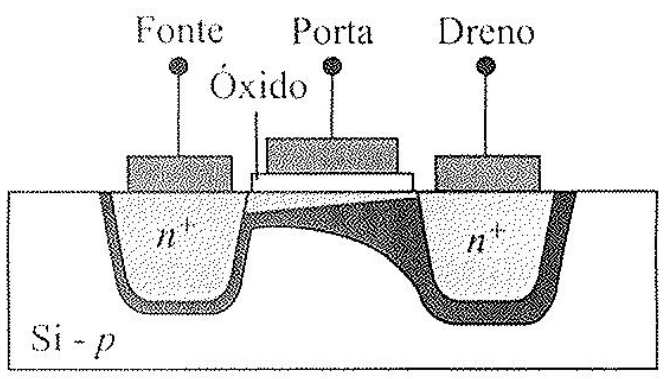

Figura 3.4: Representação esquemática de um MOSFET (reproduzido de [23])

- CMOS (Complementary Metal-Oxide Semiconductor): tecnologia que associa transistores MOSFET em série, utilizada na fabricação da maior parte dos circuitos integrados atuais.

\subsection{Efeitos de Radiação Ionizante em Dispositivos Eletrô- nicos}

A deposição de energia por radiação ionizante em um dispositivo semicondutor pode levar à criação de pares de portadores de carga, que, na presença de um campo elétrico, constituirão uma corrente ou pulso elétrico. De fato, desde a década de 1950 percebeuse que a radiação era uma fonte de falhas importante em dispositivos semicondutores, e este fato despertou o interesse de empresas do ramo de tecnologia, como a IBM, a Intel e a Texas Instruments [24]. As fontes de radiação podem ser as mais diversas: testes nucleares (primeiros registros de falhas por radiação), raios cósmicos, radiação proveniente de aceleradores de partículas, reatores e outras instalações nucleares e fontes naturais de radiação ([24],[25],[26],[27]).

Na década de 1960 já se havia observado que a eletrônica embarcada em satélites não era imune a falhas, e diversos estudos foram feitos para determinar a influência 
da radiação cósmica sobre os dispositivos eletrônicos. Observou-se que tanto partículas provenientes do Sol quanto extra-galáticas (incluindo-se prótons, nêutrons, partículas sub-nucleares e íons pesados, estes representando menos de 1\%) poderiam causar falhas nos dispositivos, fosse por via direta, fosse por meio de reações nucleares. Com o tempo, observou-se também que falhas ocorriam em dispositivos terrestres e embarcados em aviação comercial: tais efeitos eram devidos à contaminação por isótopos alfa-emissores no encapsulamento dos dispositivos ([24],[28]) e pela interação de raios cósmicos com a atmosfera terrestre, criando chuveiros de partículas que incluem prótons, nêutrons e até mesmo píons e múons ([26],[27],[29],[30]), todos eles capazes de gerar efeitos de radiação sobre dispositivos eletrônicos.

A miniaturização constante dos dispositivos eletrônicos, isto é, o maior adensamento de dispositivos em uma só pastilha de silício e sendo cada dispositivo menor, contribui para o maior aparecimento de efeitos de radiação, uma vez que a carga crítica para a mudança de estado de um bit, por exemplo, foi se tornando menor ao longo dos anos ([24],[28]). Desta forma, os esforços para a eliminação e mitigação (redução ou correção) dos efeitos de radiação sobre dispositivos eletrônicos vêm sendo intensificados, e mesmo efeitos descobertos há muito tempo, como por exemplo o decorrente das contaminações de alfa-emissores no encapsulamento, ainda são motivo de investigação, pois continuam a prejudicar tecnologias atuais ([28],[31]). No caso de sistemas de baixo custo e/ou fácil manutenção, comumente se faz a troca do dispositivo que apresente erros induzidos por radiação; todavia, no caso de eletrônica embarcada em satélites, por exemplo, deve-se garantir um tempo de operação bastante longo sem falhas que venham a comprometer o sistema.

Existem três formas básicas de tornar um sistema imune aos efeitos de radiação: a primeira consiste em construir circuitos redundantes e fazer com que a mesma informação seja tratada nos dois (ou mais) circuitos, e as falhas oriundas da radiação são prontamente corrigidas pela lógica do sistema; a segunda forma é construir blindagens 
para proteger o sistema do ambiente de radiação, e a terceira forma consiste em projetar dispositivos que, por sua própria construção (geometria, parâmetros de operação, etc), sejam mais resistentes à radiação [32]. A escolha entre os três métodos leva em conta custo e aplicabilidade. Além disso, para determinar a melhor forma de tornar os efeitos de radiação menos prejudiciais, devemos primeiro conhecer, para um dado dispositivo, quais os efeitos predominantes, sob quais condições eles se manifestam, qual a probabilidade de ocorrência e qual o prejuízo causado.

Os efeitos de radiação em dispositivos eletrônicos são separados em três classes principais: efeito de Dose Ionizante Total (TID), Dano por Deslocamento (DD) e Efeitos de Eventos Isolados (SEE).

\subsubsection{Dose Ionizante Total (Total Ionizing Dose - TID)}

Os efeitos de dose ionizante total são efeitos cumulativos causados pela dose depositada por diversas partículas, sejam elas íons pesados, prótons, nêutrons, elétrons ou fótons. A baixa deposição de energia destas partículas por diferentes processos não produz instantaneamente uma alta geração de pares elétron-lacuna que vá afetar o dispositivo, porém produz um efeito de acúmulo de cargas no óxido de silício, sendo, portanto, mais importante em dispositivos baseados em junções MOS.

O dióxido de silício utilizado em semicondutores é, em geral, amorfo, de forma que a junção entre o óxido e o silício puro (bulk) é uma região onde existe a perturbação do potencial periódico da rede, além de existirem átomos de oxigênio que também perturbam a periodicidade do potencial, levando-se à criação de armadilhas . Estas armadilhas podem tornar-se centro de acumulação de lacunas, uma vez que, sob a ação de um campo elétrico, as lacunas não conseguem se mover o suficiente para fora do óxido, pois sua mobilidade no dióxido de silício é ordens de grandeza menor que a dos elétrons [14]. Embora haja uma certa recombinação entre elétrons e lacunas, existe um acúmulo de carga líquida positiva armadilhada no óxido de silício, em especial na 
região de interface. Este acúmulo pode ser parcialmente corrigido por um tratamento térmico (annealing), podendo este ser induzido ou não. A irradiação em um dispositivo em operação, ou seja, com um campo elétrico interno potencializa o efeito.

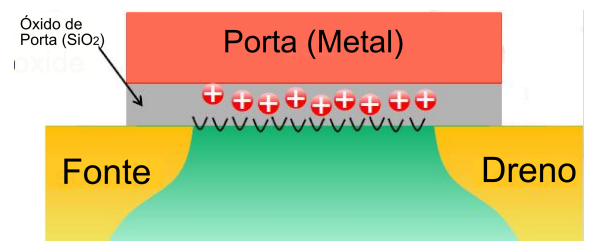

Figura 3.5: Armadilhamento de cargas positivas no óxido de porta (adaptada de [33].)

Os efeitos destas cargas armadilhadas são diversos, porém podemos sumarizá-los na degradação dos parâmetros elétricos dos dispositivos: diminuição da transcondutância, aumento das correntes de fuga por meio da criação de canais parasitas (ocasionando aumento da potência consumida), redução da tensão de breakdown, aumento do ruído rosa $^{1}$, mudanças na curva característica do dispositivo e mudança no valor de tensão de limiar (threshold) [25].

\subsubsection{Dano por Deslocamento (Displacement Damage - DD)}

Os danos por deslocamento são gerados pela componente não-ionizante da perda de energia por partículas como nêutrons, núcleos de recuo, prótons e elétrons de alta energia [34]. Colisões atômicas não-ionizantes levam ao deslocamento de átomos da rede, podendo criar diversos defeitos cristalinos, tais como vacâncias, pares de Frenkel, deslocamento para posições intersticiais, entre outros. A Figura 3.6 ilustra os defeitos cristalinos que caracterizam os danos por deslocamento [25]. Tais defeitos agem como regiões de acúmulo de carga devido ao efeito armadilha. Aumentos de temperatura podem provocar o annealing do cristal, minizando os efeitos indesejáveis, e embora possa ocorrer recuperação a temperatura ambiente, esta é desprezível.

\footnotetext{
${ }^{1}$ ruído com intensidade que varia inversamente com a frequência, portanto dominante a baixas frequências, que é ocasionado pelas flutuações estatísticas das propriedades dos materiais
} 


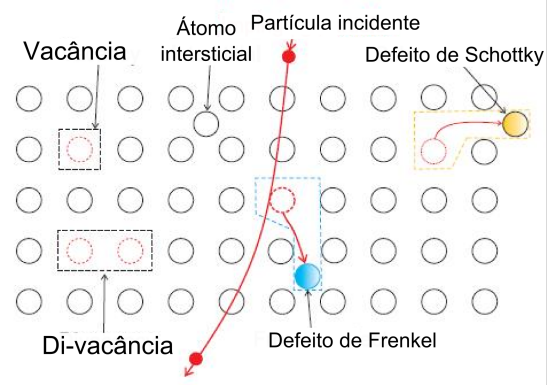

Figura 3.6: Ilustrações dos defeitos cristalinos causados pela incidência de radiação (adaptada de [25])

Os danos por deslocamento afetam principalmente transistores de junção bipolar e dispositivos como CCDs, uma vez que podem degradar o ganho do dispositivo, se usado como amplificador. Dispositivos do tipo MOS não são muito afetados por danos por deslocamento.

\subsubsection{Efeitos por Eventos Isolados (Single Event Effects - SEE)}

São chamados de Efeitos por Eventos Isolados (Single Event Effects) os efeitos em dispositivos eletrônicos causados pela incidência de uma única partícula ionizante, desde que esta partícula seja capaz de gerar uma quantidade de pares elétron-lacuna suficientemente grande para causar perturbações no circuito em operação. Em geral, as partículas causadoras de SEE são os íons pesados, desde partículas alfa ([26],[28]) até os elementos transurânicos, assim como os múons e píons ([26],[29]) e os produtos de reações e processos de espalhamento, que podem envolver nêutrons, prótons e partículas sub-nucleares ([26],[29],[35],[36]). Prótons podem gerar efeitos de eventos isolados por meio de ionização direta em dispositivos muito sensíveis ([37],[38]).

Dada a enorme variedade de processos que podem provocar a ionização que, por sua vez, cria o efeito indesejado, é muito mais prático estudar os SEE a partir da deposição de energia no dispositivo, deposição esta que irá gerar as ionizações. Em silício, uma partícula com LET de $1 \mathrm{MeV} / \mu m$ irá criar $2,8 \times 10^{5}$ pares elétron-lacuna por $\mu m$, o que 
corresponde a uma densidade de carga de $\pm 44,5 \mathrm{fC} / \mu \mathrm{m}$. Evidentemente, partículas com LET maior irão gerar maior quantidade de $\operatorname{pares}^{2}$, e a questão se reduz a determinar qual o mínimo LET capaz de gerar uma carga tal que resulte em um evento detectável no dispositivo, e a partir de qual valor de LET (carga) ocorre a saturação dos eventos. A tolerância a SEE diminui à medida que novas tecnologias tornam os dispositivos cada vez menores e mais densos, uma vez que as capacitâncias envolvidas e a quantidade de carga necessária para armazenamento de informações são menores, acarretando que partículas incapazes de gerar efeitos em dispositivos de 30 anos atrás, hoje são motivo de preocupação [29].

Ao penetrar num dispositivo semicondutor, um íon pesado irá depositar energia pelos processos já descritos no item 2.2, gerando um traço de ionização. As cargas neste processo são coletadas por deriva no campo elétrico. A ionização primária é também capaz de criar outros pares elétron-lacuna no semicondutor, em um processo que dura um intervalo da ordem de picossegundos. A alta concentração de pares elétron-lacuna na região do traço e em volta dela, muito maior do que a concentração de pares devido aos dopantes, forma o chamado plasma elétron-lacuna, uma região que exibe comportamento coletivo dos pares e que perturba o campo elétrico, se comportando como um condutor independente, que irá coletar todas as cargas geradas na ionização, num processo chamado de efeito funil (funnelling) ([27],[37]). Portadores de carga começam então a se movimentar pelo plasma e em volta dele até sua dissipação, quando os pares restantes irão se difundir pelo semicondutor ([27],[29],[37]). O pulso de corrente no semicondutor é então formado pela soma das contribuições direta e através do funnelling. A Figura 3.7 ilustra os processos, e a Figura 3.8 ilustra a forma do pulso, que é afetada pelo dispositivo considerado e pela quantidade de áreas sensíveis independentes existentes no dispositivo [39].

\footnotetext{
${ }^{2} \mathrm{LET}$ no valor de $97 \mathrm{MeV} / \mathrm{mg} / \mathrm{cm}^{2}$ corresponde a uma densidade de carga de $1 \mathrm{pC} / \mu \mathrm{m}$
} 


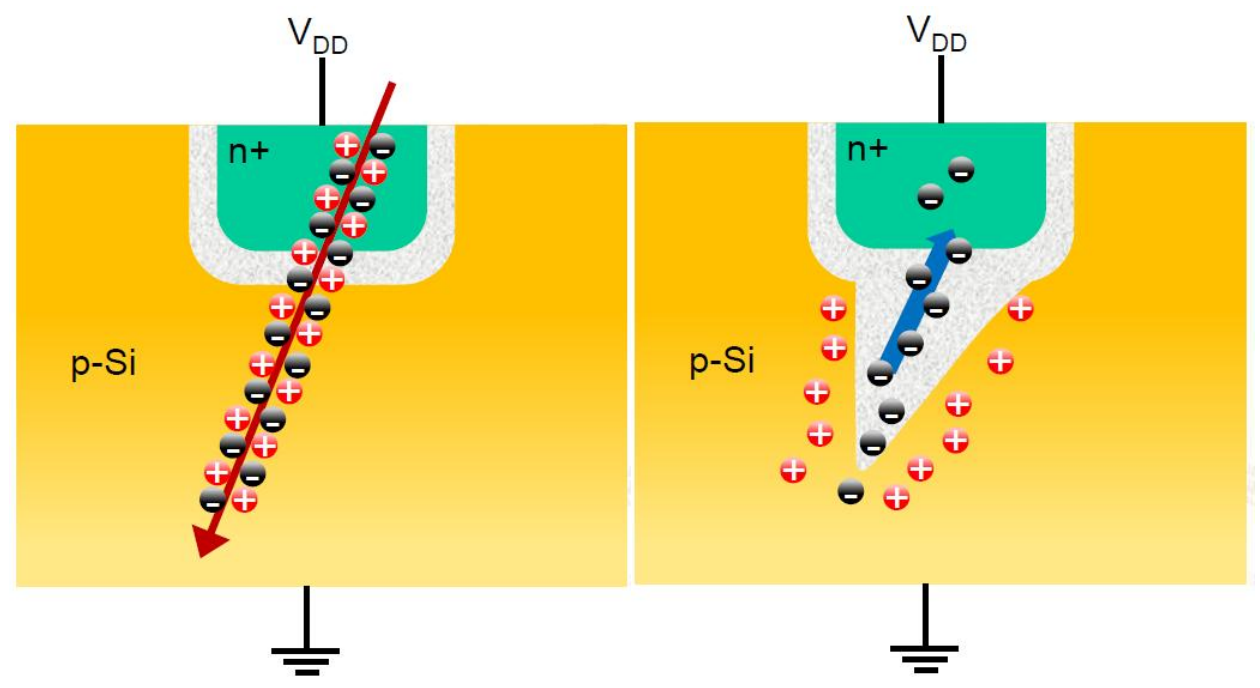

(a) Deriva

(b) Funil

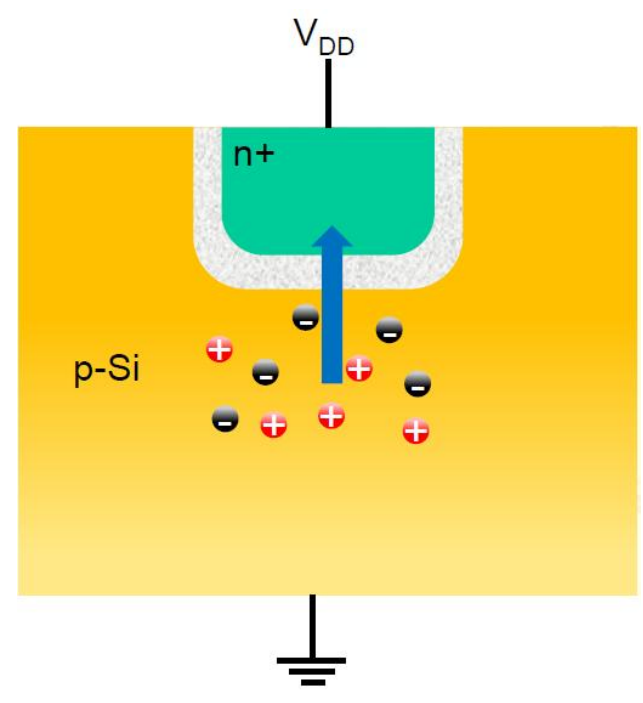

(c) Difusão

Figura 3.7: Ilustrações dos efeitos provocados pela passagem de um íon em um transistor. (a)Ionizações na passagem do íon. (b)Efeito-funil que permite maior coleção de carga. (c) Difusão do excesso de portadores restante. (Figuras adaptadas de [33]) 


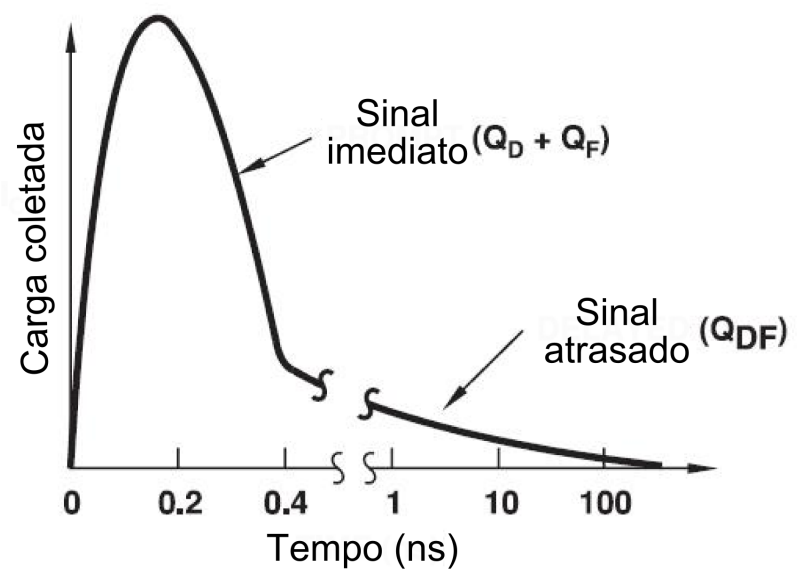

Figura 3.8: Forma do pulso gerado por um Efeito de Evento Isolado (SEE) (Figura adaptada de [27]).

A integral da carga coletada deve ser maior ou igual à carga crítica (mínima carga cujo efeito pode ser observado) do dispositivo, para que seja caracterizado um SEE. O mínimo valor de LET que gera no dispositivo uma carga crítica $Q_{C}$ capaz de provocar um SEE é chamado de LET de limiar (threshold LET, $L E T_{t h}$ ). O modelo RPP (Rectangular Paralellepiped) mostra que podemos considerar a camada sensível do dispositivo como um capacitor de placas paralelas, cuja capacitância $\mathrm{C}$ é dada em termos de suas dimensões e da permissividade do meio ([27],[29],[34]):

$$
C=\frac{Q}{\Delta V}=\epsilon \cdot \frac{S}{d}=\epsilon \cdot \frac{x y}{d}
$$

onde Q é a carga coletada, $\Delta V$ é a diferença de potencial aplicada, $\epsilon$ é a permissividade elétrica do meio, d a distância entre as placas (aplicação da tensão) e S a área das placas, que pode ser dada em termos dos lados x e y, assumindo um capacitor de placas retangulares. A carga gerada pelo íon na região sensível do dispositivo é calculada pela conversão da energia depositada em pares elétron-lacuna, na relação de 0,01 pC gerado para cada $\mathrm{MeV}$ de energia depositada.

Os estudos que visam quantificar a taxa de SEE o fazem por meio da medida da seção 
de choque de SEE, uma medida indireta da probabilidade de ocorrência de eventos. A seção de choque é calculada por:

$$
\sigma=\frac{\text { eventos }}{\Phi}
$$

onde $\Phi$ é a fluência do feixe acumulada durante o ensaio, em [partículas $\left./ \mathrm{cm}^{2}\right]$, o que faz com que a unidade de seção de choque seja uma unidade de área. Na condição de irradiação perpendicular, a seção de choque representa a área média do dispositivo sensibilizada durante o ensaio. No caso em que toda a área sensível apresente efeitos, tem-se a seção de choque de saturação, isto é, seu valor não aumenta, mesmo que aumente-se o LET incidente e, portanto, a carga depositada ([29],[34]).

Um experimento que avalie a seção de choque em função do LET tem como resultado uma distribuição de dados como mostrada na Figura 3.9, em que os dados seguem uma distribuição cumulativa de Weibull (equação 3.5), onde $\sigma_{\text {sat }}$ é a seção de choque de saturação, $L E T_{t h}$ é o LET de limiar e W e s são parâmetros de ajuste.

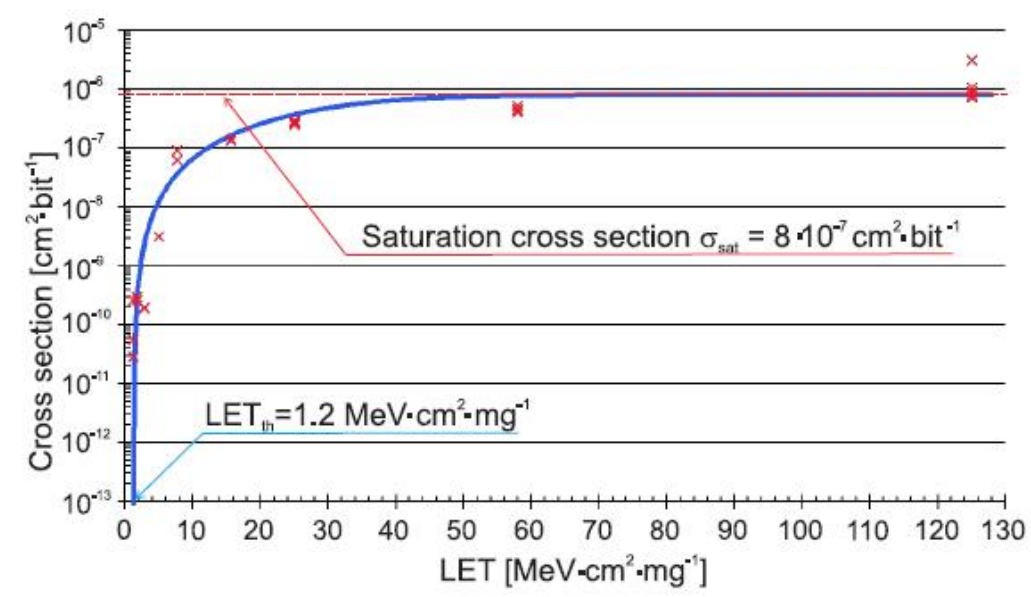

Figura 3.9: Exemplo de dados de seção de choque de SEE em função do LET incidente em um FPGA Xilinx Virtex VQVR300 e ajuste teórico (extraído de [25]). 


$$
\sigma=\sigma_{s a t}\left[1-e^{-\left(\frac{L E T-L E T_{t h}}{W}\right)^{s}}\right]
$$

O ajuste desta função a dados de seção de choque permite determinar o LET de limiar, caso não tenham sido feitas exaustivas medidas nesta faixa de LET, e a seção de choque de saturação. A seção de de choque de saturação é o valor representativo de que eventos ocorrem em toda a área sensível do dispositivo. Dada em unidade de área, podemos associar este valor à área sensível do dispositivo no modelo do capacitor ([29],[34]), conforme a Equação 3.3:

$$
x y=\frac{\sigma_{\text {sat }}}{\text { Número de regiões sensiveis }}
$$

O LET de limiar permite estimar a carga crítica e, conhecendo-se a tensão mínima que caracteriza um SEE no dispositivo (um parâmetro do dispositivo), é possível calcular a espessura da camada ativa pelo mesmo modelo, grandeza que seria obtida mais facilmente se fosse possível medir diretamente a quantidade de carga gerada no dispositivo. Porém, isto só é possível através de um sistema de aquisição, que possui impedâncias a serem consideradas. Modelos mais adequados e considerando dispositivos mais complexos envolvem simulações de Monte Carlo e uma descrição detalhada da geração e tranporte de cargas ([36],[40],[41],[42]).

Podemos dividir os Efeitos de Eventos Isolados (SEE) em duas classes: destrutivos, que tornam o dispositivo inoperante de forma definitiva, e não-destrutivos, que geram interferências ou falhas momentâneas que podem ser corrigidas com a reinicialização do sistema ou do ciclo [25]. 


\section{SEE Não-Destrutivos}

- Single Event Upset - SEU: a geração de carga produz picos de corrente/tensão que afetam a lógica (on/off) do dispositivo. Em geral, esses efeitos podem ser resumidos como a transformação de um bit de 0 para 1 ou vice-versa. Tais efeitos afetam principalmente dispositivos digitais, embora também possam ser observados em dispositivos analógicos. No caso de dispositivos digitais afetados em vários bits, este efeito é chamado de Multiple Bit Upset - MBU;

- Single Event Transient - SET: um efeito transiente (pulsos de voltagem/corrente) que se propaga através de todo o circuito, podendo ocasionar diversos SEU. Sua correção é complexa, uma vez que o efeito transiente gerado no dispositivo pode ser detectado apenas em outro ponto do circuito. Novas tecnologias são mais suscetíveis a SET, pois a carga crítica é menor.

- Single Event Functional Interrupt - SEFI: sub-classe de SEU relacionada à dispositivos digitais de alta densidade como FPGAs, pois a radiação pode afetar o sistema lógico do componente.

\section{SEE Destrutivos}

- Single Event Latch-Up - SEL: um tiristor ${ }^{3}$ parasita é ativado em circuitos CMOS por uma partícula de alto LET, causando uma espécie de "curto-circuito", gerando alto fluxo de corrente e sobreaquecimento que podem destruir o dispositivo. Como o tiristor parasita é ativado nas camadas profundas (abaixo dos canais fonte e dreno), é importante que a partícula seja capaz de depositar energia nesta região.

- Single Event Burn-out - SEB: dispositivos de potência em estado desligado podem ser ativados por uma partícula capaz de gerar carga suficiente para queimar o dispositivo.

\footnotetext{
${ }^{3}$ tiristores são dispositivos semicondutores multicamadas que operam em regime de chaveamento e são compostos por, no mínimo,três junções semicondutoras.
} 
- Single Event Gate Rupture - SEGR: afeta principalmente dispositivos de potência do tipo MOS. A coleção de cargas na interface $\mathrm{Si} / \mathrm{Si} O_{2}$ quebra sua rigidez dielétrica, aumentando o campo na porta e levando a uma condição de alta corrente capaz de queimar o dispositivo.

\subsubsection{Técnicas e Normas}

As técnicas para investigação de TID em geral envolvem fontes de radiação X, gama, além de aceleradores de prótons e elétrons. Como TID é um efeito de dose, os ensaios são feitos avaliando a resposta do dispositivo a diferentes doses de radiação. Os ensaios para estudo de DD podem ser realizados por meio de íons pesados acelerados, sendo porém mais comuns os ensaios com nêutrons provenientes de reatores ou de instalações de spallation ${ }^{4}$. Os ensaios para verificação de SEE podem ser conduzidos com nêutrons [35] (que provocam SEE por via indireta), lasers [37], aceleradores de prótons e íons pesados ([24],[29],[37]) e fontes radioativas alfa-emissoras ou fissionáveis.

Os experimentos com laser baseiam-se na formação de uma quantidade de pares elétron-lacuna no semicondutor semelhante à gerada na passagem de um íon pesado pela camada ativa do dispositivo. Para tanto, necessita-se de um laser de pulso ultracurto, com luminosidade da ordem de $10^{15} \mathrm{~W} / \mathrm{cm}^{2}$ e comprimento de onda adequado. Os experimentos com laser emulam os resultados de íons pesados de uma forma mais simples e barata, além de permitir a varredura de área em busca de regiões sensíveis de forma mais econômica que um microfeixe iônico. Todavia, o tamanho do spot é muito maior do que o traço de ionização de um íon pesado, não correspondendo, portanto, a exatamente ao mesmo fenômeno [37].

Os experimentos para verificação de susceptibilidade a SEE com íons pesados devem ser conduzidos de forma a garantir um fluxo uniforme no dispositivo sob ensaio (Device Under Test - DUT) e baixo o suficiente para que seja possível separar eventos distintos

\footnotetext{
${ }^{4}$ spallation é a produção de nêutrons de alta energia por meio do espalhamento inelástico de prótons de alta energia em alvos pesados.
} 
e evitar outros tipos de dano ao dispositivo (doses altas demais implicando TID, sobreaquecimento). Normas técnicas para estes ensaios foram estabelecidas pela Agência Espacial Européia [43], pela Sociedade Americana de Testes e Materiais [44] e pela Associação das Indústrias de Eletrônica [45], e discorrem sobre energias e faixas de LET adequados, quantidade de ensaios ideal, características dos feixes, monitoramento dos dispositivos, cálculos, entre outros. As principais recomendações são:

- Área do feixe: o feixe deve ter uma área grande o suficiente para cobrir toda a área de interesse. A princípio, a recomendação é de um feixe de 1-2 cm de diâmetro [45].

- Uniformidade: o feixe deve ser uniforme em intensidade dentro de uma tolerância de $10 \%$ na área considerada.

- Fluxo: os fluxos de partículas devem estar compreendidos na faixa de $10^{2}$ e $10^{5}$ íons $/ \mathrm{cm}^{2} / \mathrm{s}$. Tal requisito visa garantir que o dispositivo não seja atingido por mais de um íon durante um ciclo de aquisição de dados.

- Fluência: o fluxo acumulado no tempo deve estar compreendido entre $10^{7} \mathrm{e}$ $10^{8}$ íns $/ \mathrm{cm}^{2}$.

- Eventos: no caso da ocorrência de 100 eventos, o teste pode ser encerrado mesmo sem atingir a fluência mínima [45].

- Energia e LET: a energia e o LET do feixe no dispositivo devem ser conhecidos dentro de uma variação máxima de $10 \%$. O LET pode ser conhecido a partir da energia e de simulações computacionais. Para que o LET não varie mais que 10\%, deve-se garantir que a curva de Bragg (Figura 2.1) na região onde a carga é coletada (camada ativa) forme um platô, condição geralmente satisfeita quando o alcance é muito maior que a espessura da camada ativa. 
- Alcance: o alcance mínimo do feixe deve ser de $30 \mu \mathrm{m}$ em silício. Todavia, este requisito é mais importante para estudos de SEL (em que a junção relevante está muito abaixo da camada ativa), sendo que nos demais casos se pode considerar que o alcance deve apenas ser muito maior que a espessura da camada ativa [44].

- Feixes: deve-se realizar o ensaio com diversos feixes, de preferência alguns feixes com o mesmo LET, pois os efeitos podem variar com a espécie iônica. Se possível, deve-se tomar dados até duas vezes o LET de saturação. Do contrário, ao menos $120 \mathrm{MeV} / \mathrm{mg} / \mathrm{cm}^{2}$ é o limite recomendado.

Existem ainda outras recomendações, como por exemplo a de um sistema de manipulação de DUTs e possibilidade de inclinação $\theta$ com relação ao feixe, quando se obtém um LET efetivo referente a uma maior deposição de energia numa menor espessura, ou seja, maior deposição no volume sensível:

$$
L E T_{e f f}=\frac{L E T}{\cos \theta}
$$

Caso em que o fluência deve ser corrigida por:

$$
\Phi_{e f f}=\Phi \cdot \cos \theta
$$

Os requisitos das normas técnicas devem ser ajustados futuramente, uma vez que a rápida evolução dos dispositivos semicondutores pode alterar a forma como devem ser estudados os Efeitos de Eventos Isolados.

Neste trabalho, utilizou-se a técnica de espalhamento Rutherford para obter os fluxos e uniformidade recomendados. Considerou-se como alcance mínimo $10 \mu \mathrm{m}$, uma vez que em geral a espessura ativa é da ordem de 1-5 $\mu \mathrm{m}$ [23]. 


\section{Capítulo 4}

\section{Cinemática de Espalhamento}

\section{Elástico}

Neste capítulo são apresentados os cálculos de cinemática e seções de choque utilizados para determinar o fluxo e energia das partículas espalhadas nos experimentos.

\subsection{Espalhamento Elástico de Duas Partículas}

Quando duas partículas interagem sem haver mudança de energia interna destas partículas, conservando-se portanto energia e momento, chamamos este processo de espalhamento elástico. De modo geral, podemos assumir as partículas iniciais como tendo massas $m_{1}$ e $m_{2}$, e as partículas após a interação (colisão) com massas $m_{3}$ e $m_{4}$, a conservação de energia (supondo a partícula 2 em repouso) fica:

$$
m_{2} c^{2}+E_{1}+m_{1} c^{2}=E_{3}+m_{3} c^{2}+E_{4}+m_{4} c^{2}
$$

sendo que $m_{i} c^{2}$ corresponde à energia de repouso da partícula $i$. Segue que:

$$
E_{1}+\left(m_{1}+m_{2}-m_{3}-m_{4}\right) c^{2}=E_{3}+E_{4}
$$




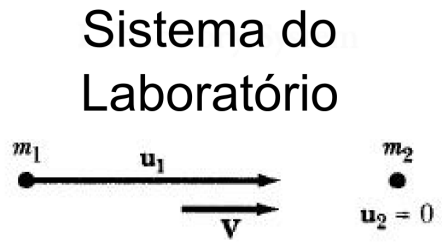

(a) Condição Inicial

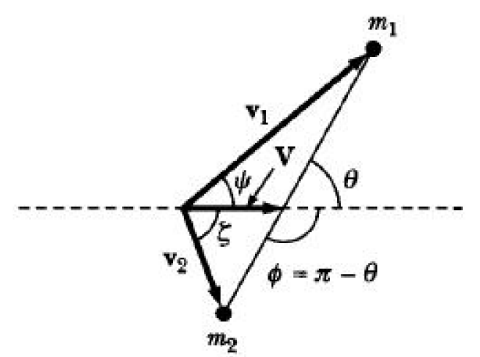

(c) Condição Final

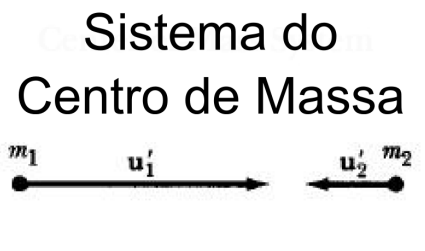

(b) Condição Inicial

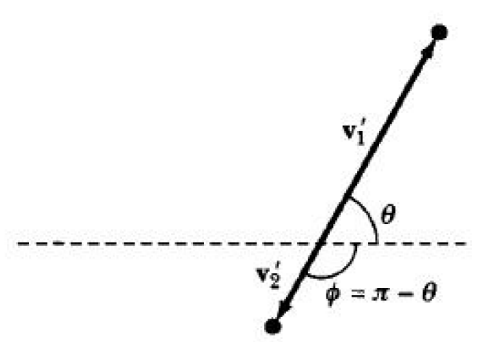

(d) Condição Final

Figura 4.1: Espalhamento de duas partículas, nos referenciais de laboratório e centrode-massa(adaptada de [46]).

onde o segundo termo do lado esquerdo é chamado de Q da reação e reflete a mudança da energia de centro de massa do sistema. No caso do espalhamento elástico, $Q=0$, de modo que $E_{1}=E_{1}^{\prime}+E_{2}^{\prime}$, onde o sobrescrito indica o estado após o espalhamento e as partículas iniciais e finais são as mesmas, ou seja, não há reação nem processos inelásticos. Quanto à conservação de momento, caso a colisão não seja frontal, isto é, ocorra com um parâmetro de impacto $b$, as partículas serão espalhadas em ângulo, conforme a Figura 4.1:

De modo que

$$
\begin{gathered}
\overrightarrow{p_{1}}={\overrightarrow{p_{1}}}^{\prime}+{\overrightarrow{p_{2}}}^{\prime} \\
p_{1}=p_{1}^{\prime} \cos \theta+p_{2}^{\prime} \cos \phi \\
p_{1}^{\prime} \operatorname{sen} \theta=p_{2}^{\prime} \operatorname{sen} \phi
\end{gathered}
$$

Que se reduz a um sistema simples, no caso não relativístico, de quatro incógnitas 


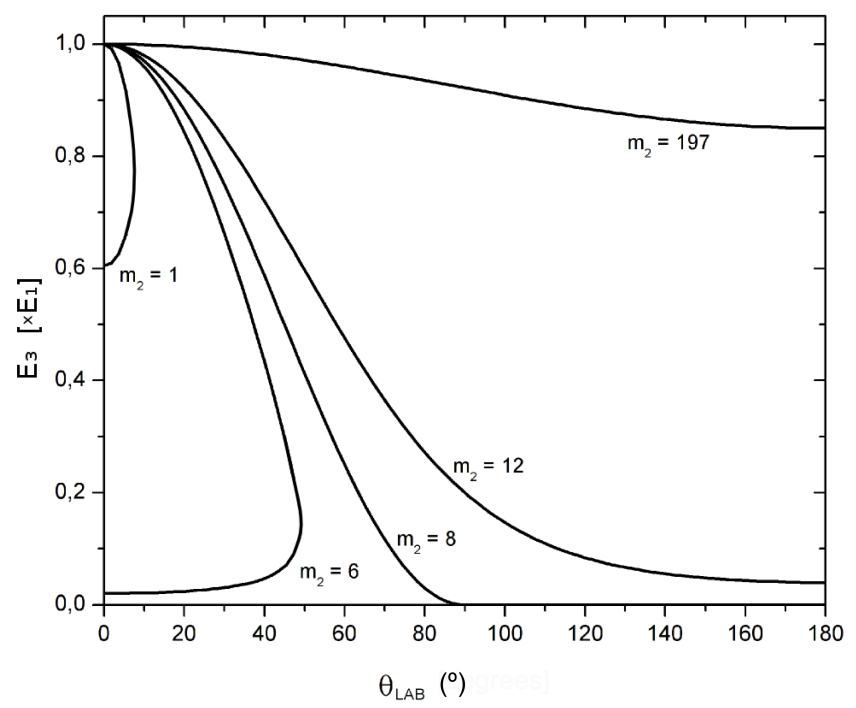

Figura 4.2: Cinemática direta e inversa para projétil de ${ }^{8} L i$ (cortesia de Erich Leistenchneider).

e três equações, cuja solução é:

$$
\frac{E_{1}^{\prime}}{E_{1}}=\frac{m_{1}^{2}}{\left(m_{1}+m_{2}\right)^{2}}\left[\cos \theta+\sqrt{\frac{m_{2}^{2}}{m_{1}^{2}}-\operatorname{sen}^{2} \theta}\right]^{2}
$$

Da equação 4.1 podemos observar que para determinadas relações $m_{2}^{2} / m_{1}^{2}$ existe um ângulo máximo a partir do qual o sistema não possui solução. Tal situação é a de ocorrência de cinemática inversa, isto é, projétil mais pesado que o alvo. Tal situação é ilustrada na Figura 4.2:

Os cálculos de cinemática são importantes no contexto deste trabalho, pois devemos prever a energia das partículas espalhadas num dado ângulo, usado para irradiação de dispositivos eletrônicos com feixes de íons pesados. A ocorrência de cinemática inversa limita o ângulo de espalhamento, além de, para um dado ângulo, haver duas soluções em energia, de modo que isto deve ser levado em conta dependendo do material espalhador que se deseja utilizar. 


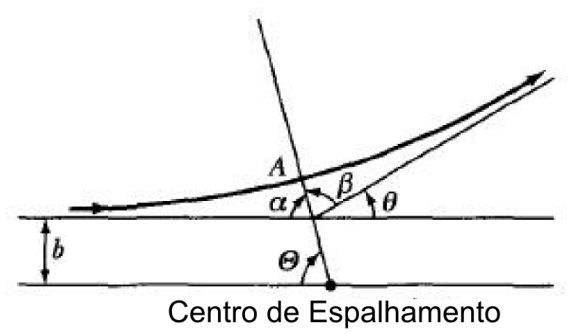

Figura 4.3: Espalhamento de uma partícula de massa reduzida por um potencial (adaptada de [46])

\subsection{Seção de Choque de Espalhamento}

Se partículas com um determinado parâmetro de impacto $b$ atingem um alvo fixo, é possível saber o ângulo de espalhamento. Num experimento de Física Nuclear, não é possível conhecer os parâmetros de impacto, então utiliza-se a grandeza chamada de seção de choque, definida como sendo o número de partículas espalhadas num dado ângulo para cada partícula do alvo, sobre o número de partículas incidentes, e deve ser entendida como a probabilidade de observar uma partícula a um dado ângulo. Uma vez que a probabilidade de observação das partículas depende do ângulo sólido (distância e área) do centro espalhador à região de observação, define-se a seção de choque diferencial como:

$$
\sigma(\theta)=\frac{d \sigma}{d \Omega} \quad\left[\frac{\text { área }}{\text { esterradiano }}\right]
$$

O cálculo da seção de choque para um potencial é feito assumindo o sistema como tendo apenas uma partícula com massa reduzida

$$
\mu=\frac{m_{1} m_{2}}{m_{1}+m_{2}}
$$

espalhada por um centro de força (Figura 4.3).

Definindo $r$ como a coordenada relativa entre a partícula e o centro espalhador, o 
momento angular é dado por $L=p b=\mu r^{2} \dot{\Theta}$, de modo que a energia total é

$$
E=\frac{1}{2} \mu \dot{r}^{2}+\frac{L^{2}}{2 \mu r^{2}}+V(r)
$$

Usando a formulação Lagrangiana ([46],[47]), obtemos:

$$
\Theta=\int_{\infty}^{r_{\min }} \frac{b d r}{r^{2} \sqrt{1-\frac{V}{E}-\frac{b^{2}}{r^{2}}}}
$$

Sendo a energia baixa e o núcleo-alvo pesado, podemos assumir que não existe interação nuclear, sendo o campo elétrico do núcleo o único responsável pelo espalhamento, isto é,

$$
V(r)=\frac{Z_{1} Z_{2} e^{2}}{r}
$$

De modo que, $\operatorname{com} \theta=\pi-2 \Theta$ resulta como solução da integral:

$$
\frac{d \sigma}{d \Omega}=\left(\frac{Z_{1} Z_{2} e^{2}}{4 E}\right)^{2} \frac{1}{\operatorname{sen}^{4}\left(\frac{\theta}{2}\right)}
$$

Esta é a seção de choque de espalhamento Rutherford no referencial do centro-demassa, derivada por E. Rutherford em 1911, e nos permite calcular a taxa de partículas num dado ângulo conhecendo-se a energia do feixe e número atômico do feixe e do alvo. Esta função diverge em $\theta=0$, pois corresponde a um parâmetro de impacto tendendo ao infinito [48]. A unidade de seção de choque é, em geral, o barn $\left(1\right.$ barn $\left.=10^{-24} \mathrm{~cm}^{2}\right)$.

O cálculo da seção de choque a partir de dados experimentais é feito considerandose o número de núcleos espalhadores por $\mathrm{cm}^{2}$ no alvo $\left(N_{\text {alvo }}\right)$, o número de eventos observados $\left(N_{\text {contagens }}\right)$, o número de partículas do feixe por segundo $\left(N_{\text {feixe }}\right)$, o ângulo sólido $\Delta \Omega$ compreendido pelo detector e o jacobiano (transformação de coordenadas entre os sistemas de centro-de-massa e de laboratório), sendo dada por: 


$$
\frac{d \sigma}{d \Omega}=\frac{N_{\text {contagens }} J_{\text {acobiano }}}{N_{\text {feixe }} N_{\text {alvo }} \Delta \Omega}
$$

O jacobiano pode ser expresso por [49]:

$$
\frac{\left(1+x^{2}+2 x \cos \left(\Theta_{e s p}^{C M}\right)\right)^{3 / 2}}{\left(1+x \cos \left(\Theta_{e s p}^{C M}\right)\right)}
$$

onde $\Theta_{e s p}^{C M}$ é o ângulo de espalhamento no referencial do centro de massa e x é dado por

$$
x=\sqrt{\frac{m_{\text {ion }}^{2} E_{\text {inicial }}}{m_{\text {alvo }}^{2}\left(E_{\text {inicial }}+Q\right)}}
$$

, onde $E_{\text {inicial }}$ é a energia do íon incidente e $m_{\text {ion,alvo }}$ referem-se às massas do íon incidente e do alvo, respectivamente.

A simples manipulação desta equação permite, conhecendo-se a seção de choque (cálculo de Rutherford), calcular o número de partículas espalhadas num dado ângulo, e, portanto, conhecer o fluxo naquela direção.

Os cálculos de cinemática, seção de choque e perdas de energia permitem prever as melhores condições experimentais para a irradiação dos circuitos eletrônicos, além de correções angulares entre o detector monitor e o dispositivo sob teste. 


\section{Capítulo 5}

\section{Materiais e Métodos}

Neste capítulo são apresentados os equipamentos e procedimentos utilizados na tomada de dados.

\subsection{O Acelerador Pelletron}

O presente trabalho buscou iniciar o estudo de efeitos de radiação de íons pesados sobre circuitos eletrônicos no Brasil, e sendo o Acelerador Pelletron do LAFN-USP o único acelerador de íons pesados no Brasil com tensão de operação de até $8 \mathrm{MV}$, é de vital importância conhecer em detalhes seu funcionamento. O Acelerador Pelletron 8UD é em acelerador eletrostático tipo Tandem, em que um íon com carga negativa é acelerado por uma diferença de potencial positiva até uma região de trocas de carga, passando a ser novamente acelerada após a troca de cargas. Veremos em detalhe este mecanismo adiante.

\subsubsection{Fonte de Íons}

A geração de feixes iônicos com carga negativa pode ser feita de diversas formas, como por exemplo por meio de fontes de plasma ou fontes de sputtering. No caso do Ace- 
lerador Pelletron 8UD, usa-se uma fonte MC-SNICS (Multi-Cathode Source of Negative Ions by Cesium Sputtering), produzida pela NEC (National Electrostatics Corporation). Neste tipo de fonte de íons, uma quantidade de césio é aquecida a cerca de $120^{\circ} \mathrm{C}$ por meio de uma resistência elétrica, produzindo-se vapor de césio metálico no interior da fonte de íons. Parte desse vapor deposita-se sobre o ionizador, que consiste de uma superfície de tântalo de formato cônico, aquecida a $1000-1200^{\circ} \mathrm{C}$, produzindo íons $\mathrm{Cs}^{+}$. A utilização de tântalo como material do ionizador é devida à sua alta função trabalho [19]. Estes íons carregados positivamente são então atraídos por um potencial negativo de $5 \mathrm{kV}$, aplicado ao cátodo. O cátodo consiste de um cadinho metálico que comporta o material (em pó) do qual serão extraídos os íons negativos, sendo que um único cátodo pode conter mais de uma espécie atômica de modo a prover diferentes feixes. A fonte de íons comporta até 32 cátodos diferentes, donde vem o nome multi-catodo. O feixe positivo de Cs, ao ir de encontro ao cátodo, não apenas se deposita neste, criando uma camada muito fina em sua superfície, mas também provoca sputtering no material, isto é, arranca átomos do material, ejetando-os. Neste processo de sputtering, os átomos arrancados passam através da fina camada (monocamada) de césio depositada sobre a superfície. Devido à sua alta eletropositividade, ocorre o fenômeno de ionização superficial [19]. Os íons negativos (carga -e) gerados neste processo são repelidos e, portanto, acelerados pelo potencial positivo de $20 \mathrm{kV}$ aplicado ao extrator e passam através de um furo no ionizador. Um esquema do processo pode ser visto na Figura 5.1. Após a passagem pelo extrator, o feixe negativo é acelerado por uma tensão de $90 \mathrm{kV}$ [50], além de focalizado, direcionado e colimado em direção ao primeiro eletroímã seletor, cuja função é descrita na próxima seção. 


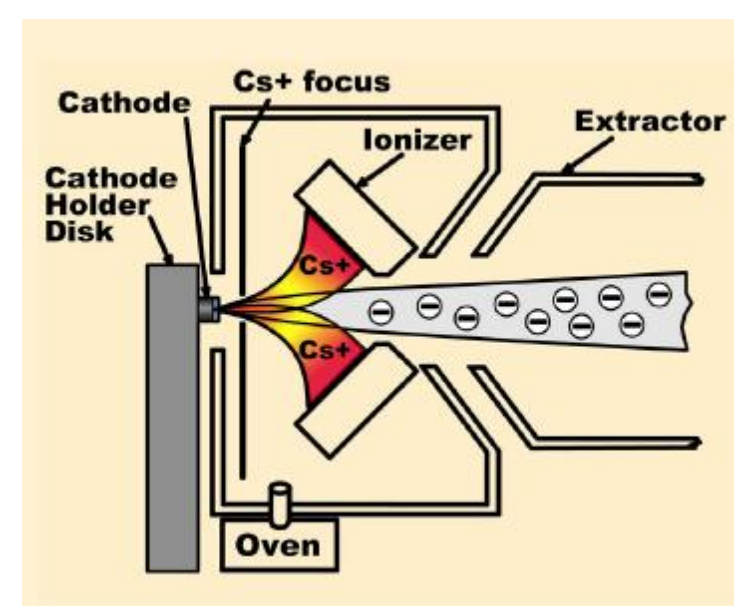

Figura 5.1: Esquema simplificado do processo de extração de feixes negativos (extraído de [50]

\subsubsection{Acelerador}

Após a produção na fonte de íons, o feixe passa através de um eletroíma seletor de massas, o ME-20, onde 20 significa a máxima razão $m E / q^{2}(a . m . u . \times M e V)$ das partículas que o eletroímã consegue defletir em $90^{\circ}$. A deflexão em $90^{\circ}$ é responsável pela seleção de massa dos íons de interesse, uma vez que o campo magnético é ajustado de forma que só sejam defletidos com trajetória central os íons com rigidez magnética

$$
B \rho=\frac{m v}{q}
$$

onde $\mathrm{m}, \mathrm{v}$ e q são respectivamente a massa, a velocidade e a carga do íon, e $\rho$ é o raio da trajetória.

Após a seleção de massas, o feixe entra no acelerador propriamente dito. O acelerador consiste de colunas com divisores resistivos e anéis metálicos para a distribuição suave e uniforme de campo elétrico. No centro do acelerador está o terminal, onde a tensão de aceleração (positiva de até $8 \mathrm{MV}$ ) é aplicada [51]. O carregamento do terminal é feito por meio de duas correntes com cilindros metálicos (pellets) isolados por conexões 
de nylon. O carregamento dos pellets com carga positiva é feito por meio de indução elétrica, assim como a transferência desta carga ao terminal. Na região do terminal existem 3 dispositivos: o voltímetro gerador, que consiste em um sistema que mede a corrente através de um capacitor de área variável, cuja tensão é a própria tensão do terminal, servindo para fazer o controle grosseiro de energia; a agulha de corona, cujo objetivo é usar a leitura do voltímetro gerador, e das fendas, como veremos adiante, para manter a energia constante [49], e um carretel com diversas folhas de carbono cuja função é efetuar a troca de carga do feixe. O sistema de carregamento é ilustrado na Figura 5.2. Embora o interior do tubo acelerador fique em vácuo para a passagem do feixe, todo o ambiente dentro do tanque é imerso em hexafluoreto de enxofre, um gás altamente isolante, a uma pressão de 4 a 6 atm.

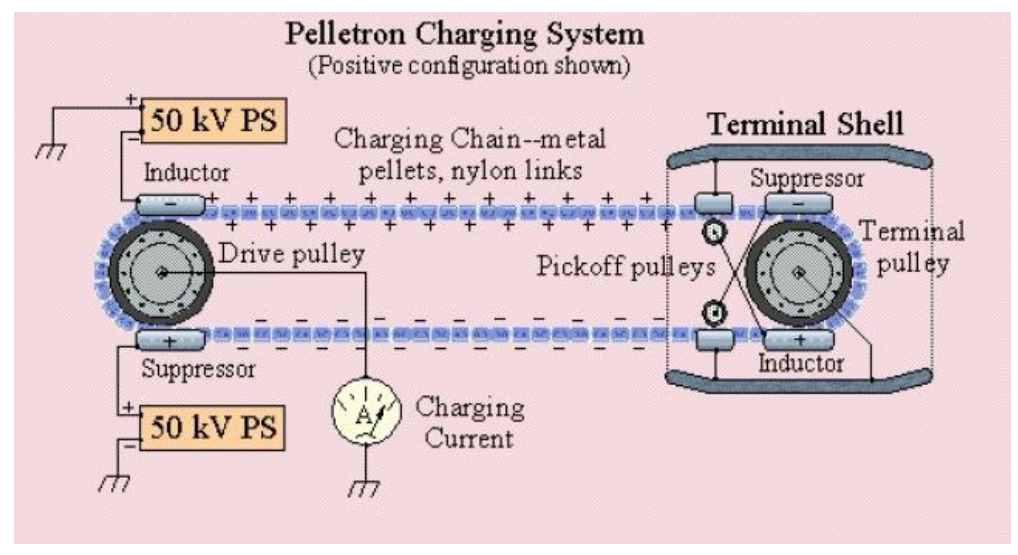

Figura 5.2: Esquema simplificado do processo de carregamento do terminal em um acelerador Pelletron (extraído de [52]).

A distribuição de tensão no acelerador é feita de forma que os extremos estejam aterrados e o terminal na tensão de operação. Desta forma, ao entrar no acelerador, as partículas do feixe (com carga -e) são aceleradas até terminal, ganhando portanto uma energia

$$
E_{1}=V
$$

onde V é a tensão no terminal. Neste ponto, existe uma folha de carbono de espessura da 
ordem de $5 \mu \mathrm{g} / \mathrm{cm}^{2}$, onde o feixe inicialmente negativo perde elétrons (conforme 2.3), tornando-se positivo. A troca de cargas faz com que no segundo estágio da máquina o feixe ganhe energia

$$
E_{2}=q V
$$

onde q é a carga positiva gerada (em unidades de carga elementar), de modo que a energia total, desprezando a contribuição de $90 \mathrm{keV}$ da fonte de íons, passa a ser:

$$
E=(1+q) V
$$

Após a saída do acelerador, o feixe deve passar por um segundo eletroíma analisador (equação 5.1), uma vez que a distribuição de estados de carga reflete-se em uma distribuição de energia. No ME-200, eletroíma com relação máxima 200, o controle preciso do campo magnético é necessário para se conhecer com precisão a energia do feixe. Para isto, conta-se com uma amostra de água dentro do entreferro do íma, imersa portanto no campo magnético da ordem de 0,7 T do ME-200. Incidindo-se sobre a amostra uma onda eletromagnética com frequência de Larmor e com intensidade tal que $H_{o s c}<<H_{M E 200}$, tem-se o fenômeno de ressonância magnética, em que os prótons da amostra irão absorver os fótons e passarão a um nível de energia superior ([53],[54]). O campo magnético do ímã no qual está imersa a amostra é proporcional à frequência de Larmor, e podemos relacionar a energia do feixe com a frequência por meio da equação [54]:

$$
E=M u\left[\left(1+2 \frac{Z^{2} f^{2} k}{(M u)^{2}}\right)^{1 / 2}-1\right] M e V
$$

onde $\mathrm{M}$ é o número de massa do íon, u é a unidade de massa atômica em $\mathrm{MeV}$ ( u=931,478 MeV), k é a constante de calibração do eletroímã e f é a frequência de ressonância.

A medida da frequência de Larmor é feita através de uma bobina de indução, na 
qual um sinal é gerado quando da transição dos prótons do nível de energia superior ao inferior. Um esquema do sistema é apresentado na Figura 5.3.

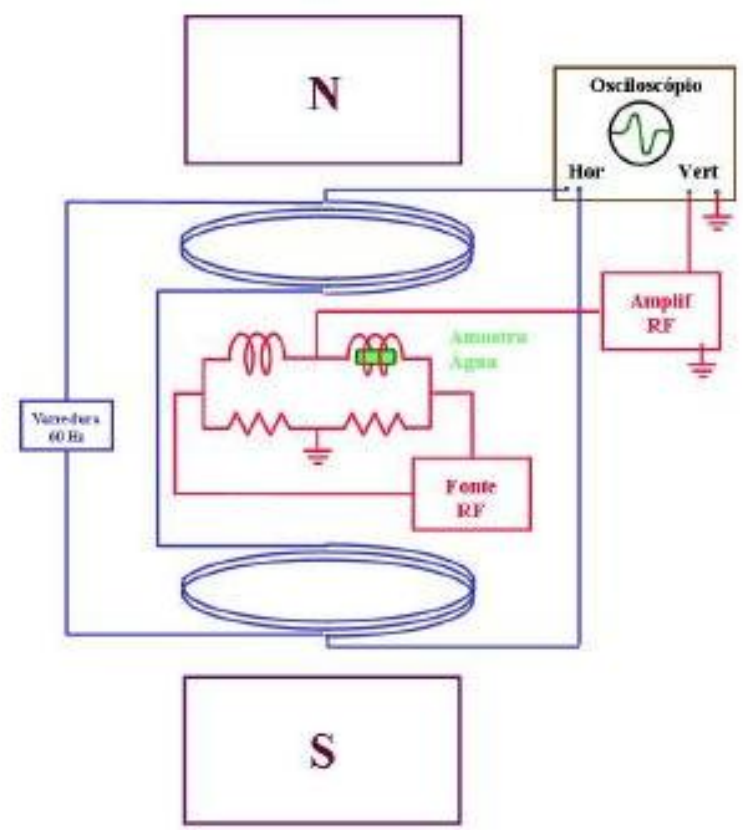

Figura 5.3: Esquema simplificado do processo de medida da frequência de ressonância magnética (cortesia de Nemitala Added).

Após a passagem pelo eletroímã analisador, o feixe deve passar entre duas fendas que fazem o controle fino da energia do acelerador. Caso a energia do feixe esteja abaixo do esperado pela frequência de ressonância, que mantém o controle do campo magnético, a curvatura gerada no feixe é maior do que $90^{\circ}$ e um sinal elétrico (corrente de feixe) lido na fenda superior é maior que na inferior. Um circuito faz a comparação destes dois sinais e controla a indução de carga aos pellets de modo a corrigir a energia, atuando de modo idêntico para o caso de energia superior ao ajustado.

Após as fendas, o feixe passa por um último eletroímã (Switching Magnet), cuja função é desviá-lo para uma das 7 canalizações disponíveis no Acelerador Pelletron. A Figura 5.4 mostra uma visão geral do prédio do acelerador, a Figura 5.5 dá destaque à área experimental e a Figura 5.6 mostra um esquema dos elementos do acelerador. 


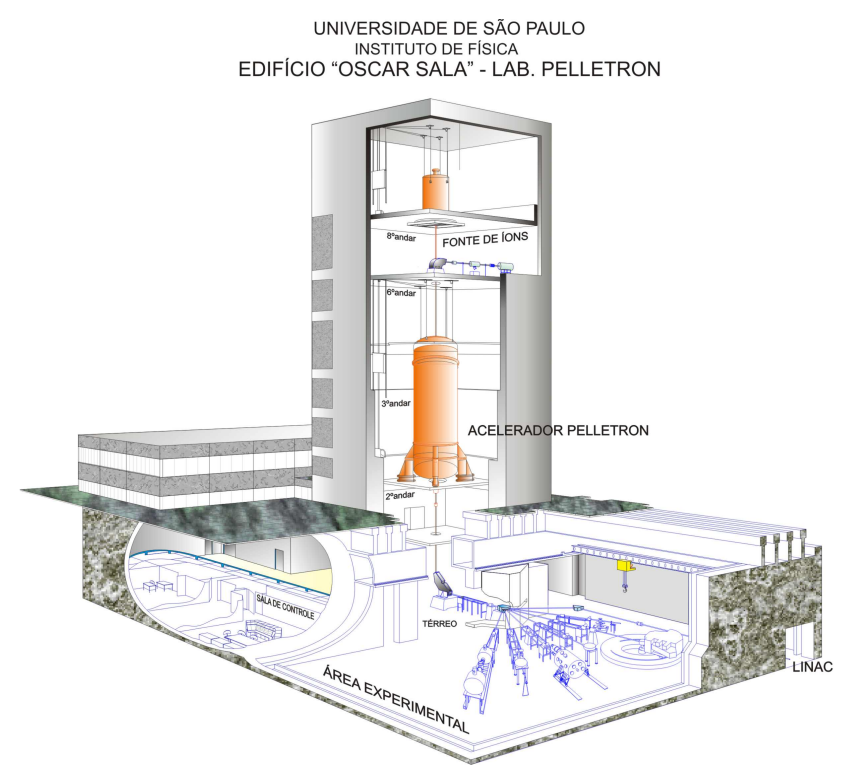

Figura 5.4: Visão geral do Acelerador Pelletron (cortesia de João Carlos Terassi).

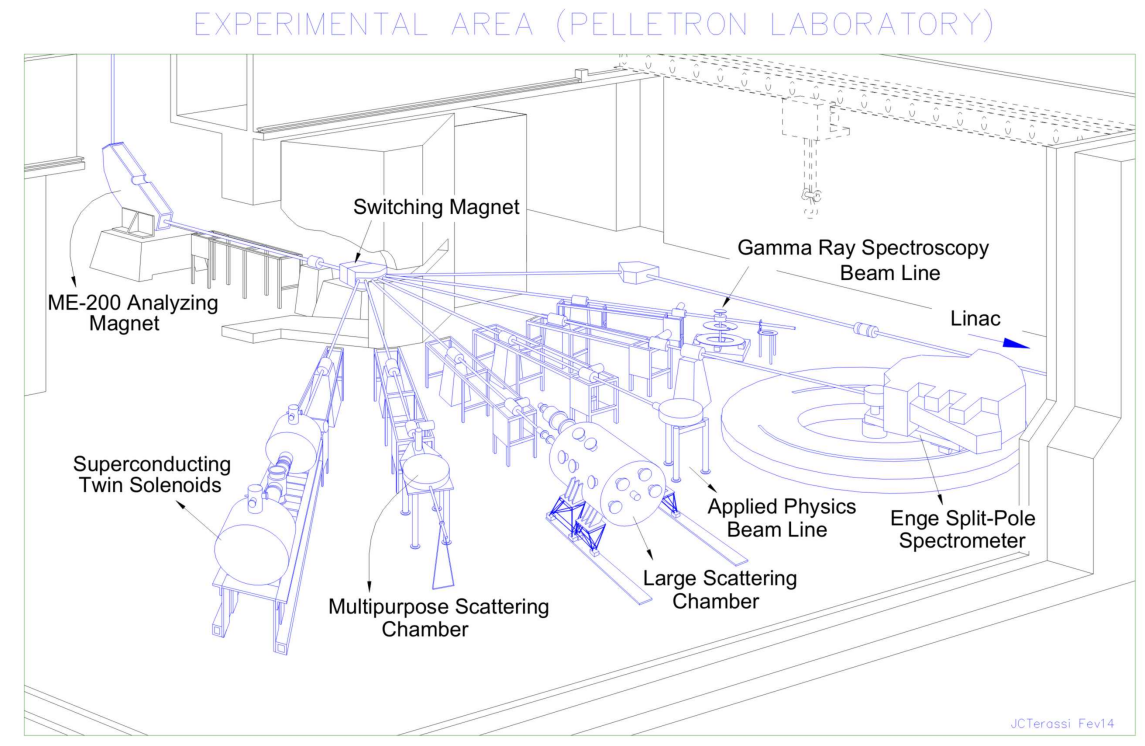

Figura 5.5: Detalhe da sala experimental, onde a linha utilizada nos experimentos realizados neste trabalho foi a 30B (Multipurpose Scattering Chamber) (cortesia de João Carlos Terassi). 


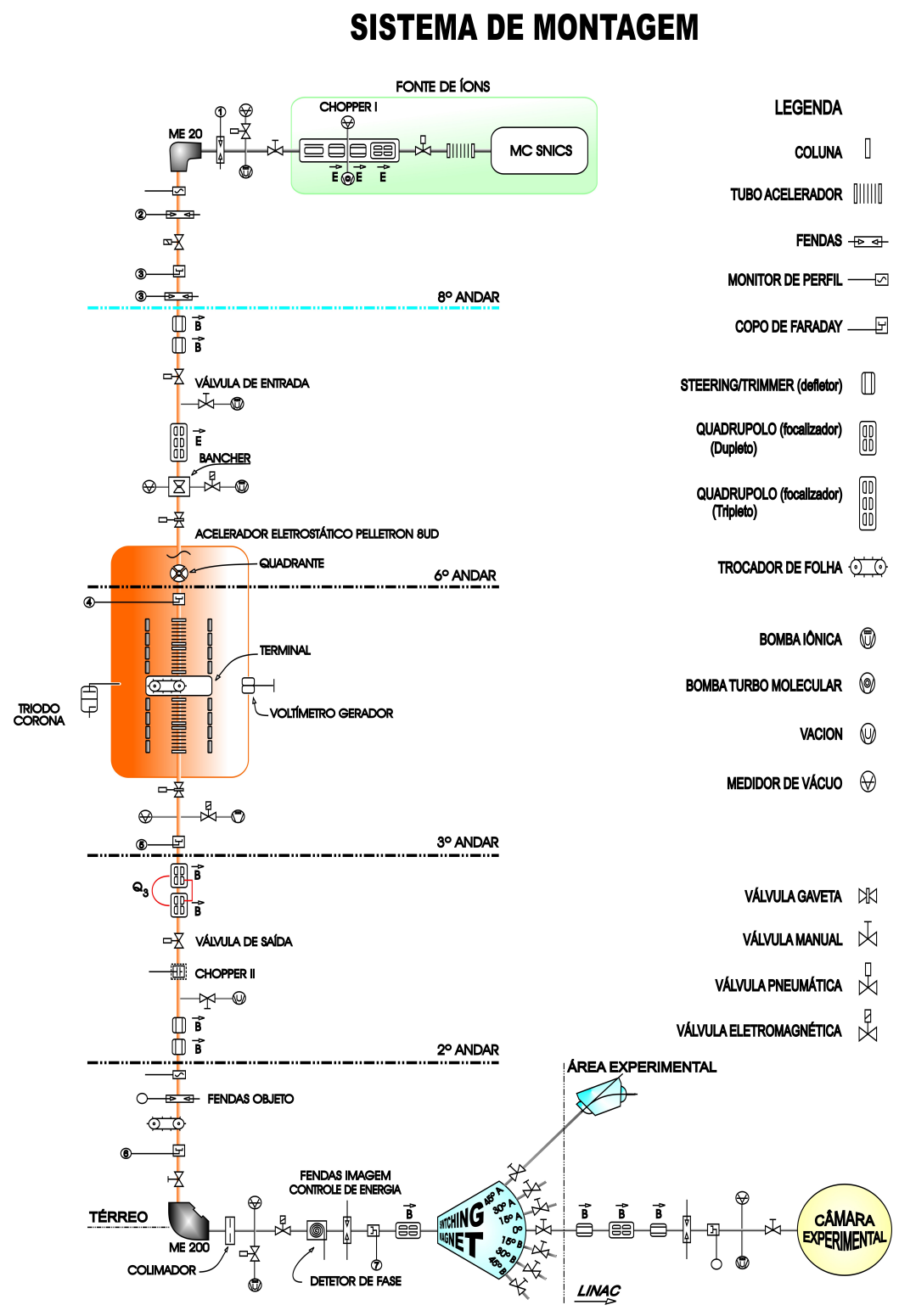

Figura 5.6: Diagrama geral do acelerador Pelletron com todos os elementos ópticos (cortesia de João Carlos Terassi). 


\subsection{A Canalização 30B}

Os experimentos foram realizados na canalização $30^{\circ} \mathrm{B}$ da área experimental do Laboratório Aberto de Física Nuclear. Esta linha possui uma câmara de espalhamento de uso geral de 1 metro de diâmetro e cerca de 30 centímetros de altura, duas bombas turbo-moleculares para mantê-la numa pressão da ordem de $10^{-6}$ Torr e um prolongamento que pode ser usado tanto para feixe externo direto quanto para medida de corrente de feixe. Dentro da câmara existe um braço giratório que pode ser utilizado tanto para fixação de detectores de partículas quanto de dispositivos a serem irradiados. A câmara dispõe de diversas flanges laterais para passadores de sinal. A Figura 5.7 apresenta um desenho esquemático da câmara, e na Figura 5.8 são mostradas algumas fotos da câmara.

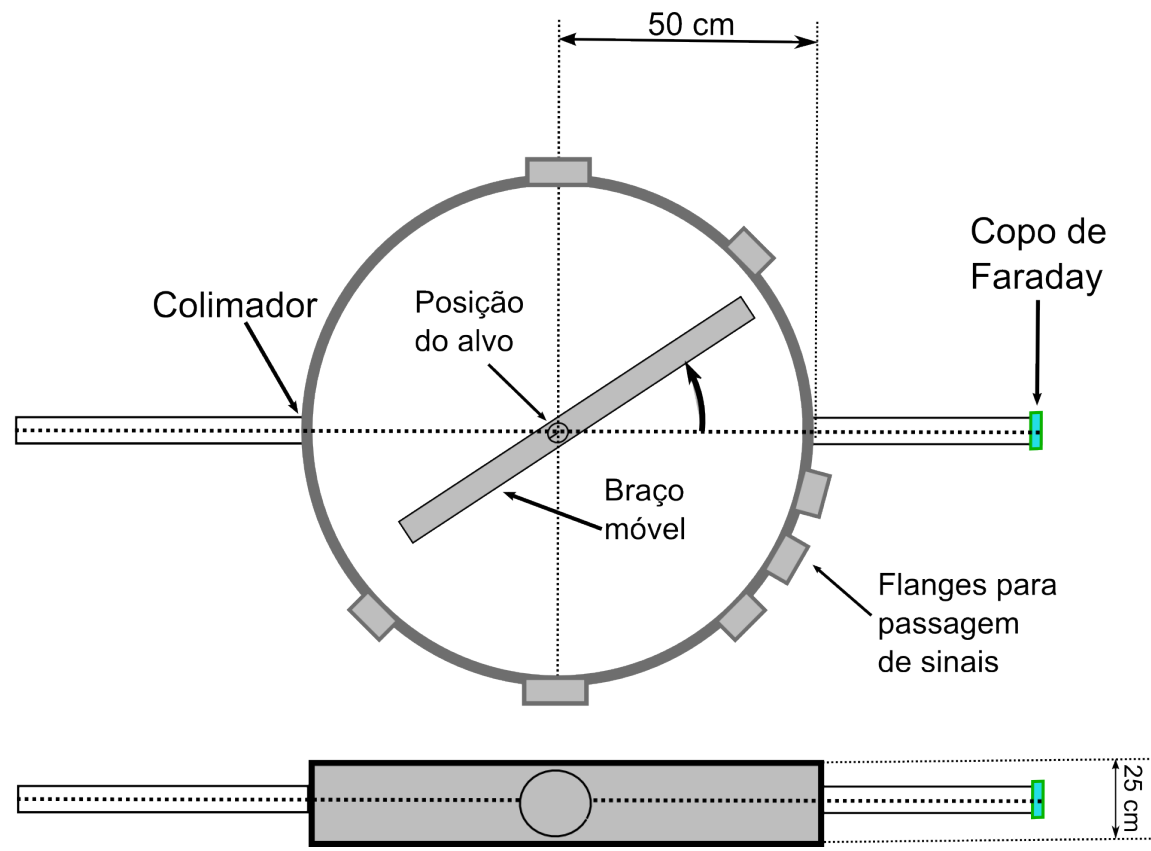

Figura 5.7: Desenho esquemático indicando as principais características da câmara da canalização 30B, como as diversas flanges e o braço móvel. 


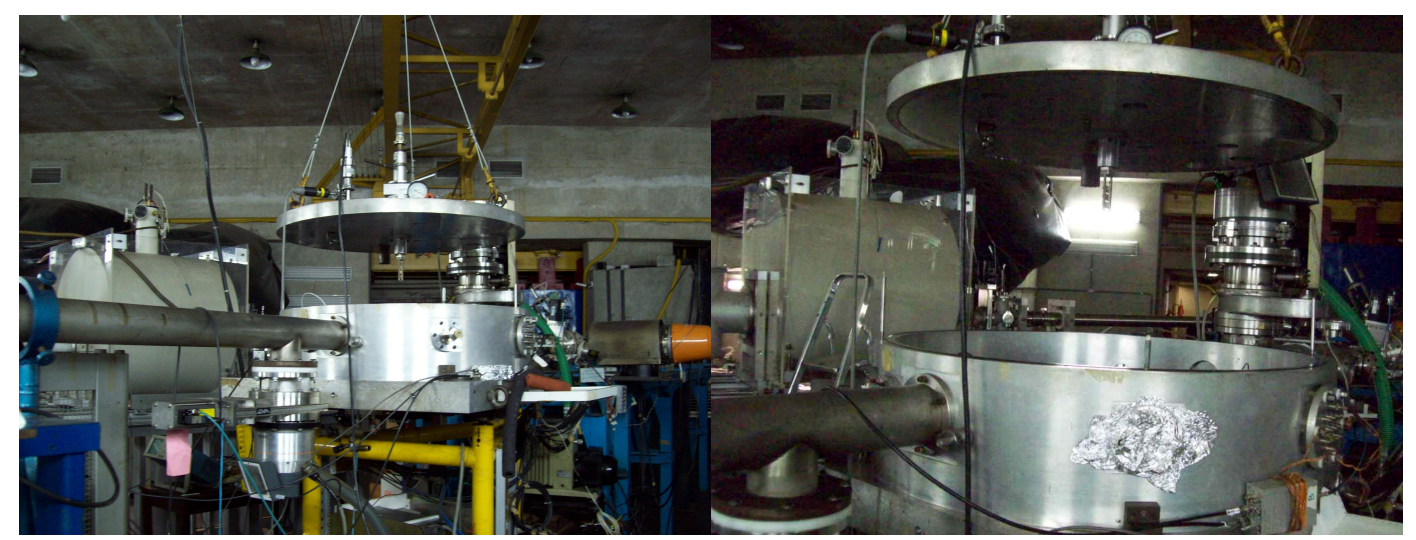

(a)

(b)

Figura 5.8: Visão externa da câmara instalada na canalização 30B do Acelerador Pelletron 8UD

\subsubsection{Sistemas Desenvolvidos para Uso nos Experimentos}

Embora a câmara 30B possua uma grande versatilidade, foram necessários alguns desenvolvimentos específicos para o estudo dos efeitos de feixes de íons pesados em dispositivos eletrônicos. A utilização de dispositivos com pinagem elevada, muitas vezes com restrições ao uso de cabos coaxiais (BNC), levou à necessidade de adaptar um antigo passador de sinal multipino do tipo flat cable a uma das flanges.

No caso de extração de feixe em ar para análise de dispositivos que não podem ser colocados em vácuo, seja por conta da alta potência elétrica desenvolvida pelo dispositivo, seja pelas dimensões da placa controladora à qual o dispositivo está acoplado, foi necessária a construção de um sistema adaptador para o antigo sistema de feixe externo do Laboratório de Análises de Materiais com Feixes Iônicos (LAMFI). O sistema de extração de feixe pode ser colocado em diversas posições na câmara, desde que haja uma flange compatível.

A montagem de janelas no sistema de feixe externo é feita por meio da colagem de uma folha de alumínio ou mylar aluminizado sobre uma arruela, usando resina epóxi para isso, fixando a arruela no sistema com um o-ring de vedação. O procedimento de 
colagem é bastante delicado, visto que uma colagem imperfeita dá origem a vazamentos. A Figura 5.9 mostra as partes constituintes do arranjo e uma vista externa dos detalhes do sistema montado.

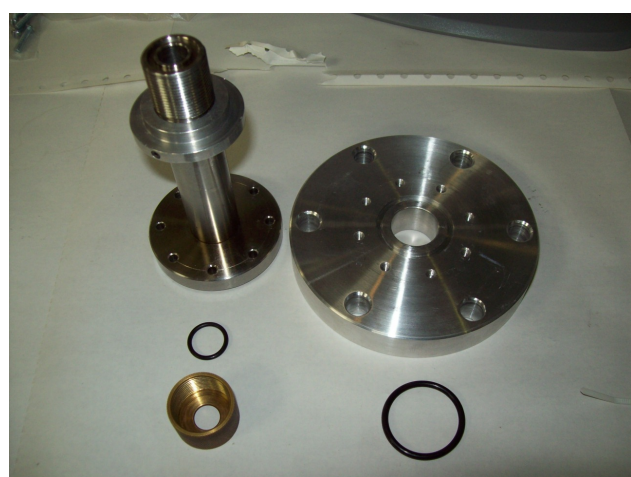

(a) Desmontado

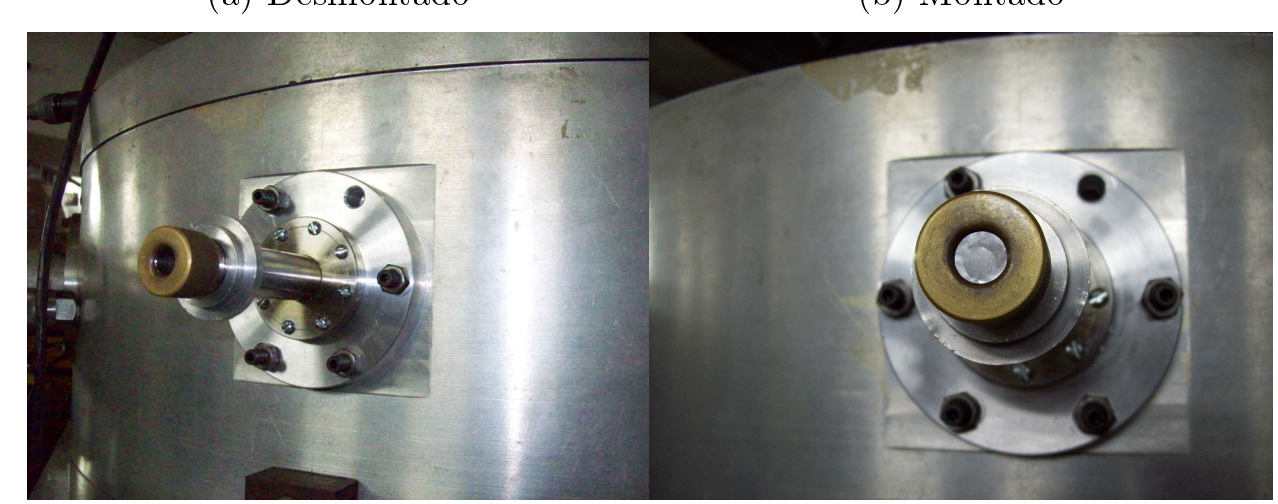

(c) Na câmara

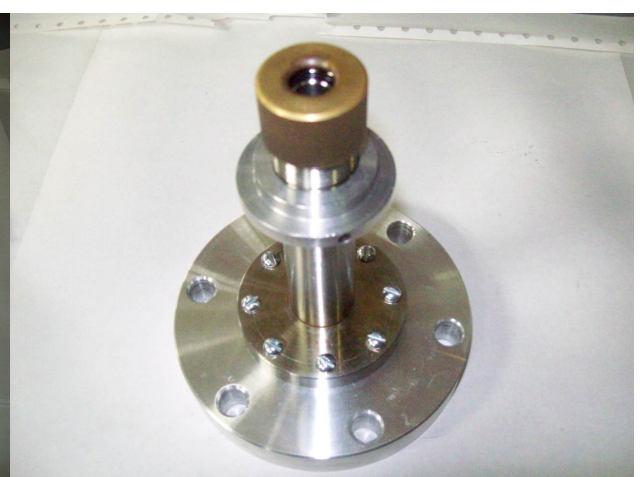

(b) Montado (d) Detalhe da janela

Figura 5.9: (a)Sistema de feixe externo desmontado. (b)Sistema montado. (c) Sistema instalado a $45^{\circ}$ na câmara. (d)Detalhe da janela de Alumínio

Além disso, foi projetado e construído um sistema para fixação de circuitos para irradiação em feixe externo (Figura 5.10). Tal sistema consiste de uma régua metálica graduada com um furo para ser encaixada no sistema de feixe externo. Perpendicular a esta régua encontram-se duas réguas verticais, nas quais encontram-se fixos dois suportes de placa de circuito impresso. Este sistema permite o posicionamento da placa de circuito impresso nos 3 eixos cartesianos com precisão de $0,5 \mathrm{~mm}$. 


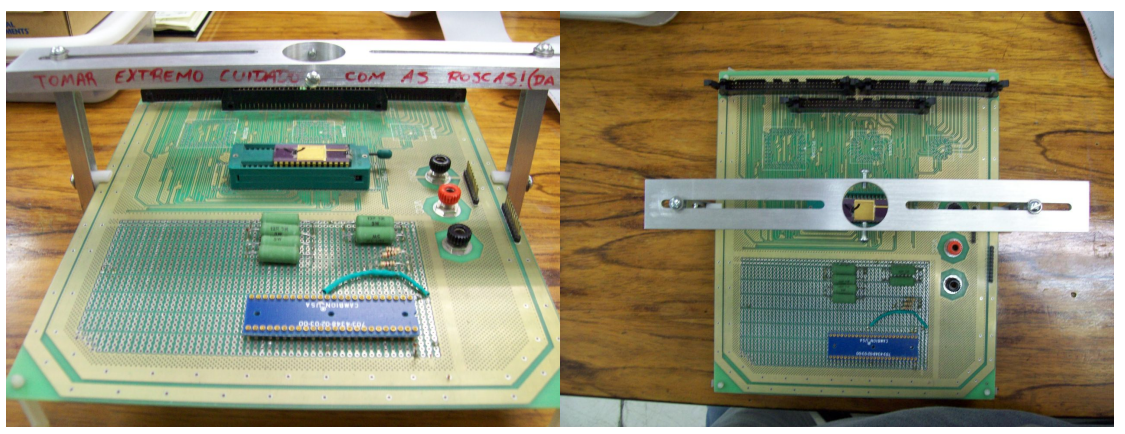

(a)

(b)

Figura 5.10: Sistema de fixação de placas de circuito impresso para irradiação com feixe externo (Porta-Placa)

\subsection{Configuração Experimental}

\subsubsection{Feixe Espalhado}

Para buscar atender, ao menos aproximadamente, os requisitos das normas (3.2.4) de estudo de SEE, utilizou-se uma montagem tradicional de espalhamento Rutherford, de modo que no centro da câmara havia alvos de ouro com espessuras variando entre 0,18 e $4,65 \mathrm{mg} / \mathrm{cm}^{2}$ (Figura 5.11). As diversas espessuras permitiam uma rápida mudança no fluxo do feixe espalhado apenas pela mudança da espessura do meio espalhador, de acordo com a expressão 4.4, embora com prejuízo à energia do feixe (conforme 2.2), além do straggling tanto angular quanto em energia.

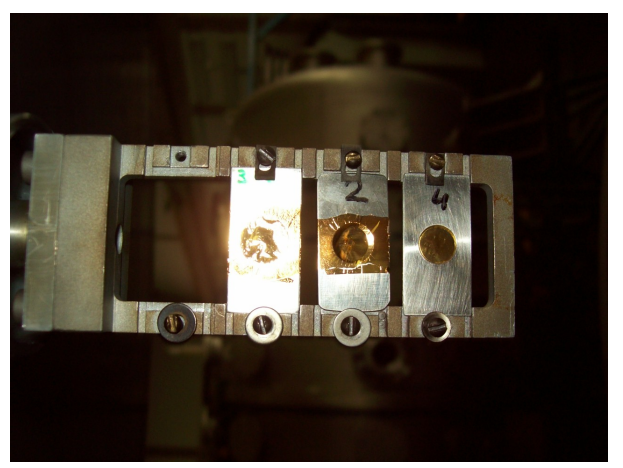

Figura 5.11: Vista da coluna de alvos da câmara 30B. 
Como a corrente de feixe típica obtida no acelerador Pelletron é da ordem de nA, atingindo um máximo de centenas de nA, pode-se calcular o fluxo de partículas espalhadas para diversos ângulos e distâncias em relação ao centro da câmara. O gráfico na Figura 5.12 mostra valores calculados considerando uma folha de ouro de aproximadamente $0,28 \mathrm{mg} / \mathrm{cm}^{2}$ de espessura e corrente de feixe de $200 \mathrm{nA}$.

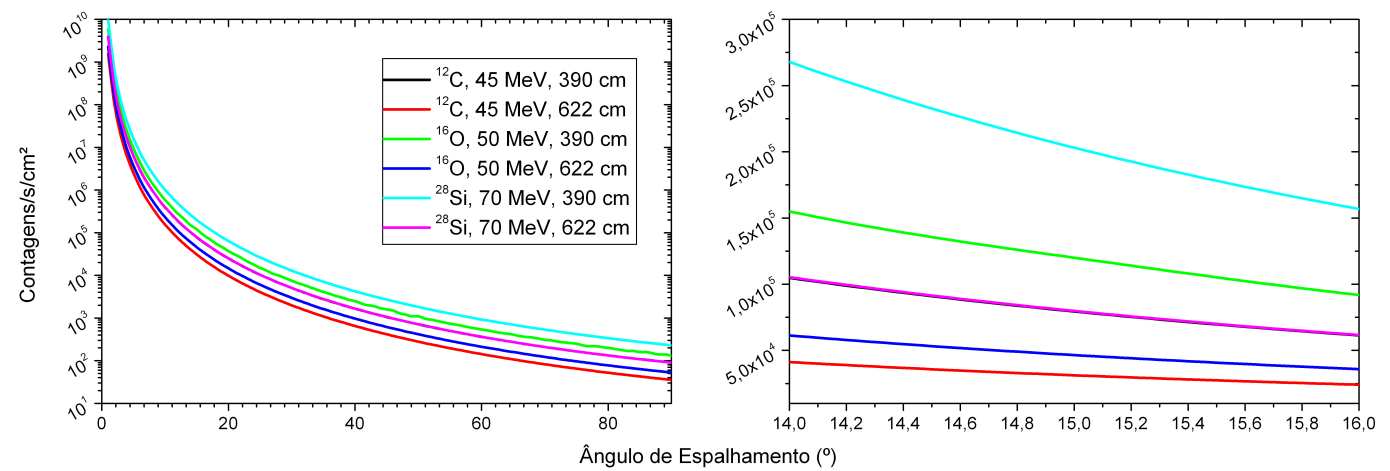

Figura 5.12: Cálculos de espalhamento Rutherford para 3 diferentes feixes em diferentes energias, considerando posição interna e externa do circuito irradiado. À direita, detalhe da região em torno de $15^{\circ}$

Observa-se que os valores de fluxo calculados estão de acordo com os requisitos das normas, devendo-se levar em conta que a corrente de feixe utilizada nos cálculos é um limite superior. Além disso, pequenas variações angulares $\left(\sim 1^{o}\right)$, que podem ser observadas à direita na Figura 5.12 não tornam afetam a fluência de partículas espalhadas em mais de 10\%. Superestimando a dimensão típica dos dispositivos ensaiados como sendo da ordem de $5 \mathrm{~mm}$, pode-se facilmente calcular que a abertura angular total correspondente é inferior a $0,75^{\circ}$ para um irradiação dentro da câmara, a cerca de 390 mm a partir do centro da câmara, e inferior a $0,50^{\circ}$ para irradiação externa, a cerca de $622 \mathrm{~mm}$ a partir do centro da câmara.

Cabe ressaltar que o detalhe da Figura 5.12 mostra uma expansão em torno de $15^{\circ}$, a posição de irradiação externa possível que teria maior não-uniformidade. Foi construído um porta-detector especial para ser acoplado ao porta-placa para medir a 


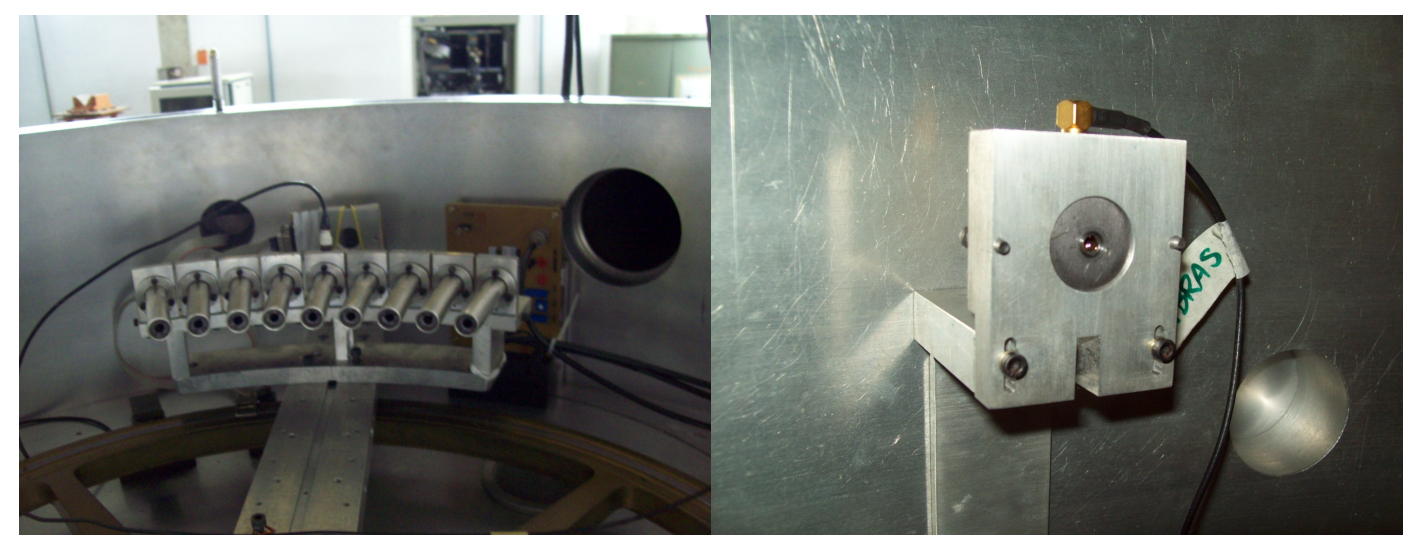

(a) Móvel

(b) Fixo

Figura 5.13: (a)Porta-detectores montado no braço móvel da câmara. (b)Porta-detector fixo.

uniformidade do feixe externo na posição de irradiação a $15^{\circ}$.

A determinação da fluência total de partículas no ângulo de irradiação foi feita por meio de 2 detectores de sílicio do tipo barreira de superfície, posicionados dentro da câmara, um deles fixo em um ângulo e outro no braço móvel, conforme Figura 5.13, adquirindo em singles, isto é, evento por evento. Estes detectores são diodos polarizados reversamente cuja altura do pulso de tensão gerado ao ser atingido por uma partícula carregada é proporcional à energia desta ([3],[55]).

A cada detector estava conectado um pré-amplificador e um amplificador para amplificação e conformação do sinal. Do amplificador, o sinal unipolar relativo a cada detector era enviado a uma entrada do ADC (Analog-to-Digital Converter) do sistema CAMAC ([3],[55]), enquanto o sinal bipolar era enviado a um analisador monocanal (TSCA), cuja função era enviar um pulso lógico no padrão NIM ([3],[55]) toda vez que o sinal de entrada passasse pelo crivo de seleção, dado por uma janela de tensão. As saídas geradas por cada TSCA eram combinadas num módulo Fan-in/Fan-out atuando como porta OU, isto é, que gerava uma saída, idêntica à entrada, toda vez que houvesse um sinal de qualquer um dos detectores. Esta saída era enviada a um Gate and Delay Generator, que gerava um sinal de gate, isto é, um sinal negativo no padrão 
NIM com largura ajustável, semelhante a um pulso quadrado. Este sinal de gate tinha como objetivo determinar uma janela temporal para os eventos de interesse. Este sinal era enviado à porta strobe do ADC do sistema CAMAC, e, uma vez que os sinais de gate eram sempre coincidentes com os pulsos de tensão do detector, levando em conta o atraso introduzido pelos módulos eletrônicos, ou seja, ocorriam na mesma janela de tempo, o sistema adquiria todos os eventos detectados.

O sistema CAMAC é um sistema de aquisição de dados bastante utilizado em física nuclear, devido à sua grande versatilidade, onde o experimentador pode definir quais leituras dos módulos serão feitas e também em qual ordem, além do agrupamento dos dados, etc. Para utilização com interfaces mais modernas, foi desenvolvido um sistema CAMAC-USB [56], que conta com um ADC e um TDC (Time-to-Digital-Converter módulo para medida de intervalos de tempo).

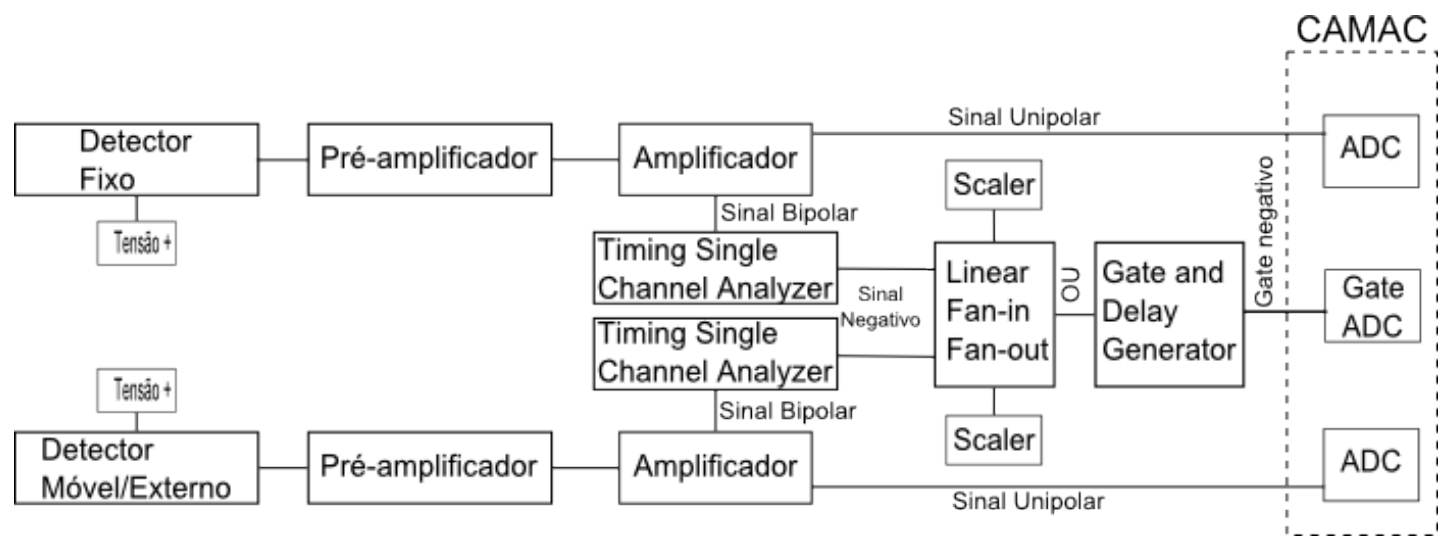

Figura 5.14: Esquema da eletrônica utilizada para aquisição dos sinais dos detectores de barreira de superfície

Quando possível, um dos detectores foi montado simetricamente em relação ao dispositivo sob teste (DUT), porém, quando isto não era possível, o detector era colocado em um ângulo de 15, 30 ou 45 graus e o cálculo da fluência do feixe era feito com as contagens registradas pelo detector, corrigidas pelo ângulo sólido e seção de choque.

No tocante à escolha de feixes, especialmente para a utilização de feixe externo, 
deve-se levar em conta as perdas de energia no alvo e na janela, de modo que seu alcance dentro do dispositivo sob teste é diminuído. Resultados de cálculos de stopping power que permitem escolher qual o feixe mais pesado possível de ser utilizado externamente são mostrados na Figura 5.15, as curvas de Bragg para alguns feixes e energias disponíveis são mostrados na Figura 5.16. No caso dos feixes mais pesados, o pico de Bragg não pode ser visualizado pois a energia disponível no acelerador faz com que o freamento destes íons já se inicie na região do pico de Bragg.

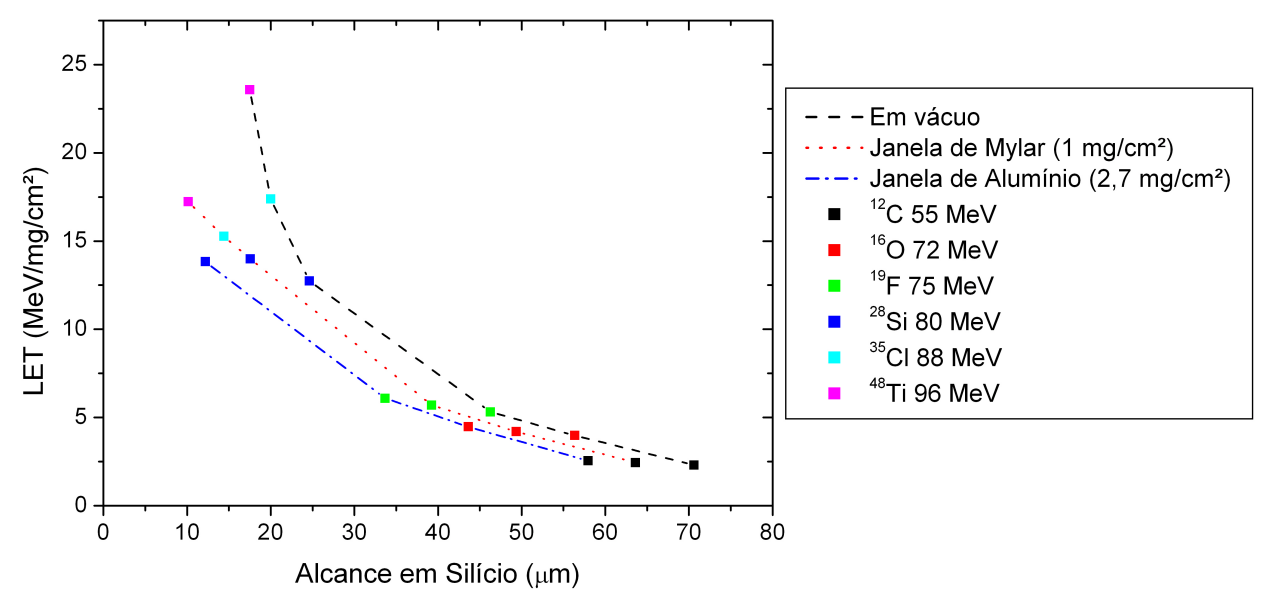

Figura 5.15: Cálculos de LET médio em função do alcance em silício para diversos feixes, energias e janelas

O cálculo rápido dos LETs e fluxos nos dispositivos para diferentes feixes, energias, posições de irradiação, espessuras de alvo, janela e dispostivo foram implementados por meio de uma planilha Excel que calcula a cinemática de espalhamento e as seções de choque de Rutherford e busca os valores de energia em uma base de dados de stopping power gerada a partir do programa LET Calculator, do BNL [22]. O programa LET Calculator utiliza a parametrização semi-empírica ZBL [8] e completa os intervalos com valores interpolados por uma curva natural spline [57]. No caso de feixes pesados com baixa penetração em silício, a curva de LET em função do alcance (Figura 5.16) não 
apresenta um platô em uma região profunda o suficiente do dispositivo (mínimo de $10 \mu \mathrm{m})$, isto é, a taxa de deposição de energia não é constante no intervalo. Nestas condições, obtemos um valor médio de LET da seguinte forma:

$$
L E T_{\text {medio }}=\frac{\int_{0}^{P} \operatorname{LET}(x) d x}{P}
$$

onde é utilizado para o valor de profundidade $P=10 \mu \mathrm{m}$, um valor superior para profundidade da camada ativa do dispositivo.

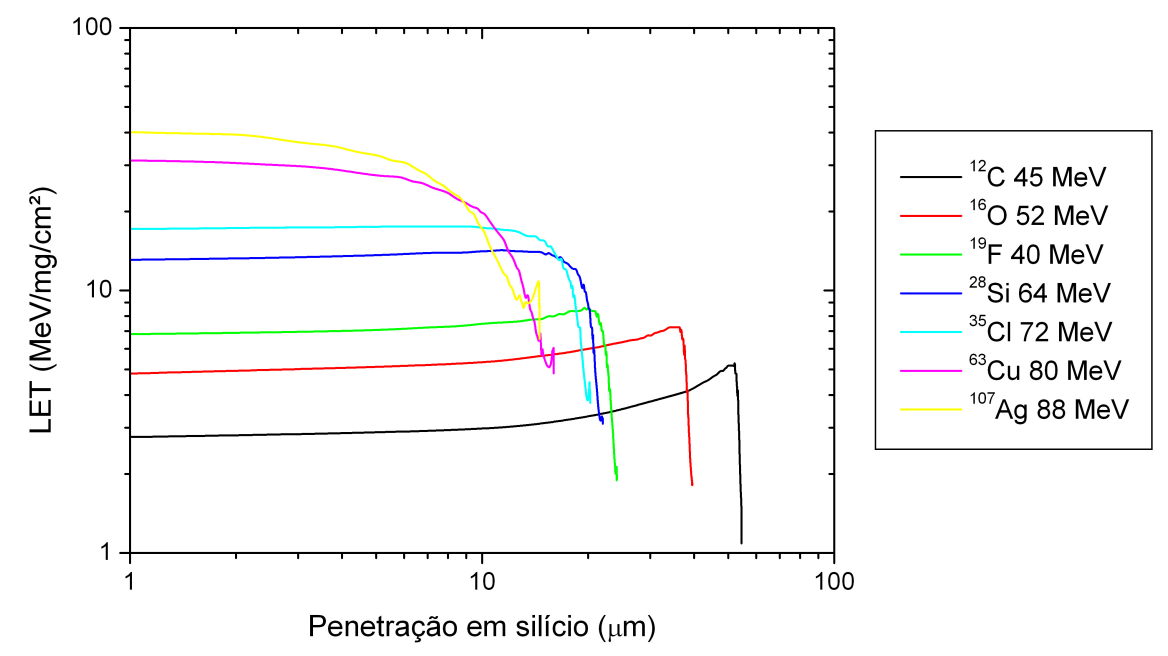

Figura 5.16: Cálculos de LET em função do alcance em silício para diversos feixes e energias (em vácuo) disponíveis no acelerador Pelletron 8UD.

Por último, dois testes de interesse geral do laboratório foram realizados: tais testes referem-se ao desempenho das folhas de troca de carga quando se utilizam feixes pesados $(\mathrm{A}>30)$, atividade rara no laboratório até o momento, mas que deve tornar-se mais frequente com o início dos estudos de radiação em dispositivos eletrônicos e com a entrada em operação do pós-acelerador LINAC. Tais testes, feitos com feixe de ${ }^{63} \mathrm{Cu}$ à tensão de 7 MV no terminal, consistiram em medir a transmissão da folha em função do tempo de feixe e também a intensidade de cada estado de carga (dentre os mais 
prováveis) gerados no stripper.

\subsubsection{Dispositivos Sob Teste}

Para que os feixes de íons pesados atinjam a camada sensível do dispositivo sob teste, todos os dispositivos a serem irradiados com íons pesados devem primeiramente ter sua capa retirada, seja por meios mecânicos ou químicos, uma vez que tal capa epoxi é grossa o suficiente para bloquear completamente o feixe. A Figura 5.17 mostra um dispositivo cuja capa foi removida, deixando o circuito integrado exposto.

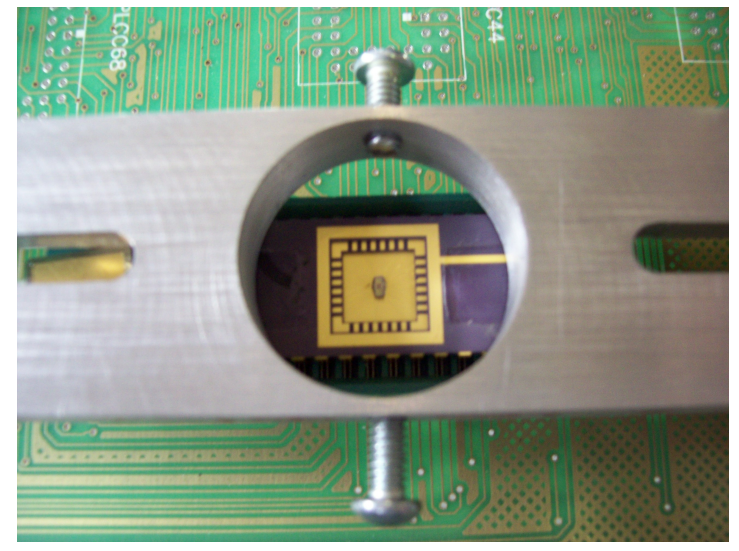

Figura 5.17: Dispositivo cuja capa foi removida para irradiação

Três experimentos foram realizados ao longo do projeto para detectar Single Event Effects, cada qual com sistemas diferentes, dos quais várias delas se mostraram inadequadas para a detecção de eventos isolados de radiação. Um dos sistemas (Figura 5.18) consistia em um circuito comparador com 3 contadores individuais, dos quais 2 deles estavam isolados do ambiente de radiação e outro estava exposto ao feixe. No momento de ocorrência de um SEE, a sincronia entre os três contadores seria quebrada. Num primeiro momento, tal avaliação de quebra de sincronia era feita visualmente em três mostradores, embora nos experimentos posteriores uma interface computacional tenha sido desenvolvida para o registro de eventos e monitoramento remoto na sala de controle. Este sistema chegou a ser irradiado em ar a $45^{\circ}$ (feixe externo) no primeiro 
experimento e em vácuo a $15^{\circ}$ e $30^{\circ}$ nos seguintes, através da instalação do passador multipino.

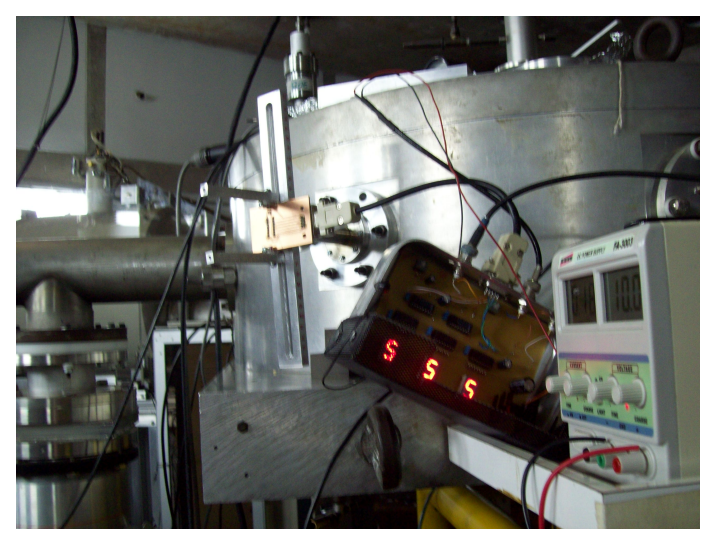

Figura 5.18: Montagem do sistema comparador de contadores

A segunda montagem consistia em monitorar a corrente de dreno e a tensão do gate de um transistor exposto ao feixe. A ocorrência de SEEs deveria poder ser observada nas curvas de monitoramento, realizadas por um sistema de aquisição de dados NI-PXI, com uma taxa de aquisição de 250 Samples/s. O sistema é mostrado na Figura 5.19. Este sistema foi irradiado em ar a $15^{\circ}$ e $45^{\circ}$.

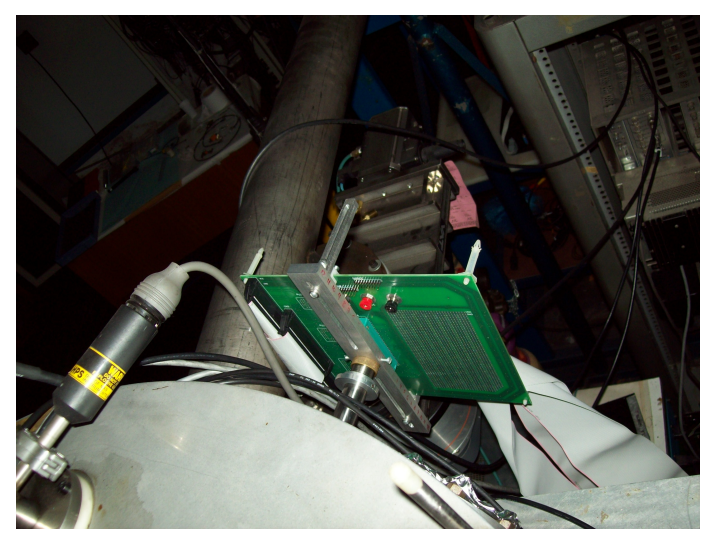

Figura 5.19: Sistema de aquisição por módulo NI-PXI montado na posição de irradiação com feixe externo 
A terceira montagem utilizou um transistor MOSFET tipo-P de uso comercial 3N163 (Figura 5.20), um dispostivo interessante de ser testado uma vez que este tipo de MOSFET é utilizado como dosímetro de radiação de baixo custo [58]. Após a remoção da capa protetora, o dispositivo foi mantido durante a irradiação com tensão de gate constante igual a -0,13 V e com tensão, também constante, entre fonte e dreno de -4,5V. A corrente de dreno era então amplificada por um amplificador operacional LM324 e coletada por um ADC de 12 bits. A ocorrência de um evento deveria provocar um pulso observável. Todavia, o longo tempo requerido pelo sistema para adquirir o sinal e a baixa duração de um SEE típico, fizeram com que este sistema pudesse registrar apenas 0,02\% dos eventos possíveis. No segundo experimento envolvendo este dispositivo, o sistema de aquisição foi modificado, utilizando-se um osciloscópio de alta frequência (1 GHz - 10 GSamples/s) RTO1012 da Rohde \& Schwarz com trigger digital para monitorar a corrente de dreno, que deveria manter-se constante em $100 \mu A$ na ausência de eventos. O trigger digital mostrou-se imprescindível, uma vez que a forma de onda apenas era salva em arquivo quando um evento passasse pelo crivo de discriminação, economizando assim memória em disco. Este dispositivo foi irradiado em vácuo a $15^{\circ}$.

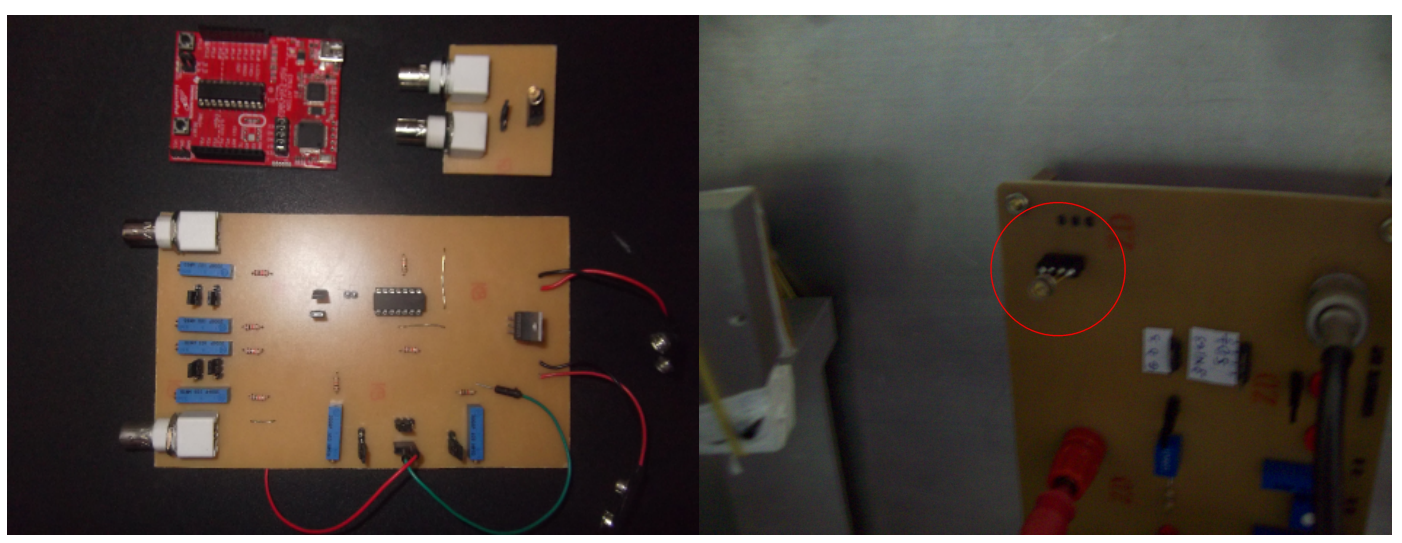

(a) Desmontado

(b) Montado

Figura 5.20: (a)Placas constituintes da primeira versão da montagem. (b)Placa com o dispositivo 3N163 (detalhe) na posição de irradiação em vácuo 
A Figura 5.21 ilustra a montagem geral, tendo-se em mente que todos os ângulos podiam ser variados.

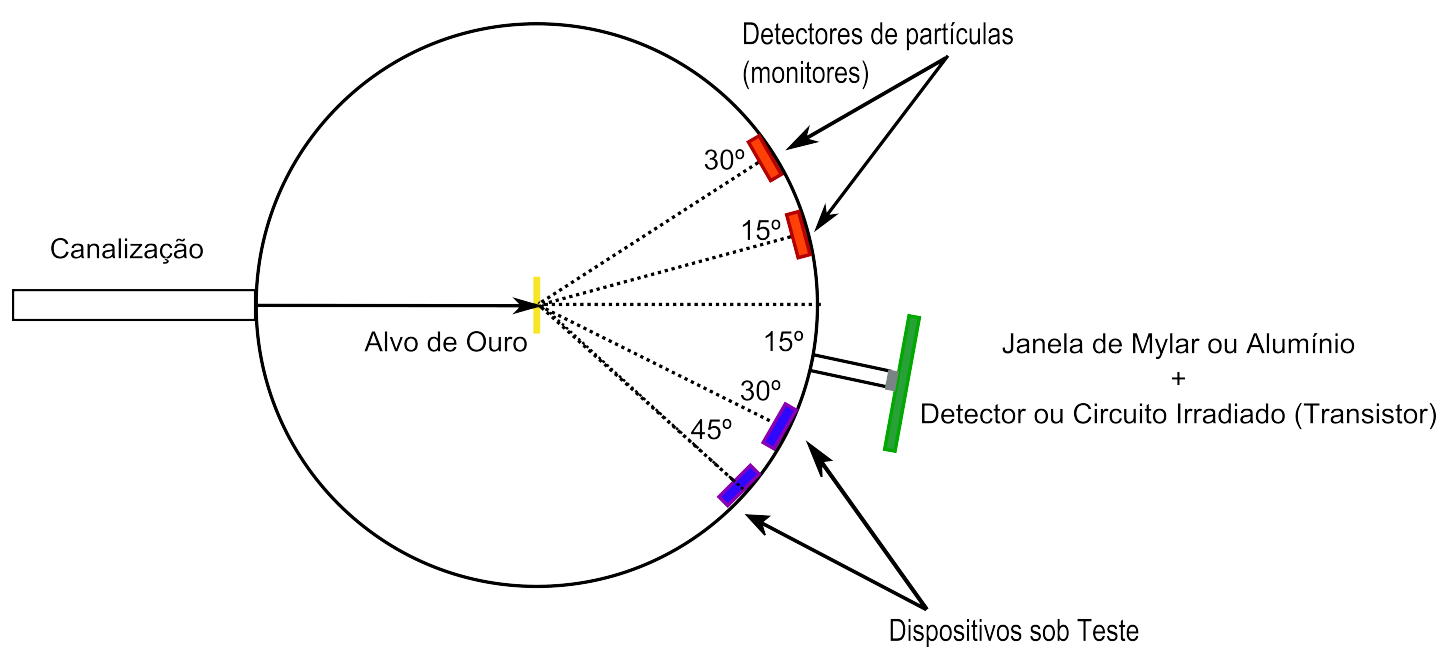

Figura 5.21: Uma visão geral da montagem (os ângulos indicados nesta figura foram variados ao longo dos experimentos) 


\section{Capítulo 6}

\section{Resultados e Discussão}

Neste capítulo serão apresentados os resultados obtidos com a caracterização do feixe e os ensaios de radiação sobre dispositivos eletrônicos.

\subsection{Caracterização dos Feixes de Íons Pesados}

\subsubsection{Troca de carga}

As medidas da produção de estados de carga na folha de carbono tiveram como resultado os dados mostrados na Figura 6.1, onde se observa que os valores de carga mais prováveis calculados com o programa CHARGE [20] com base na parametrização de Sayer (Eq. 2.5) são menores do que os observados. Conforme [21], estados de carga elevados podem não ser bem bem reproduzidos pelo modelo, embora não haja descrição de qual o valor limite de validade do seu modelo. Além disso, o efeito da óptica do acelerador deve ser considerado. Tal informação é relevante para que se possa utilizar feixes com estados de carga (elevados) maiores, resultando em feixes com maior energia, necessários tanto para as aplicações em irradiações de dispositivos eletrônicos quanto para o uso em física nuclear básica com o pós-acelerador LINAC. 


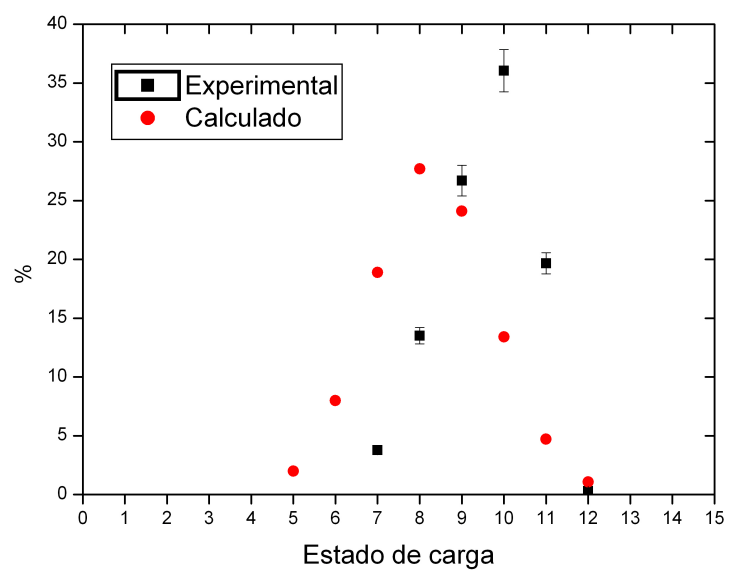

Figura 6.1: Estados de carga positiva produzidos na folha de carbono do acelerador, utilizando feixe de ${ }^{63} \mathrm{Cu}$ e tensão no terminal de $7,0 \mathrm{MV}$

A utilização de feixes pesados em aceleradores com stripper de carbono apresenta o problema da durabilidade das folhas de troca de carga, que perdem mais rapidamente sua eficiência de troca de carga quanto maior a massa do feixe, para uma dada corrente no setor de baixa energia. A medida de eficiência de troca de carga para o feixe de ${ }^{63} \mathrm{Cu}$ a 7,0 MV de tensão no terminal, foi feita avaliando-se a relação entre a corrente no copo de Faraday 5 (após a troca do estado de carga) e a corrente no copo de Faraday 4 (antes da folha de carbono). Os resultados são apresentados na Figura 6.2. A relação entre as correntes é inicialmente maior do que a unidade pois, mesmo havendo perda de feixe entre um copo de Faraday e outro, o estado de carga é multiplicado e a corrente é definida como a quantidade de carga por segundo incidindo no copo. Observa-se que inicialmente a queda de eficiência é sutil, havendo uma perda acentuada por volta dos 10 minutos, seguida de uma queda brusca por volta dos 20 minutos, instante a partir do qual a diminuição de intensidade no copo 5 volta a ser lenta, apresentando valores de corrente nos copos 4 e 5 praticamente iguais. Tal resultado mostra que a perda de eficiência da folha de carbono não ocorre a uma taxa constante. 


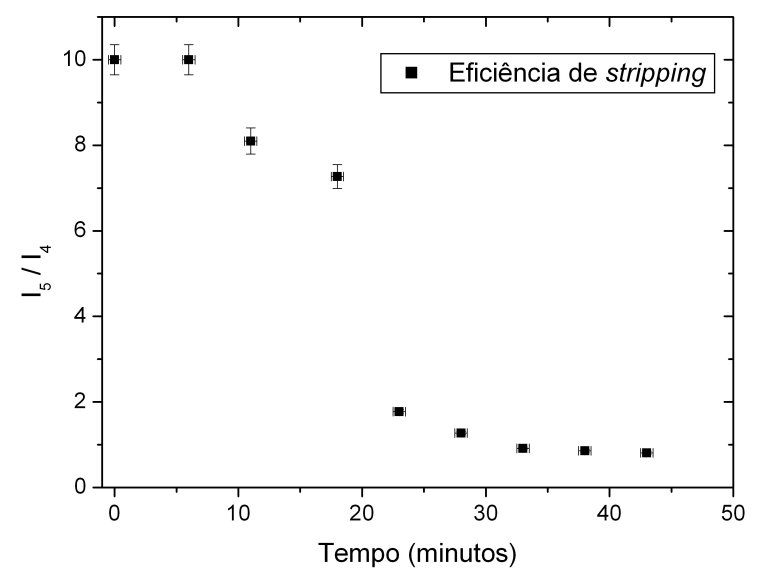

Figura 6.2: Relação entre as correntes de feixe antes e após a folha de carbono em função do tempo

Verificou-se também que o desgaste da folha não é uniforme, sendo possível mudar a posição de incidência do feixe na folha e obter ainda cerca de uma hora de feixe nas condições mencionadas, embora com intensidade baixa. Deve ser avaliada futuramente se a perda de intensidade se dá com a mesma taxa para todos os diferentes estados de carga, além do estudo de métodos de produção de folhas de carbono com maior durabilidade ([59],[60]). O uso de stripper gasoso não é recomendado por sua baixa capacidade de produzir estados de carga elevados com alta intensidade.

\subsubsection{Feixe Externo para Irradiação}

O feixe iônico externo perde energia na janela de extração e também no ar. Por isso, é necessário avaliar se a perda de energia é pequena o suficiente para não tornar as irradiações impraticáveis. Um detector de barreira de superfície foi colocado dentro da câmara e outro fora, simetricamente posicionados a $45^{\circ}$, sendo que o detector externo estava separado do ambiente de vácuo por uma janela de alumínio de $10 \mu m$ e cerca de $3 \mathrm{~mm}$ de ar. A Figura 6.3 mostra os espectros de partículas coletados por esses detectores dentro e fora da câmara relativos a três feixes estudados. 
Utilizando o programa SRIM/TRIM [8], foram simuladas as trajetórias de 1500 partículas de cada um dos feixes considerados na Figura 6.3, com energia inicial igual à prevista pela cinemática do espalhamento, percorrendo a mesma distância dentro do alvo de ouro, estimada pela metade da espessura dividida pelo cosseno de $45^{\circ}$, a janela de alumínio e a mesma distância em ar $(3 \mathrm{~mm})$. A partir das energias das partículas transmitidas, os resultados experimentais são comparados com as simulações na Tabela 6.1. A queda na área dos picos é devida aos diferentes ângulos sólidos compreendidos.

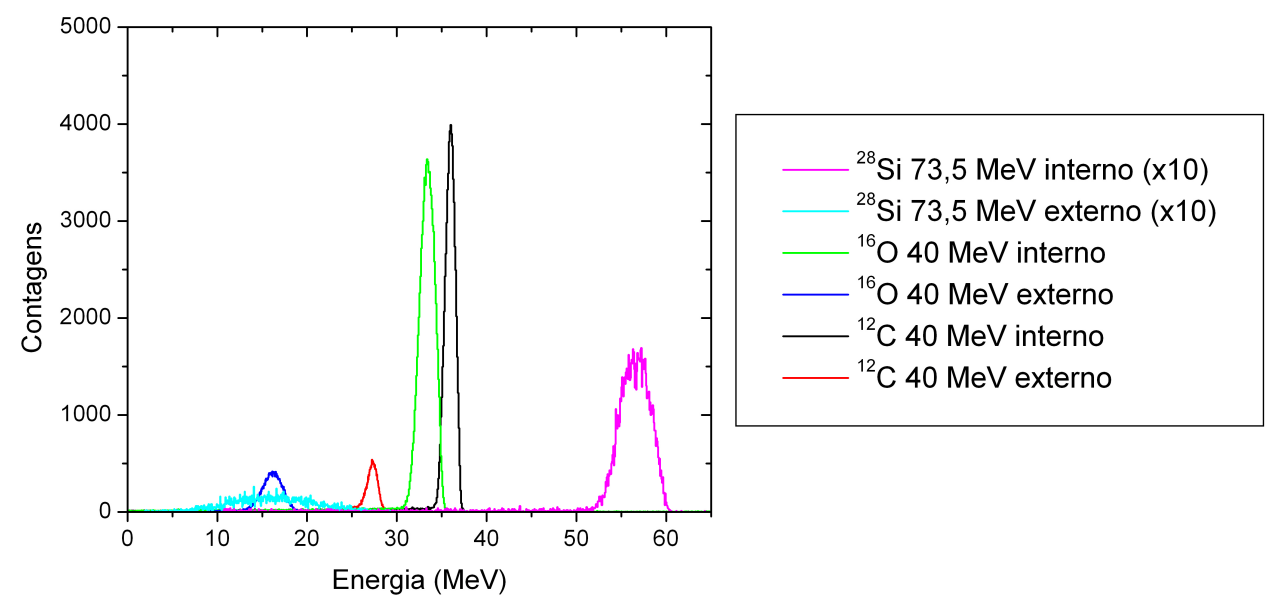

Figura 6.3: Espectros de partículas obtidos nos detectores interno e externo para três espécies iônicas. A energia indicada na legenda refere-se à energia inicial do feixe [61].

Tabela 6.1: Valores de perda de energia e straggling relativo entre os feixes externo e interno.

\begin{tabular}{c|cc|cc}
\hline \multirow{2}{*}{ Feixe Iônico } & \multicolumn{2}{|c|}{ Perda de energia $(\mathrm{MeV})$} & \multicolumn{2}{c}{ FWHM $(\mathrm{MeV})$} \\
\cline { 2 - 5 } & Experimental & Simulada & Experimental & Simulada \\
\hline${ }^{12} \mathrm{C} 40 \mathrm{MeV}$ & $8,7(10)$ & 9,7 & $1,2(4)$ & 1,6 \\
${ }^{16} \mathrm{O} 40 \mathrm{MeV}$ & $17,3(13)$ & 18,9 & $2,3(7)$ & 2,0 \\
${ }^{28} \mathrm{Si} 73,5 \mathrm{MeV}$ & $40,4(17)$ & 43,4 & $9,6(12)$ & 3,1 \\
\hline
\end{tabular}

Partindo da associação existente entre a largura-a-meia-altura (FWHM) do pico e 
o straggling, pois formalmente o straggling é o segundo momento centrado na média da distribuição [8], ou seja, é o desvio-padrão da distribuição, observamos que, conforme esperado, existe um aumento do straggling em energia do feixe externo com relação ao interno, além da própria diminuição da energia média do feixe espalhado. A diminuição é condizente com os cálculos realizados com o programa SRIM/TRIM, de modo que as condições previstas expostas na Figura 5.15 são válidas para irradiações com feixes externos, ou seja, feixes pesados até massa 28 (silício) podem ser utilizados com janela de alumínio de $10 \mu \mathrm{m}$ e até mesmo ${ }^{48} \mathrm{Ti}$ com janela de mylar de espessura de $1 \mathrm{mg} / \mathrm{cm}^{2}$. O aumento experimental do valor da largura dos picos devido ao straggling em energia no caso do feixe de ${ }^{28} \mathrm{Si}$ é muito maior que o simulado provavelmente devido ao baixo número de contagens. Caso a situação seja semelhante mesmo no caso de maior número de contagens, o feixe de ${ }^{28} \mathrm{Si}$ não pode ser utilizado com janela de alumínio.

Para cumprir os requisitos das normas técnicas ([43],[44],[45]), devemos ter em conta que o feixe iônico deve ser uniforme dentro de $10 \%$ de variação na região de irradiação. Foi feita uma medida de uniformidade do feixe externo utilizando feixe de ${ }^{16} \mathrm{O}$ com energia inicial de $50 \mathrm{MeV}$, espalhado em folha de ouro de $0,28 \mathrm{mg} / \mathrm{cm}^{2}$ a $15^{\circ}$. Devido à impossibilidade de colocação do suporte de medição (porta-placa) nos eixos cartesianos usuais, adotou-se um sistema de referência rotacionado de $45^{\circ}$. Foram obtidos espectros de partículas num detector barreira de superfície em intervalos de $1 \mathrm{~mm}$ por cerca de 7 minutos cada ponto. A uniformidade do feixe é apresentada na Figura 6.4 [61], onde se observa que a medida no eixo X (no sistema adotado) apresenta uma pequena variação, ao passo que a medida no eixo Y é bastante uniforme, consideradas as barras de erros. Uma projeção de ambas as medidas nos eixos usuais deve refletir melhor a uniformidade do feixe. Ressalta-se que, como mostrado na Figura 5.12, a posição de irradiação externa a $15^{\circ}$ é um dos piores cenários possíveis em termos de uniformidade que pode ser conseguido. Medidas a $30^{\circ}$ ou a $45^{\circ}$ devem apresentar melhores resultados, embora tais valores já sejam compatíveis com as exigências das normas. 


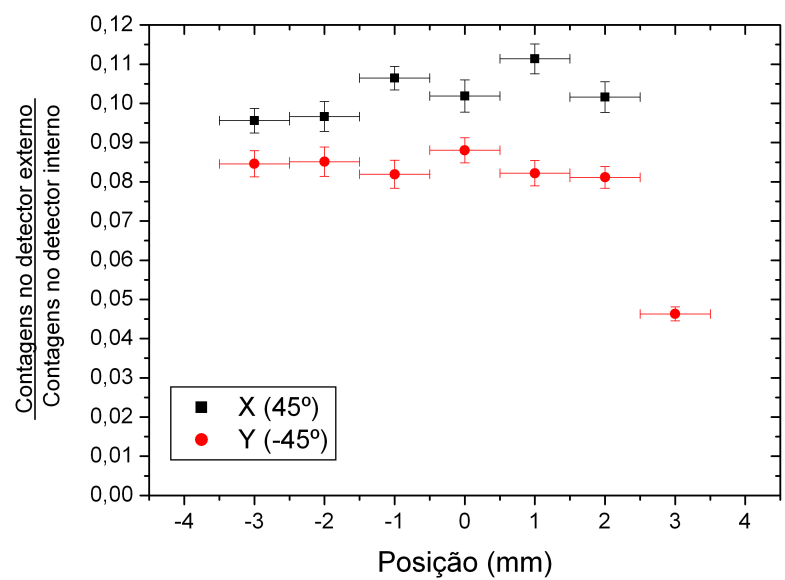

Figura 6.4: Medidas da uniformidade do feixe no sistema de coordenadas rotacionado em $45^{\circ}$ [61].

\subsection{Estudos de Efeitos de Eventos Isolados em Dispositivos Eletrônicos}

Diversos esforços foram feitos ao longo deste projeto para identificar corretamente um efeito de evento isolado. Sumarizamos os resultados a seguir.

\subsubsection{Sistemas Contador, NI-PXI e 3N163-Baixa Amostragem}

O sistema comparador entre contadores não acusou nenhum efeito de radiação durante nenhum dos experimentos realizados. De fato, o único momento em que este deixou de funcionar foi ao testá-lo com feixe direto (cerca de $10^{10}$ partículas/s), o que ocasionou uma falha térmica no dispositivo sob teste. O sistema com o transistor retangular monitorado pelo NI-PXI apresentou um pulso de corrente ao ser irradiado a $45^{\circ}$ com feixe externo de ${ }^{16} \mathrm{O}$ a $46,5 \mathrm{MeV}$ de energia inicial, provendo um valor de LET de $5,9 \mathrm{MeV} / \mathrm{mg} / \mathrm{cm}^{2}$ na superfície do dispositivo. Este pulso de corrente apresentou um aumento rápido com o tempo, após o qual teve um tempo de decaimento da ordem 
de segundos. O pulso observado é apresentado na Figura 6.5.

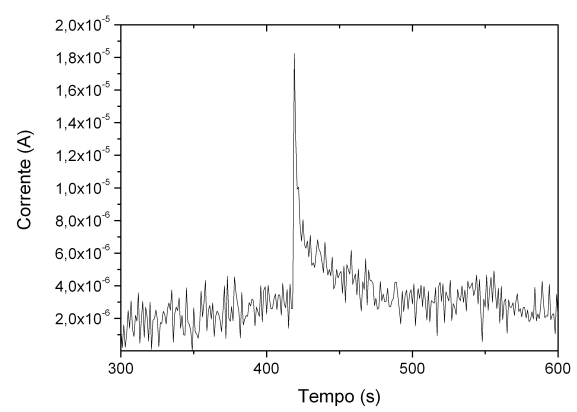

Figura 6.5: Primeiro pulso de corrente observado em função do tempo de aquisição.

Uma análise cuidadosa do sinal revelou que a carga gerada era alta demais, além do fato de ter sido observado apenas um pulso durante vários minutos de medida (e nos vários experimentos). Tais fatos levaram ao descarte deste sinal como sendo proveniente de um efeito de radiação, sendo portanto considerado um sinal espúrio gerado pelo sistema de aquisição de dados.

O primeiro estudo com o transistor 3N163 foi feito com um sistema de aquisição com baixa taxa de amostragem. Ao utilizar um feixe de ${ }^{63} \mathrm{Cu}$ a $63 \mathrm{MeV}$ foi observado um pulso negativo de corrente entre a fonte e o dreno do transistor, que poderia ser indicativo de um efeito de evento isolado. Todavia, a correlação deste pulso com um ruído senoidal tornou possível seu descarte, além da observação de apenas um evento em vários minutos de medida. O sinal observado é mostrado na Figura 6.6.

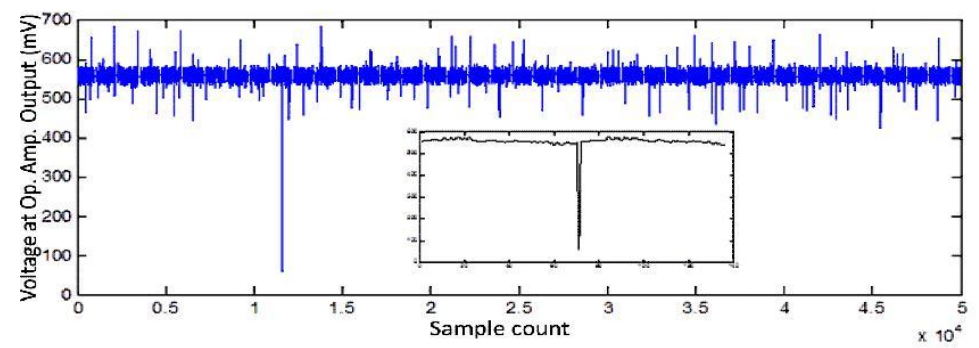

Figura 6.6: Sinal gerado pelo transistor 3N163. 


\subsubsection{N163-Alta Taxa de Amostragem}

O experimento com o mesmo transistor do tipo MOSFET 3N163 adquirindo dados com o osciloscópio de alta frequência $(1 \mathrm{GHz})$ tornou possível a observação de efeitos de radiação correspondentes a eventos isolados (SEE) na forma de pulsos de tensão no osciloscópio. Foram utilizados diversos feixes iônicos e energias neste experimento, visando a obtenção da curva de seção de choque de SEE para o dispositivo em questão e análises mais profundas da formação do sinal. A Tabela 6.2 sumariza os feixes utilizados. As energias efetivas e LET superficial são relativos ao espalhamento a $15^{\circ}$ em alvo de ouro. A espessura do alvo foi selecionada de modo a obter melhor relação possível entre energia e taxa. Para cada irradiação foi adquirido também o espectro de energias do feixe com o detector barreira de superfície (monitor) posicionado a $45^{\circ}$, para o cálculo da fluência total acumulada no dispositivo. A Figura 6.7 mostra exemplos dos espectros do detector para os feixes de ${ }^{6} \mathrm{Li}$ e ${ }^{16} \mathrm{O}$.

Tabela 6.2: Feixes iônicos e energias utilizados nas irradiações em vácuo, energia efetiva após o espalhamento no alvo, alcance e valores de LET superficial e LET médio em $10 \mu m$ de silício

\begin{tabular}{cccccc}
\hline $\begin{array}{c}\text { Feixe } \\
\text { Ionico }\end{array}$ & $\begin{array}{c}\text { Energia } \\
(\mathrm{MeV})\end{array}$ & $\begin{array}{c}\text { Energia Efetiva } \\
(\mathrm{MeV})\end{array}$ & $\begin{array}{c}\text { Alcance } \\
(\mu \mathrm{m})\end{array}$ & $\begin{array}{c}L E T_{\text {superficial }} \\
\left(\mathrm{MeV} / \mathrm{mg} / \mathrm{cm}^{2}\right)\end{array}$ & $\begin{array}{c}L E T_{10 \mu m} \\
\left(\mathrm{MeV} / \mathrm{mg} / \mathrm{cm}^{2}\right)\end{array}$ \\
\hline${ }^{6} \mathrm{Li}$ & 30 & 29,8 & 148 & 0,53 & 0,55 \\
${ }^{12} \mathrm{C}$ & 45 & 44,5 & 55,4 & 2,5 & 2,6 \\
${ }^{16} \mathrm{O}$ & 52,5 & 51,6 & 38,9 & 4,4 & 4,7 \\
${ }^{19} \mathrm{~F}$ & 42 & 40,7 & 23,8 & 6,5 & 7,04 \\
${ }^{28} \mathrm{Si}$ & 66 & 63,9 & 21,6 & 12,4 & 13,3 \\
${ }^{35} \mathrm{Cl}$ & 75 & 71,5 & 19,5 & 16,6 & 17,5 \\
${ }^{35} \mathrm{Cl}$ & 67 & 63,3 & 17,5 & 17,0 & 17,5 \\
${ }^{35} \mathrm{Cl}$ & 60 & 56 & 15,8 & 17,4 & 17,8 \\
${ }^{35} \mathrm{Cl}$ & 52 & 48,8 & 13,8 & 17,7 & 17,4 \\
${ }^{63} \mathrm{Cu}$ & 82 & 76,8 & 14,1 & 31,8 & 27,8 \\
${ }^{107} \mathrm{Ag}$ & 97,5 & 87,8 & 13,1 & 44,9 & 39,8 \\
\hline
\end{tabular}




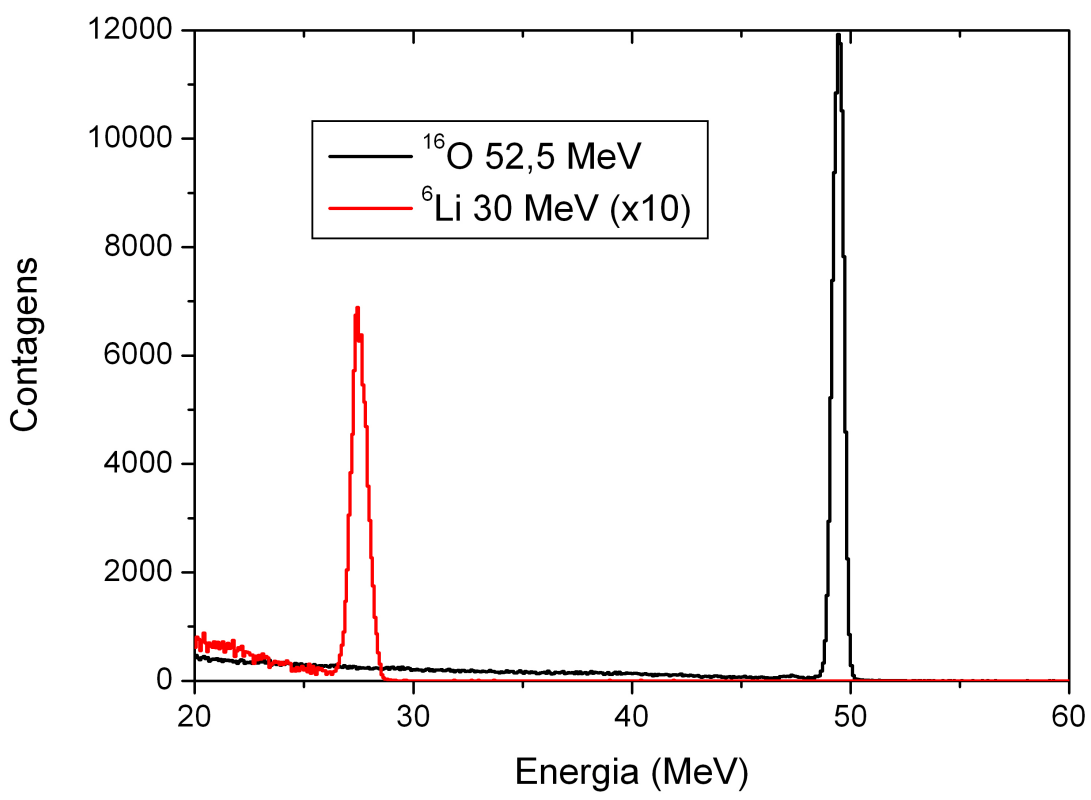

Figura 6.7: Espectros obtidos com o detector de barreira de superfície a $45^{\mathrm{O}}$ para os feixes de ${ }^{6} \mathrm{Li}$ e ${ }^{16} \mathrm{O}$.

A aquisição dos dados foi feita de forma que, a cada evento, a forma de onda visualizada no osciloscópio foi salva num arquivo ASCII em sequência, de forma que, se num dado caso foram visualizados 100 eventos, o arquivo ASCII correspondente contém os valores dos bins de um histograma com 100 picos, sendo que a distância entre um pico e o próximo corresponde à escala de tempo utilizada. A aquisição era encerrada num número pré-determinado de eventos acima do limiar de tensão também pré-determinado em $7 \mathrm{mV}$ acima do zero. A Figura 6.8 mostra os sinais gerados no osciloscópio referentes a cada um dos feixes utilizados, onde se observa a grande variação existente na amplitude dos sinais para um mesmo feixe e energia. A Figura 6.9 mostra os sinais correspondentes a três íons com a escala de tempo expandida para melhor visualização da forma do sinal, onde se observa a estrutura de picos duplos e pequenas oscilações após o pico principal. 


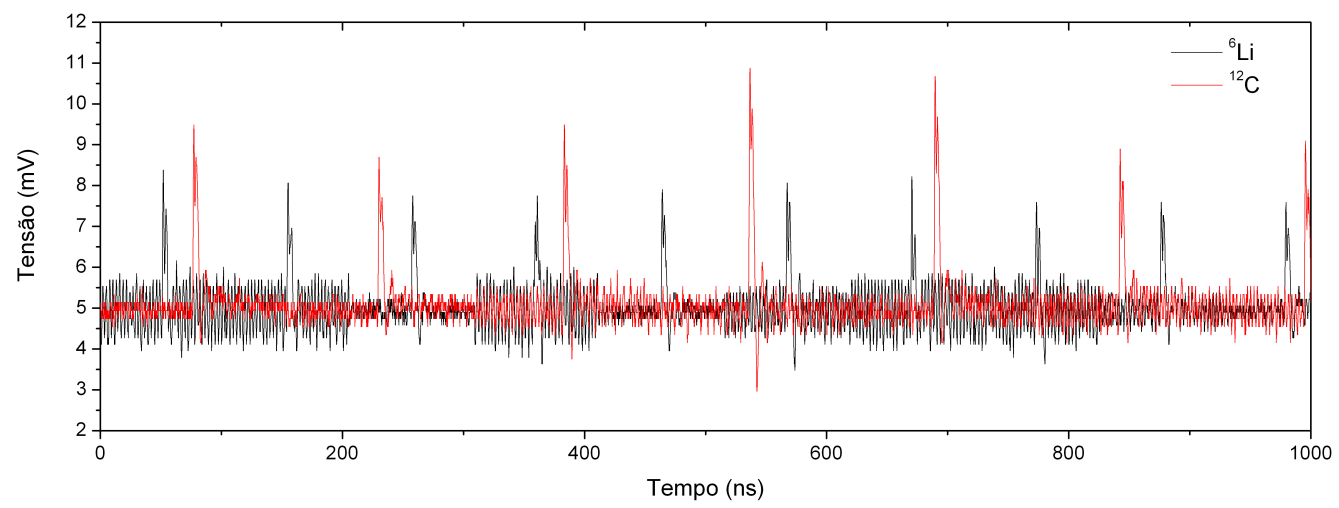

(a)

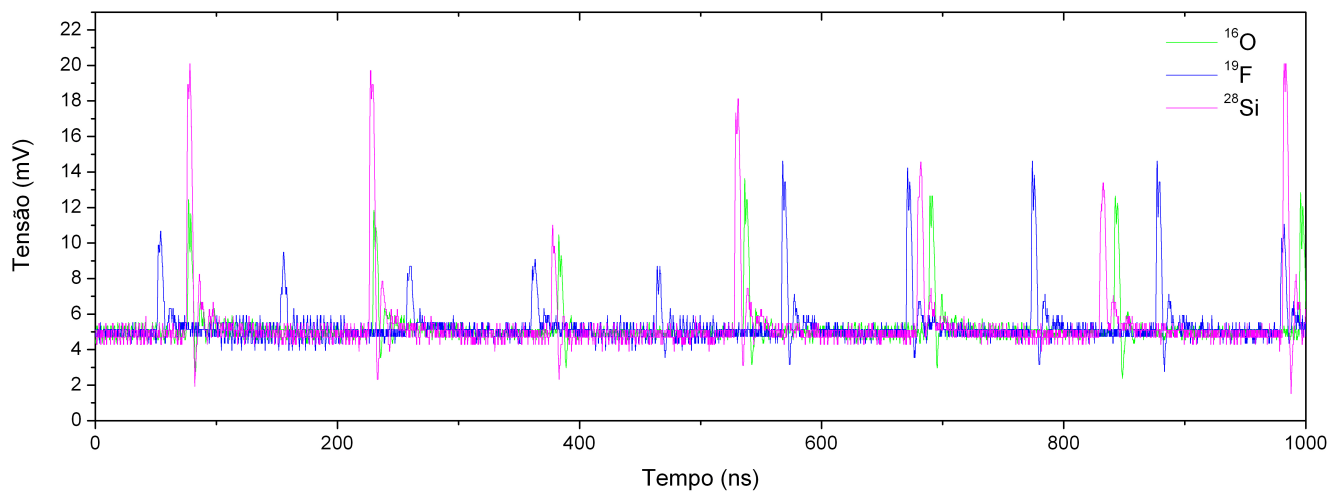

(b)

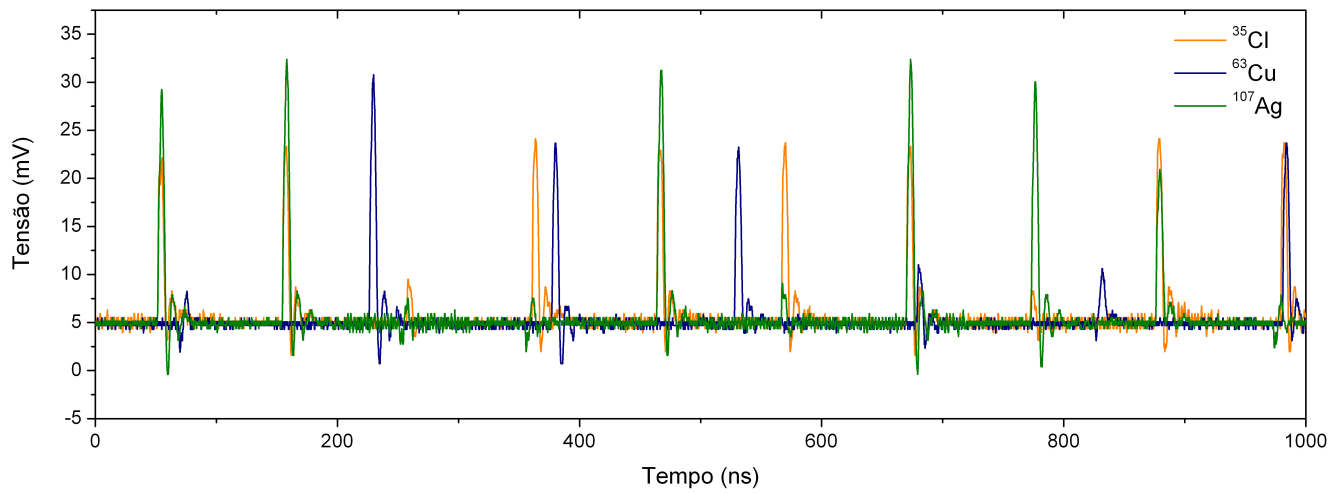

(c)

Figura 6.8: (a) Sinais obtidos com os feixes de ${ }^{6} \mathrm{Li}$ e ${ }^{12} \mathrm{C}$. (b) Sinais obtidos com os feixes de ${ }^{16} \mathrm{O},{ }^{19} \mathrm{~F}$ e ${ }^{28} \mathrm{Si}$. (c) Sinais obtidos com os feixes de ${ }^{35} \mathrm{Cl},{ }^{63} \mathrm{Cu}$ e ${ }^{107} \mathrm{Ag}$. 


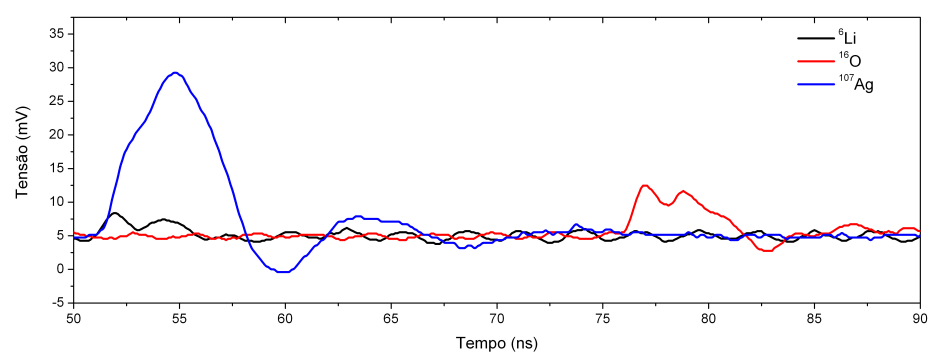

Figura 6.9: Detalhe da forma do sinal para íons de ${ }^{6} \mathrm{Li},{ }^{16} \mathrm{O}$ e ${ }^{107} \mathrm{Ag}$. Nota-se a estrutura de picos duplos e a oscilação após o pico principal.

Tomando como número de eventos o número pré-fixado na aquisição, pôde-se calcular facilmente a fluência no dispositivo utilizando o número de contagens no detector barreira de superfície através da Equação 4.4, e extrair o valor da seção de choque de SEE para a condição através da Equação 3.4. Podemos utilizar como valor de LET o calculado na superfície do dispositivo ou o LET médio calculado considerando a penetração de $10 \mu m$ em silício, calculado segundo a Equação 5.3. A Figura 6.10 ilustra a variação da seção de choque com os diferentes feixes iônicos, para ambos os cálculos de LET.

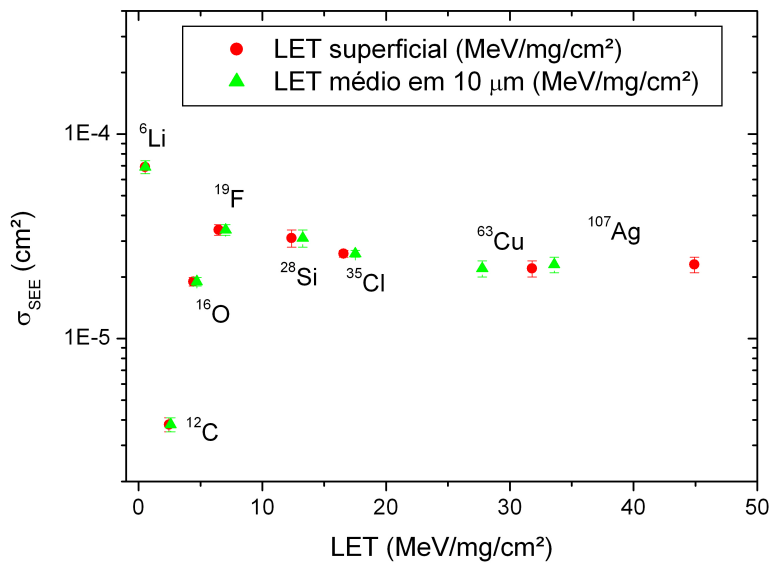

Figura 6.10: Seção de choque de SEE calculada com os diferentes valores de LET para cada um dos íons utilizados. 
Para valores de LET acima do relativo ao lítio, observamos que a curva tem uma subida rápida até atingir um patamar (saturação), como era de se esperar (vide Figura 3.9). Observamos também que os valores de LET calculados por ambos os métodos não alteram a forma da curva, pois as diferenças são significantes apenas na parte saturada dos dados.

A grande variação nos picos de SEE observados motivou a análise de cada pico. Para tanto, um programa na plataforma ROOT [62] foi desenvolvido para procurar os picos no sinal, ajustar uma função gaussiana a cada pico e obter os parâmetros desta curva. De modo geral, a eficiência do programa é de aproximadamente 85\%, ou seja, cerca de $15 \%$ dos picos, em média, não são encontrados. A dificuldade do programa em encontrar os picos e ajustar uma gaussiana no caso dos dados para o lítio, onde a relação sinal/ruído é bem menor, tornou necessária a utilização de um filtro passabaixas por meio da transformada de Fourier. Foi escolhida como frequência de corte 0,02 Hz, de modo a minimizar o ruído preservando ao máximo a estrutura do sinal original. Os dados obtidos foram então histogramados em duas dimensões. Detalhes da forma do sinal como a estrutura de picos duplos, conforme Figura 6.9, foram ignorados no programa por razões de simplicidade e facilidade na convergência.

Embora tenha sido observado que os dados relativos ao lítio sigam a mesma sistemática dos outros íons no tocante à forma do pico, relação da amplitude com o LET e a largura, o fato da seção de choque ser muito maior do que o esperado (contradizendo o modelo) não pôde ser explicado, nem assumindo desvios na fórmula de Rutherford para calibração e nem mesmo assumindo a ocorrência de reações e espalhamentos nucleares, por meio de cálculos utilizando o Potencial de São Paulo [63]. De fato, as correções das seções de choque de SEE considerando reações nucleares são, em geral, muito menores [64]. Desta forma, novas investigações devem ser conduzidas com feixes de ${ }^{6,7} \mathrm{Li}$, além de outros feixes mais leves que carbono, como berílio e boro, de modo a verificar se houve influência do sistema de aquisição ou de ruídos oriundos da sala experimental 
na tomada de dados, ou se algum fenômeno físico ainda não compreendido está presente. Por estas razões, o ponto relativo ao lítio não foi considerado nas análises deste trabalho.

A primeira análise de interesse foi a verificação de diferentes energias para um mesmo íon com LET muito semelhante poderiam gerar diferentes respostas, devido ao menor alcance. Este estudo foi conduzido com feixe de ${ }^{35} \mathrm{Cl}$ em quatro diferentes energias (vide Tabela 6.2). Conforme observado nos histogramas de amplitudes e larguras de pico (desvio-padrão da gaussiana ajustada) combinados para todas as energias (Figura 6.11), não existe nenhuma separação entre as diferentes condições. Isto confirma a previsão de que a causa do SEE é a deposição de energia do íon, não a energia do íon em si.

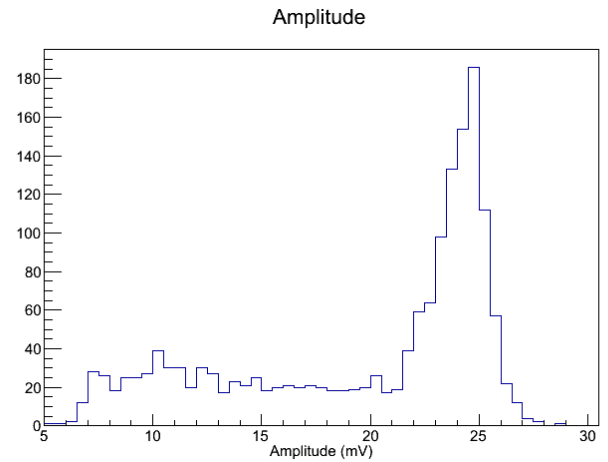

(a)

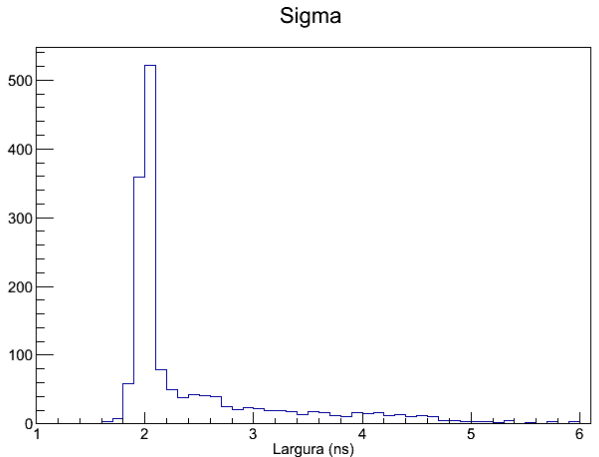

(b)

Figura 6.11: (a)Histograma de amplitudes dos picos de SEE com feixes de cloro a 75 , 67, 60 e $52 \mathrm{MeV}$. (b)Histograma de larguras dos picos de SEE com feixes de cloro nas mesmas energias.

A análise dos dados correspondentes a todos os íons permite buscar correlações entre o LET da partícula incidente e os parâmetros do sinal, conforme histograma bi-paramétrico apresentado na Figura 6.12: 


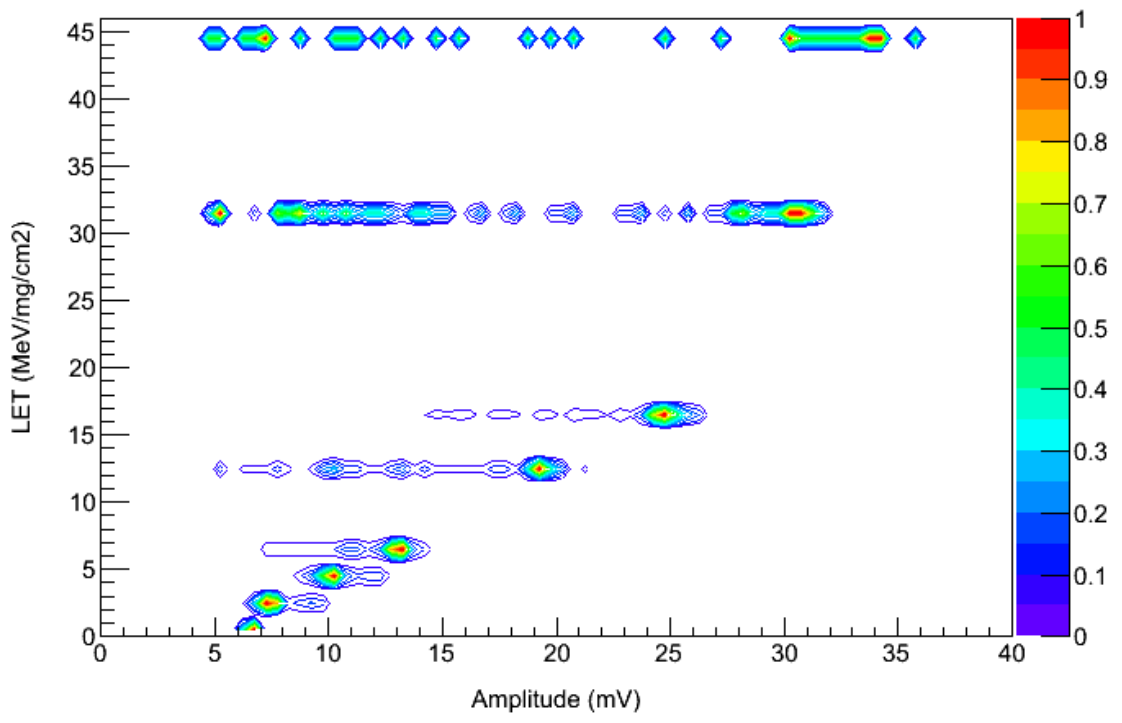

Figura 6.12: Histograma bi-dimensional normalizado de amplitudes dos picos e LET superficial dos íons (calculados com o programa SRIM/TRIM).

Como pode ser observado na Figura 6.12 e na Figura 6.8, o aumento do LET da partícula incidente gera um sinal no dispositivo com maior amplitude. Todavia, existe uma grande dispersão nos valores de amplitude, que pode ser causada pela região de incidência do íon no dispositivo ([65],[66]) ou um efeito camada morta do dispositivo (uma camada de silício não-sensível acima da camada sensível), onde ocorre perda de energia da partícula. Não conhecemos a espessura desta camada morta, porém nota-se que o efeito é mais pronunciado para íons mais pesados, que possuem uma taxa de deposição de energia maior e alcance menor dentro do dispositivo. Este efeito faz com que o íon atinja a camada sensível com um valor de LET desconhecido, uma vez que a variação do LET com a energia, nas condições obtidas para íons de massa elevada no Acelerador Pelletron, é muito rápida. Nestas condições, o cálculo de LET realizado previamente com base no SRIM (eixo vertical do gráfico) não é válido, devendo ser realizado um novo cálculo com base na energia efetiva da partícula. A tendência linear seguida pelas áreas mais intensas do histograma bi-dimensional no caso dos íons mais 
leves permite utilizar os valores de LET calculados como verdadeiros e ajustar uma curva LET versus Amplitude, conforme Figura 6.13, com o objetivo de corrigir o LET efetivo dos íons de cobre e prata na área sensível do dispositivo.

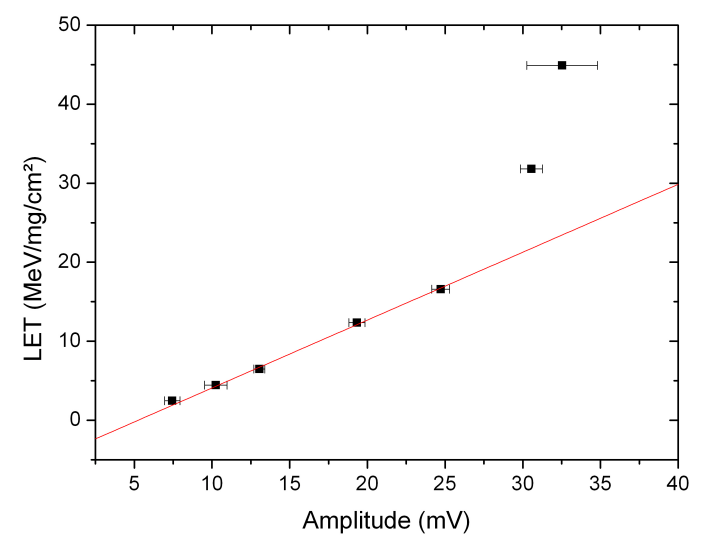

Figura 6.13: Ajuste linear dos valores de LET em função da amplitude dos picos para o cálculo do LET efetivo dos íons de ${ }^{63} \mathrm{Cu}$ e ${ }^{107} \mathrm{Ag}$.

A reta de calibração é dada por:

$$
\operatorname{LET}\left(\mathrm{MeV} / \mathrm{mg} / \mathrm{cm}^{2}\right)=-4,5(4)+0,86(3) \times \operatorname{Amplitude}(\mathrm{mV})
$$

donde se obtém os valores de LET efetivo dos íons ${ }^{63} \mathrm{Cu}$ e ${ }^{107} \mathrm{Ag}$ iguais a 21,7(11) e 23,4(22) $\mathrm{MeV} / \mathrm{mg} / \mathrm{cm}^{2}$, respectivamente, o que corresponde a uma energia efetiva de cerca de $50 \mathrm{MeV}$ para os íons de cobre e $52 \mathrm{MeV}$ para os íons de prata. Um estudo mais aprofundado levando em consideração a dispersão em amplitudes dos picos e a variação da curva de Bragg nesta faixa de energias, para íons pesados, deve fornecer mais informações a respeito da camada morta do dispositivo. A correlação entre a área dos picos, que representa a carga, e o LET, deve fornecer informações a respeito da região de coleta de cargas (espessura sensível) e, a partir da medida da carga coletada no caso dos íons mais pesados, permitir estimar também a espessura da camada morta. Estas análises dependem de um estudo cuidadoso da influência do sistema de aquisição 
sobre os sinais, de modo a não estimar erroneamente a carga gerada. Uma estimativa com base nos dados obtidos permitiu estimar a espessura da camada sensível entre 5 e $10 \mu m$, porém este valor é passível de alterações em uma análise mais refinada.

A dispersão em amplitudes no caso dos íons mais pesados pode ser devido ao efeito da camada morta ou ao efeito de radiação de um íon contaminante incidindo sobre o dispositivo. O feixe proveniente do acelerador Pelletron é isento de contaminações significativas, de modo que, a única ocorrência possível de contaminação é oriunda de partículas de ouro espalhadas do alvo que possam atingir o dispositivo. De fato, como pode ser visto nos espectros do detector barreira de superfície para as irradiações com íons de cobre e íons de prata (Figura 6.14), existe um pico correspondente ao espalhamento de ouro a $45^{\circ}$ (posição do detector). A integral deste pico permite conhecer a taxa de ouro espalhado a $45^{\circ}$, e daí é possível calcular, considerando o espalhamento Rutherford (vide Capítulo 4), a taxa a $15^{\circ}$. No entanto, o cálculo da taxa mostra que apenas $0,02 \%$ dos íons incidentes no dispositivo poderiam ser associados ao ${ }^{197} \mathrm{Au}$, de modo que esta hipótese na explicação da dispersão deve ser descartada.

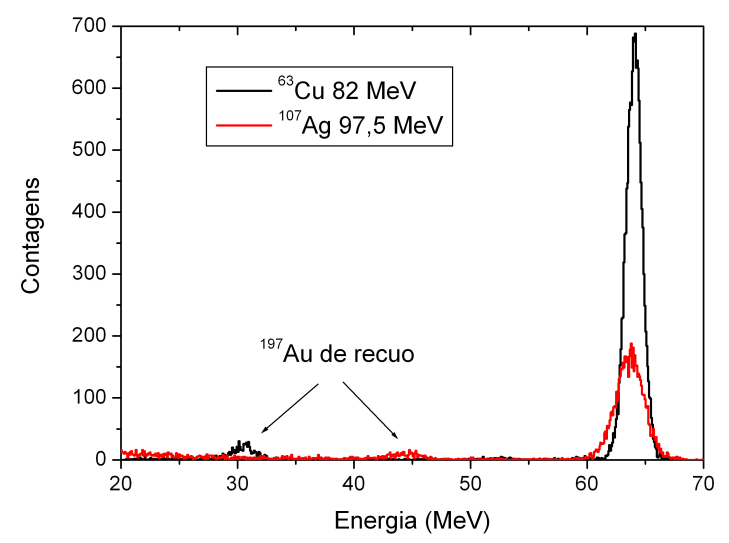

Figura 6.14: Espectros obtidos com o detector de barreira de superfície a $45^{\circ}$ para os feixes de ${ }^{63} \mathrm{Cu}$ e ${ }^{107} \mathrm{Ag}$, onde é possível observar o recuo do ${ }^{197} \mathrm{Au}$. 
No caso da distribuição de larguras (desvio-padrão da gaussiana) e amplitudes, é possível observar uma leve tendência de diminuição da largura do pico com o aumento de sua amplitude, de forma semelhante a uma dependência hiperbólica, que poderia estar relacionada à integral da função gaussiana ajustada aos picos e que representa a carga acumulada, que é grandeza-chave nos fenômenos de SEE. Tendo em vista a grande variação de formas de picos para cada íon incidente e o pequeno número de contagens para alguns deles, não é possível realizar um estudo adequado desta dependência, ficando, entretanto, claro que um estudo posterior com maior número de picos deve ser conduzido de forma a corroborar ou descartar esta hipótese. Não foi observada nenhuma tendência clara entre as larguras dos picos e os valores de LET.

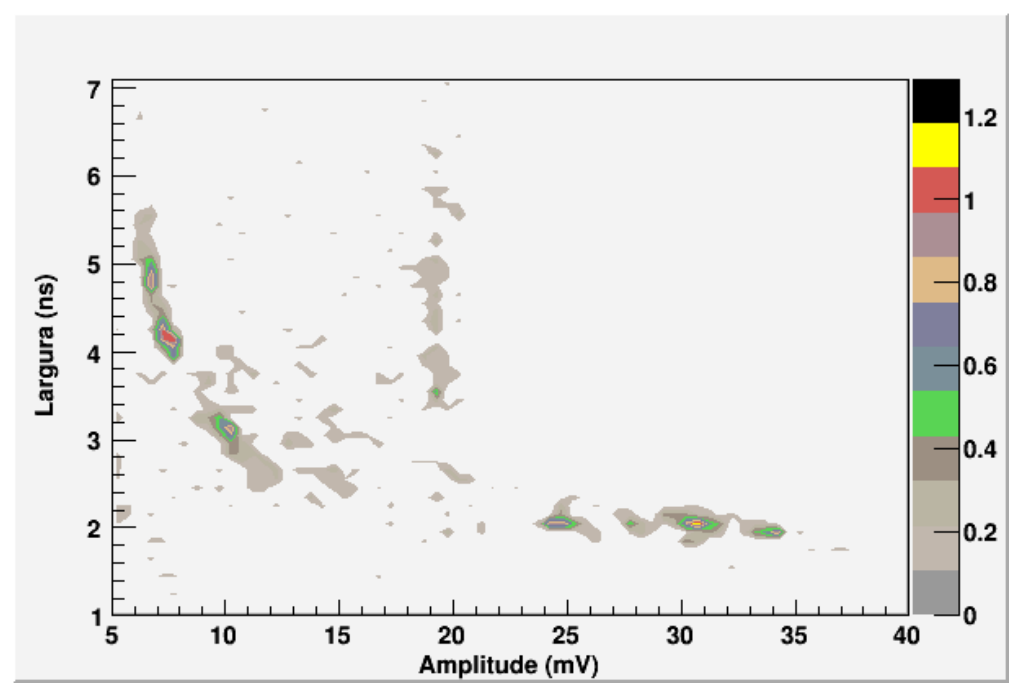

Figura 6.15: Histograma bi-dimensional normalizado de larguras e amplitudes dos picos.

Os pontos medidos de seção de choque de ocorrência de SEE são ajustados por uma curva de Weibull (Equação 3.5), donde se obtém os parâmetros característicos da resistência à radiação do dispositivo sob teste com íons pesados. A Figura 6.16 mostra o ajuste utilizando os valores de LET não-corrigidos (A) e corrigidos (B), e a Tabela 6.3 apresenta os valores dos parâmetros. Os parâmetros da curva não são alterados pela mudança dos valores de LET efetivo dos íons de cobre e de prata. 


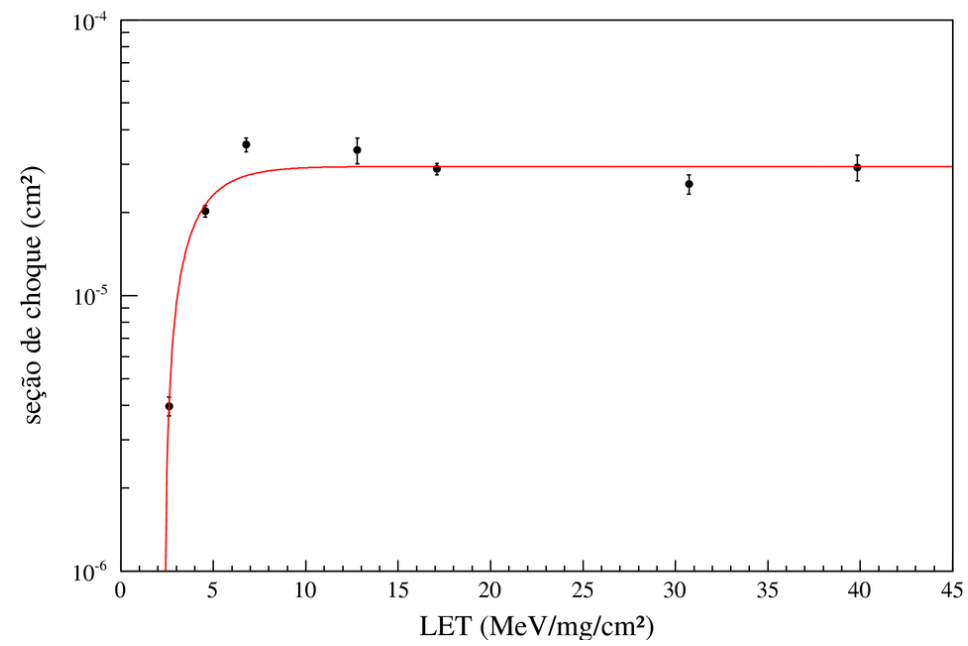

(a) LET Não-corrigido

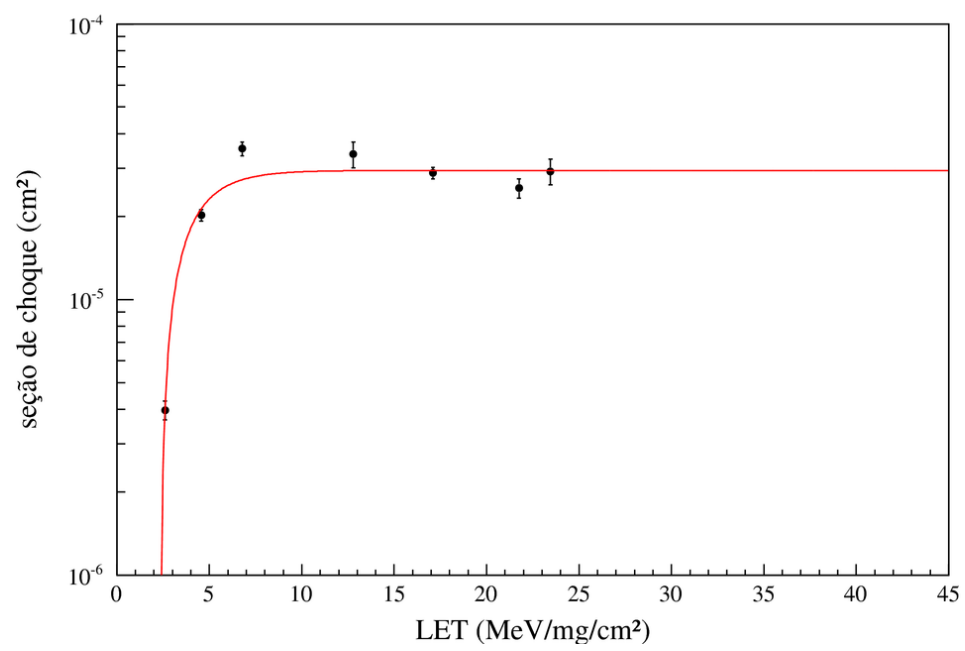

(b) LET Corrigido

Figura 6.16: Pontos experimentais de seção de choque de SEE (excluindo o lítio) e ajuste teórico. (a)valores de LET calculados. (b) valores de LET calculados considerando as correções para o cobre e a prata

Conforme mencionado na seção 3.2.3, o valor da seção de choque de saturação corresponde à área transversal sensível total do dispositivo. Neste caso, podemos adotar para a área sensível o modelo do paralelepípedo e imaginá-la quadrada, de modo que o 
Tabela 6.3: Parâmetros do ajuste teórico

\begin{tabular}{cc}
\hline Parâmetro & Valor \\
\hline$\sigma_{\text {sat }} \mathrm{cm}^{2}$ & $2,94(10) \cdot 10^{-5}$ \\
$L E T_{\text {th }}\left(\mathrm{MeV} / \mathrm{mg} / \mathrm{cm}^{2}\right)$ & $2,35(36)$ \\
$\mathrm{w}\left(\mathrm{MeV} / \mathrm{mg} / \mathrm{cm}^{2}\right)$ & $1,06(11)$ \\
$\mathrm{s}$ & $0,62(10)$ \\
\hline
\end{tabular}

comprimento do lado da região sensível resulta em 54,2(9) $\mu m$. Um cálculo simples de velocidade de deriva no campo elétrico considerando a tensão fonte-dreno como sendo de $-4,5 \mathrm{~V}$ e as mobilidades diferentes para os elétrons e as lacunas permite prever a diferença de tempo entre os sinais gerados por elétrons e os sinais gerados pelas lacunas, caso a incidência do íon tenha ocorrido exatamente no centro da região entre a fonte e o dreno:

$$
\begin{gathered}
v_{d}=\mu \epsilon \\
\frac{1}{v_{\text {eletrons }}}=\frac{t_{e}}{x} \quad \frac{1}{v_{\text {lacunas }}}=\frac{t_{l}}{x}
\end{gathered}
$$

onde x é metade do comprimento do lado da região sensível, isto é, 27,1(5) $\mu m$. Assim:

$$
\begin{gathered}
\frac{1}{v_{\text {eletrons }}}-\frac{1}{v_{\text {lacunas }}}=\frac{t_{e}-t_{l}}{x}=\frac{\left(\mu_{l}-\mu_{e}\right) \epsilon}{\mu_{l} \mu_{e} \epsilon^{2}} \\
\frac{\left(\mu_{l}-\mu_{e}\right)}{\mu_{l} \mu_{e} \epsilon}=\frac{\left(\mu_{l}-\mu_{e}\right)}{\mu_{l} \mu_{e} \frac{V}{x}} \Longrightarrow \frac{t_{e}-t_{l}}{x^{2}}=\frac{\left(\mu_{l}-\mu_{e}\right)}{\mu_{l} \mu_{e} V} \simeq 2,5 \mathrm{~ns}
\end{gathered}
$$

Como pode ser observado na Figura 6.9, a diferença observada é da ordem de 2 ns, da mesma ordem de grandeza da estimativa com base na mobilidade dos portadores, o que nos permite sugerir que a estrutura de pico duplo seja efeito das diferentes mobilidades dos portadores de carga. 


\section{Capítulo 7}

\section{Conclusão}

O desenvolvimento deste projeto permitiu a montagem e testes de um arranjo experimental adequado para as medidas de Efeitos de Eventos Isolados em dispositivos eletrônicos. Tal sistema permite irradiações com íons tão pesados quanto ${ }^{107} \mathrm{Ag}$ em vácuo, atingindo valores de LET (calculado) até $40 \mathrm{MeV} / \mathrm{mg} / \mathrm{cm}^{2}, \mathrm{e}^{48} \mathrm{Ti} \mathrm{em}$ ar, atingindo valores de LET até $17 \mathrm{MeV} / \mathrm{mg} / \mathrm{cm}^{2}$. Os valores de LET efetivo na camada sensível do dispositivo estão sujeitos à influência da camada de passivação existente. A uniformidade do feixe está dentro dos $10 \%$ de variação requeridos pelas normas técnicas, e o fluxo de partículas é baixo o suficiente para permitir a discriminação de eventos independentes. Instrumentação para este tipo de medida foi desenvolvida e testada ao longo do projeto.

A utilização de stripper de carbono é adequada para a geração de estados de carga elevados utilizando feixes pesados, sendo que em alguns casos a produção é mais eficiente do que a prevista por modelos semi-empíricos. Todavia, a vida útil das folhas de carbono é bastante reduzida quando feixes pesados são utlizados, de forma que a produção de folhas com maior durabilidade deve ser desenvolvida.

O estudo do transistor 3N163 sob fluxo de íons pesados revelou que os eventos geram um sinal de corrente (convertido em tensão pelo sistema de aquisição) proporcional ao 
LET da partícula incidente, podendo a partir desta correlação determinar que existe significativa perda de energia dos íons mais pesados na camada morta do dispositivo, de modo que o LET efetivo destes dispositivos na região sensível é diminuído. Observouse também que, como esperado, não existe dependência da amplitude do sinal com a energia da partícula incidente, desde que a partícula possua alcance suficiente dentro do dispositivo. Embora nos experimentos realizados não tenha havido a contribuição do ouro espalhado do alvo sobre o dispositivo, este efeito deve ser levado em conta no projeto dos experimentos que utilizarem esta montagem.

Observou-se que existe uma grande dispersão nas amplitudes dos picos de tensão gerados por efeitos de eventos isolados, e a causa pode ser a perda de energia na camada morta ou mesmo a região de incidência do íon no dispositivo. Um índício de correlação entre a amplitude do sinal e sua largura e, portanto, LET, pôde ser observado, porém é necessário um novo estudo com mais estatística e análise mais refinada do sinal para avaliar esta possível correlação.

Observou-se um comportamento anômalo na irradiação com ${ }^{6} L i$, pois embora o sinal apresente as mesmas características dos outros sinais, a seção de choque calculada é da mesma ordem de grandeza da seção de choque de saturação, contrariando o modelo. Nos próximos experimentos envolvendo o transistor $3 \mathrm{~N} 163$ a irradiação com ${ }^{6} \mathrm{Li}$ será repetida, devendo-se também incluir irradiações com isótopos de berílio e boro, para melhor avaliar as possíveis causas desta anomalia.

Foi possível obter a curva de seção de choque de efeitos de eventos isolados para o transistor 3N163, obtendo-se os valores de 2,94(10).10 ${ }^{-5} \mathrm{~cm}^{2}$ e $2,35 \mathrm{MeV} / \mathrm{mg} / \mathrm{cm}^{2}$ para a seção de choque de saturação e o LET de limiar, respectivamente.

Estes resultados são importantes para o início dos estudos de efeitos de radiação com íons pesados no Brasil, atraindo desde já a atenção de grupos nacionais que não conheciam a capacidade do Acelerador Pelletron. Entre os próximos desenvolvimentos está a construção de uma linha de feixe dedicada à física aplicada com enfoque especial 
no ensaio de dispositivos eletrônicos, contando para isso com diversos sistemas de manipulação e monitoramento. Com a entrada em operação do pós-acelerador LINAC, esta linha de feixe será transferida e poderá ser feita a qualificação completa de dispositivos eletrônicos de acordo com as normas vigentes. 


\section{Referências Bibliográficas}

[1] Emico Okuno and Elisabeth Mateus Yoshimura. Física das Radiações. Oficina de Textos, 1a edição, 2010.

[2] F. Attix and W. Roesch. Radiation Dosimetry. Academic Press, second edition, 1968.

[3] Glenn F. Knoll. Radiation Detection and Measurement. New York Wiley, 2000.

[4] Roberto Linares. Estudo do freamento de Íons de $\mathrm{Cu}$ natural em Au em baixas velocidades. Dissertação de Mestrado, Universidade de São Paulo, 2005.

[5] U. Fano. Penetration of protons, alpha particles and mesons. Annual Reviews of Nuclei Science, 13:1-66, 1963.

[6] D. Griffiths. Introduction to Quantum Mechanics. Pearson Education, 2013.

[7] Roberto V. Ribas. Freamento de Íons Pesados em Sólidos. Tese de Doutorado, Universidade de São Paulo, 1982.

[8] J.P. Biersack e M.D. Ziegler J.F. Ziegler. SRIM: The Stopping and Range of Ions in Matter. SRIM Co., 2008.

[9] Roberto Linares. Estudo Sistemático do Freamento de Íons Pesados em Sólidos no Regime de Baixas Velocidades. Tese de Doutorado, Universidade de São Paulo, 2008 . 
[10] F. Brandolini, N.H. Medina, M. De Poli, P. Pavan, M. Wilhelm, A. Dewald, and G. Pascovici. Stopping power of $\mathrm{Nd}$ ions in $\mathrm{Pb}$ determined from gamma-ray lineshape analysis in Coulomb excitation. Nuclear Instruments and Methods in Physics Research B, 132:11-17, 1997.

[11] A.Akkerman, M. Murat, and J. Barak. Delta-electron spectra, inelastic crosssections and stopping powers of ions in silicon: Comparison between different models. Nuclear Instruments and Methods in Physics Research B, 2014.

[12] A.Akkerman, M. Murat, and J. Barak. Ion track structure calculations in silicon - spatial and temporal aspects. Nuclear Instruments and Methods in Physics Research B, 269:1630-1633, 2011.

[13] T. Colladant, A. L'Hoir, J.E. Sauvestre, and O. Flament. Monte-carlo simulations of ion track in silicon and influence of its spatial distribution on single event effects. Nuclear Instruments and Methods in Physics Research B, 245:464-474, 2006.

[14] G. Lutz. Semiconductor Radiation Detectors. Springer, 1999.

[15] Richard Greco, Alex Luce, Yongqiang Wang, and Lin Shao. A technique to measure stopping power difference between channeled and non-channeled ions in crystalline solids. Nuclear Instruments and Methods in Physics Research B, 261:538-540, 2007.

[16] Hans-Dieter Betz. Charge states and charge changing cross-sections of fast heavy ions penetrating through gaseous and solid media. Reviews of Modern Physics, 44(3):465-539, 1972.

[17] V.P. Shevelko, I.L. Beigman, M.S. Litsarev, H. Tawara, I.Yu. Tolstikhina, and G. Weber. Charge-changing processes in collisions of heavy many-electron ions with neutral atoms. Nuclear Instruments and Methods in Physics Research B, 269:1455-1463, 2011. 
[18] Th.R. Niklaus, G. Bonani, Z. Guo, M. Suter, and H.-A. Synal. Optimising tandem accelerator stripping efficiency by simulation of charge changing processes. Nuclear Instruments and Methods in Physics Research B, 92:115-121, 1994.

[19] R. Hellborg, editor. Electrostatic Accelerators: Fundamentals and Applications. Springer, 2005.

[20] W.T. Milner. Upak documentation. internal report, 1977. Oak Ridge National Laboratory, USA.

[21] R.O. Sayer. Semi-empirical formulas for heavy-ion stripping data. Revue de Physique Appliquée, 12:1543, 1977.

[22] Brookhaven National Lab BNL. LET calculator. http://tvdg10.phy.bnl.gov/ LETCalc.html, 2001. [último acesso: 18/02/2014].

[23] Jacobus W. Swart. Semicondutores: Fundamentos, Técnicas e Aplicações. Editora UNICAMP, Campinas, 2008.

[24] J.F. Ziegler et al. IBM experiments in soft fails in computer electronics (1978-1994). IBM Journal of Research and Development, 40(1):3-18, january 1996.

[25] Dariusz Makowski. The impact of radiation on electronic devices with the special consideration of neutron and gamma radiation monitoring. $\mathrm{PhD}$ thesis, Technical University of Lódz, 2006.

[26] Robert C. Baumann. Soft errors in advanced semiconductor devices - part I: The three radiation sources. IEEE Transactions on Device and Materials Reliability, $1(1): 17-22,2001$.

[27] James R. Schwank, Marty R. Shaneyfelt, and Paul E. Dodd. Radiation hardness assurance testing of microelectronic devices and integrated circuits: Radiaiton envi- 
ronments, physical mechanisms and foundations for hardness assurance. Document 2008-6851P, Sandia National Laboratories, 2008.

[28] D.F. Heidel, K.P. Rodbell, E.H. Cannon, Jr. C. Cabral, M.S. Gordon, P. Oldiges, and H. H. K. Tang. Alpha-particle-induced upsets in advanced CMOS circuits and technology. IBM Journal of Research and Development, 52(3):225-232, may 2008.

[29] Claude Leroy and Pier-Giorgio Rancoita. Principles of Radiation Interaction in Matter and Detection. World Scientific, 2 edition, 2009.

[30] J. F.Ziegler. Terrestrial cosmic rays. IBM Journal of Research and Development, 40(1):19-39, january 1996.

[31] M.S. Gordon, K.P. Rodbell, D.F. Heidel, Jr. C. Cabral, E.H. Cannon, and D.D. Reinhardt. Single-event-upset and alpha-particle emission rate measurement techniques. IBM Journal of Research and Development, 52(3):265-273, may 2008.

[32] K. Cirne, M.A.G. Silveira, R.B.B. Santos, S.P. Gimenez, M.D.L. Barbosa, M.H. Tabacnicks, N. Added, N.H. Medina, W.R. De Melo, L.E. Seixas Jr, and J.A. De Lima. Comparative study of the proton beam effects between the conventional and Circular-Gate MOSFETs. Nuclear Instruments and Methods in Physics Research B, 273:80-82, 2011.

[33] Simone Gerardin. SEE and TID testing: Theoretical and practical aspects. Shortcourse on Radiation Effects on Electronic Devices - WERICE 2013, October 2013.

[34] Sophie Duzellier. Radiation effects on electronic devices in space. Aerospace Science and Technology, 9:93-99, 2005.

[35] Brian D. Sierawski, Kevin M. Warren, Robert A. Reed, Robert A. Weller, Marcus M. Mendenhall, Ronald D. Schrimpf, Robert C. Baumann, and Vivian Zhu. Contribution of low energy ( $<10 \mathrm{mev})$ neutrons to upset rate in a $65 \mathrm{~nm}$ SRAM. 
In IEEE International, editor, Reliability Physics Symposium, pages 4B.2.1-4B.2.5, 2010 .

[36] H. H. K. Tang. Nuclear physics of cosmic ray interaction with semiconductor materials: Particle-induced soft errors from a physicist's perspective. IBM Journal of Research and Development, 40(1):91-108, january 1996.

[37] Francisco Rogelio Palomo Pinto. Eventos singulares em CMOS digital. apostila da Escuela Superior de Ingenieros - Universidad de Sevilla, 2012.

[38] K.P. Rodbell, D.F. Heidel, H.H.K. Tang, M.S. Gordon, P. Oldiges, and C.E. Murray. Low-energy proton-induced single-event-upsets in $65 \mathrm{~nm}$ node, siliconon-insulator, latches and memory cells. IEEE Transactions on Nuclear Science, $54(6): 2474-2479,2007$.

[39] J.R. Ahlbin, M.J. Gadlage, N.M. Atkinson, B. Narasimham, B.L. Bhuva, A.F. Witulski, W.T. Holman, P.H. Eaton, and L.W. Massengill. Effect of multipletransistor charge collection on single-event transient pulse widths. IEEE Transactions on Device and Materials Reliability, 11(3), 2011.

[40] Paul E. Dodd. Physics-based simulation of single-event effects. IEEE Transactions on Device and Materials Reliability, 5(3):343-357, september 2005.

[41] G.R. Srinivasan, H.K. Tang, and P.C. Murley. Parameter-free, predictive modeling of single event upsets due to protons, neutrons and pions in terrestrial cosmic rays. IEEE Transactions on Nuclear Science, 41(6):2063-2070, 1994.

[42] H.H.K. Tang and Ethan H. Cannon. SEMM-2: A modeling system for single event upset analysis. IEEE Transactions on Nuclear Science, 51(6):3342-3348, 2004. 
[43] ESA. Single event effects test method and guidelines. ESA/SCC Basic Specification 1, European Space Agency, October 1995. ESA/SCC Basic Specification 25100 .

[44] ASTM. Standard guide for the measurement of single event phenomena (SEP) induced by heavy ion irradiation of semiconductor devices. ASTM standard, American Society for Testing and Materials, 2006. F 1192-00.

[45] EIA/JEDEC. Test procedures for the measurement of single-event effects in semiconductor devices from heavy ion irradiation. EIA/JEDEC standard, Electronic Industries Association, 1996. EIA/JESD57.

[46] Jerry B. Marion and Stephen T. Thornton. Classical dynamics of particles and systems. Thomson Brooks/Cole, 5 edition, 2004.

[47] Rubens Lichtenthäler Filho. Reações nucleares. Notas de aula,IFUSP, 2012.

[48] Kasuo Ueta. Descrição clássica do espalhamento entre duas partículas. Apostila do Departamento de Física Nuclear do IFUSP, 2005.

[49] Djalma Rosa Mendes Jr. Estudo da Reação 8Li(p,a)5He com Feixe Radioativo de 8Li. Tese de Doutorado, Universidade de São Paulo, 2009.

[50] Laboratório Aberto de Física Nuclear. Fonte de Íons. http://web.if .usp.br/ fnc/node/307.

[51] Laboratório Aberto de Física Nuclear. Acelerador pelletron. http://web. if .usp. $\mathrm{br} / \mathrm{fnc} /$ node/308.

[52] National Electrostatics Corporation. http://www.pelletron.com.

[53] Dirceu Pereira. Limiares das reações 27Al(p,n)27Si e 12C(a,n)15O. Dissertação de Mestrado, Universidade de São Paulo, 1975. 
[54] Victor Rotberg, Dirceu Pereira, M.N. Rao, Nobuko Ueta, and Oscar Sala. Calibration of the tandem pelletron accelerator. Revista Brasileira de Fisica, 6(3), 1976.

[55] Roberto V. Ribas. Instrumentação nuclear. Notas de Aula, IFUSP, 2011.

[56] Roberto V. Ribas. A camac data acquisition system based on PC-Linux. Nuclear Instruments and Methods in Physics Research, Section A, Accelerators, Spectrometers, Detectors and Associated Equipment (Print), 483:830-832, 2002.

[57] J. H. Ahlberg, E. N. Nilman, and J. L. Walsh. The Theory of Splines and Their Applications. Academic Press, New York, 1967.

[58] L.J. Asensio, M.A. Carvajal, J.A. Lopez-Villanueva, M. Vilches, A.M. Lallena, and A.J. Palma. Evaluation of a low-cost commercial MOSFET as radiation dosimeter. Sensors and Actuators A, 125:288-295, 2006.

[59] K. Shima, S. Ishii, T. Takahashi, I. Sugai, M. Oyaizu, and T. Ishihara. Lifetime of charge stripping foils and transmission of heavy ions in 12UD-pelletron tandem accelerator. Nuclear Instruments and Methods in Physics Research B, 139:451-455, 1998.

[60] K.R. Chapman. A new method of mounting stripper foils. Revue de Physique Appliquée, 12:1547, 1977.

[61] V.A.P. Aguiar, N. Added, N.H. Medina, E.L.A.Macchione, M.H. Tabacniks, F.R. Aguirre, M.A.G. Silveira, R.B.B. Santos, and L.E. Seixas Jr. Experimental setup for Single Event Effects at the são paulo 8UD Pelletron Accelerator. Nuclear Instruments and Methods in Physics Research B, 332:397-400, 2014.

[62] CERN. ROOT. root.cern.ch. 
[63] L. C. Chamon, B. V. Carlson, L. R. Gasques, D. Pereira, C. De Conti, M. A. G. Alvarez, M. S. Hussein, M. A. Cândido Ribeiro, E. S. Rossi Jr., and C. P. Silva. Toward a global description of the nucleus-nucleus interaction. Physical Review $C$, $66,2002$.

[64] Kevin M. Warren, Robert A. Weller, Marcus H. Mendenhall, Robert A. Reed, Dennis R. Ball, Christina L. Howe, Brian D. Olson, Michael L. Alles, Lloyd W. Massengill, Ronald D. Schrimpf, Nadim F. Haddad, Scott E. Doyle, Dale McMorrow, Joseph S. Melinger, , and William T. Lotshaw. The contribution of nuclear reactions to heavy ion single event upset cross-section measurements in a highdensity SEU hardened SRAM. IEEE Transactions on Nuclear Science, 52(6), 2005 .

[65] Dale McMorrow, J. Brad Boos, Alvin R. Knudson, William T. Lotshaw, Doe Park, Joseph S. Melinger, Brian R. Bennett, Alphonse Torres, Veronique Ferlet-Cavrois, Jean-Etienne Sauvestre, Claudine D'Hose, and Olivier Flament. Transient response of III-V field effect transistors to heavy-ion irradiation. IEEE Transactions on Nuclear Science, 51(6):3324-3331, 2004.

[66] Dale McMorrow, J. Brad Boos, Joseph S. Melinger, Veronique Ferlet-Cavrois, Philippe Paillet, Olivier Duhamel, and Jacques Baggio. Measurement of the transient response of semiconductor devices to ionizing radiation. Nuclear Instruments and Methods in Physics Research B, 261:1137-1141, 2007. 